NIST

MEFEFENCE

PUOLIOATIONS

ENERGY RELATED

INVENTIONS PROGRAM

A JOINT PROGRAM OF

THE DEPARTMENT OF

ENERGY AND THE

NATIONAL INSTITUTE OF

STANDARDS AND

TECHNOLOGY

STATUS REPORT FOR

RECOMMENDATIONS

1 THROUGH 300
U.S. DEPARTMENT OF COMMERCE

Technology Administration

National institute of Standards

and Technology

Office of Technology Evaluation

and Assessment

Gaithersburg, MD 20899

$-Q C$

100

.456 

ENERGY RELATED

INVENTIONS PROGRAM

A JOINT PROGRAM OF

THE DEPARTMENT OF

ENERGY AND THE

NATIONAL INSTITUTE OF

STANDARDS AND

TECHNOLOGY

STATUS REPORT FOR

RECOMMENDATIONS

1 THROUGH 300
U.S. DEPARTMENT OF COMMERCE

Technology Administration

National Institute of Standards

and Technology

Office of Technology Evaluation

and Assessment

Gaithersburg, MD 20899

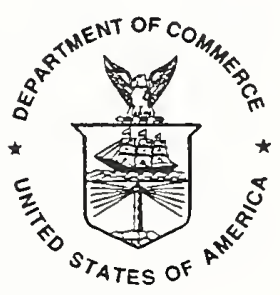

U.S. DEPARTMENT OF COMMERCE

Barbara Hackman Franklin, Secretary

TECHNOLOGY ADMINISTRATION

Robert M. White, Under Secretary for Technology

NATIONAL INSTITUTE OF STANDARDS

AND TECHNOLOGY

John W. Lyons, Director 

TABLE OF CONTENTS

\section{Section 1 Introduction}

PAGE

1.0 Background . . . . . . . . . . . . . . . . . . 1-1

1.1 Overview of Program Operation . . . . . . . . . . . . . . . . 1-1

1.2 Evaluation Procedures (NIST) . . . . . . . . . . . . . 1-2

1.3 Support Procedures (DOE) . . . . . . . . . . . . . . . 1-2

1.4 Supplementary Activities . . . . . . . . . . . . . . 1-3

1.5 Nature of This Report.................. . 1-3

Section 2 Status of Recommended Inventions

2.0 Introduction .. . . . . . . . . . . . . . . . . . 2-1

2.1 Index to Recommended Inventions... . . . . . . . . . . . . 2-1

2.2 Brief Descriptions and Status of Recommended Inventions . . . 2-9 


\section{PREFACE}

The Energy-Related Inventions Program was established in 1975. Since its inception, over 29,000 inventions have been evaluated. As of the printing of this report, 563 have been recommended to the Department of Energy. This report supersedes NISTIR 4333 and summarizes the status of recommended inventions 1 through 300 . A companion report, NISTIR 4899, summarizes the remainder of the recommended inventions. 
Section 1 Introduction

\subsection{BACKGROUND}

The Federal Nonnuclear Energy Research and Development Act of 1974 (Public Law 93-577) established a comprehensive national program, called the Energy-Related Inventions Program (ERIP), for research and development of all potentially useful energy sources and energy use technologies. The U.S. Department of Energy (DOE) conducts this program.

An important part of ERIP is to encourage innovation in the development of energy technology. To help DOE carry out this responsibility, the Act directs the National Institute of Standards and Technology (NIST) to evaluate all promising nonnuclear energy-related inventions. NIST is to give particular attention to those submitted by independent inventors and small companies. NIST has established the Office of Technology Evaluation and Assessment (OTEA) (formerly the Office of Energy Related Inventions (OERI)) to evaluate proposals.

\subsection{OVERVIEW OF PROGRAM OPERATION}

OTEA reviews and processes all evaluation requests. Evaluation is based on three general criteria: technical feasibility, potential energy-conservation or energy-supply impact, and commercial feasibility. All inventors are informed of the results of the evaluation of their submitted inventions. An invention which meets the NIST criteria for recommendation is forwarded to DOE for possible support action.

Inventions forwarded by the OTEA to DOE are recommended as "technically valid and worthy of consideration for Government support" under the ERIP Program. OTEA furnishes a report with the recommendation to explain in detail the advantages of the technology, as well as any qualifications of the recommendations, such as required testing. OTEA also provides guidance to DOE and the inventor for deciding on the nature and extent of support to be given.

Inventions may be recommended by OTEA at any stage of their development, whether conceptual, at the laboratory testing stage, or even in production or the process of being marketed. The level of support to be furnished depends largely on the amount required to move invention development forward or to resolve the question of whether development should continue. The latter question is of particular interest if the NIST evaluation is based on data furnished by the inventor and the recommendation is qualified by an expressed need for data validation under controlled testing conditions.

DOE generally accepts the NIST recommendation and provides appropriate support. However, there have been and will continue to be cases in which DOE cannot or will not provide support. DOE attempts to reach agreement with the inventor on the nature and extent of support within constraints. Constraints include the capabilities of the inventor and/or the company involved, possible duplication 
of prior or on-going DOE-funded efforts, availability of private sector support, and DOE funding limitations.

It should be noted that DOE performs no technical evaluation beyond that done by NIST. DOE does reserve the right to question and reject the NIST recommendation and to restrict support due to policy and/or funding considerations.

Each case is decided on the basis of its own merit and need. If DOE decides to support the invention, support can include: a grant, a contract, or direct assistance of a technical or business nature. DOE's objective is that, as a result of this support, the inventor should be in a position to do one or more of the following:

- Compete effectively in obtaining contracts from other sources (including existing government programs) to permit further development of the invention.

- Assemble, with confidence of success, the people and capital necessary to produce and market products derived from the invention through a business enterprise in which the inventor is a major participant.

- Negotiate arrangements with an existing company that will develop the inventor's product for commercialization.

\subsection{EVALUATION PROCEDURES (NIST)}

There are three principal steps in the evaluation process used by the NIST office of Technology Evaluation and Assessment. In the first step, Disclosure Review and Analysis, invention disclosures are either accepted or rejected for evaluation, depending upon whether or not the invention is within program scope and is a sufficiently well-prepared disclosure to enable evaluation. If accepted, a formal evaluation is initiated.

The second step, First-Stage Evaluation, is a technical screening in which brief opinions are obtained from OTEA staff evaluators, other government scientists or engineers, or consultants or contractors. If the invention is rated as "promising" in this First-Stage, Second-Stage Evaluation is initiated. ("Promising" means the invention seems to be technically feasible, has significant energy conservation or supply potential, and is deemed to be economically and commercially practical.)

In Second-Stage Evaluation, an analysis is conducted in greater depth, resulting in a formal report. If Second-Stage Evaluation confirms the finding of "promising," the disclosure and evaluation results are forwarded to DOE with a recommendation for Government support.

Throughout the process, the inventor is kept informed of the status of the evaluation. The inventor is sent a letter notifying him of the results of Firstor Second-Stage evaluations as they are completed. If Second-Stage Evaluation has been conducted, a copy of the Second-Stage invention review is also sent to 
the inventor. Statistics on NIST evaluations since the inception of the program are presented in Section 2.

\subsection{SUPPORT PROCEDURES (DOE)}

Upon receipt of a recommendation from NIST, DOE contacts the inventor, provides details of the support procedures, and requests a statement as to the nature and extent of support desired, generally in the form of a proposal or grant application. The DOE invention coordinator works with the inventor in proposal preparation to ensure effective review of support options and to develop a satisfactory statement of work and support plan. DOE then decides whether or not to provide support as well as the nature and extent of support.

If financial support is to be provided, DOE initiates procurement action, monitors progress of the procurement action, and helps to expedite processing of the paperwork until the award is made. As of December 1991 DOE has awarded a total of $\$ 29.6 \mathrm{M}$ to 394 of the inventions recommended by NIST. During the period that financial or other support is provided, the DOE invention coordinator monitors and assists the inventor's efforts, maintaining a status report for use by both DOE and NIST.

\subsection{SUPPLEMENTARY ACTIVITIES}

\subsubsection{National Innovation Workshops (NIW)}

This project was initiated in early 1980 as a means of informing inventors about the Program and increasing the percentage of higher-quality inventions submitted to OTEA. Another objective of the Workshop series is to assist inventors (thus to stimulate innovation in general) by putting them in touch with their community resources and by providing practical instruction in the various elements of the innovation process.

Workshops are conducted in a standard format as two-day seminars. On each day a plenary session and a luncheon session feature national-level speakers on invention and innovation. Three 1-1/2 hour periods each day then are designated for the conduct of 8 to 10 concurrent Workshop sessions.

The Workshops are organized as regional activities by a committee composed of representatives from such regional organizations as universities, venture or other financing groups, private sector institutions concerned with technological innovation, state and local government agencies, patent law associations, etc. Federal involvement is restricted to providing guidance and financial support. The federal role is catalytic in nature in that Workshop feasibility is demonstrated with an expectation that the regional committee will continue to hold Workshops and similar activities in the future without federal involvement.

Sixty four NIWs have been held to date, including five in calendar year 1991. Six NIWs are scheduled for calendar year 1992. Attendance has averaged about 250 inventors and small businesses. 


\subsubsection{Commercialization Planning Workshops (CPW)}

This series of workshops, managed entirely by DOE, was initiated in June 1984 as a mechanism for providing direct and immediate assistance to inventors whose inventions have been recommended by NIST. Each workshop brings together a group of 10-14 such inventors for a three-day meeting with a "faculty" of six workshop leaders who are selected by DOE on the basis of their expertise in at least one aspect of innovation (business planning, marketing, finance, licensing, etc.). Workshop attendance is limited to inventors invited by DOE and the faculty.

The three-day meeting is devised to provide a concentrated educational/informative experience for each recommended inventor; travel and other meeting expenses are paid for by the Government. The objective in each case is for the recommended inventor to develop, with the aid of the faculty, a detailed plan for commercialization of his invention. The plan then serves as the principal basis for the DOE office to conduct its initial review of the recommendation (Analysis).

\subsection{NATURE OF THIS REPORT}

This report comprises an introductory section (Section 1) and a report section (Section 2).

Section 2 is the main body of the report and contains a brief description of each invention, a summary of its status, the identity of the DOE staff coordinator for that invention, the date the invention was submitted to NIST and the date recommended to DOE. The name and address of the person to contact regarding the invention are also included whenever they are available, as are the patent numbers and DOE grant numbers. The inventions are presented in chronological order of their recommendation by NIST. 


\section{SECTION 2 \\ STATUS OF RECOMMENDED INVENTIONS}

\subsection{Introduction}

This section contains an index and brief descriptions of those inventions recommended by the Office of Technology Evaluation and Assessment at NIST to the Energy Related Inventions Program office at DOE. Each description includes a brief description of the invention, a summary of the invention status, significant dates, status, and summary of development. The name of the inventor, primary contact for information, and DOE staff coordinator are also provided. The address of the contact is provided if an award has been made. At the time of receipt, DOE assigns a number (DOE No.) to each recommended invention. These numbers are used for tracking purposes and are also the key for sequencing the descriptions presented in this section. Section 3 presents four cross reference lists for locating specific invention descriptions. These lists provide cross reference between DOE No. and Inventor name, Contact name, invention classification, and inventor state.

\subsection{Index to Recommended Inventions}

The following is an index to the recommended inventions showing invention DOE No., invention status and title. Status is described in terms of the following steps in the DOE support process.

Analysis

Decision Phase

Other Assistance

Procurement

Award

No Basis For Support

Complete
DOE review of recommendation. Inventor has submitted description of proposed work. Options for support are investigated.

Final Statement of Work derived from above options. Inventor requested to submit supporting documents for procurement action. Prepare purchase request.

Federal Laboratory testing, or business planning assistance, often leading to a grant award outside of ERIP.

Request for grant or contract in the procurement process.

Inventor awarded grant or contract. Work commences. Final report due at end of work period.

Sources of support within DOE have been investigated, but recommendation will not be supported, e.g., inventor not interested, no area of DOE support could be identified, conflict with other DOE awardees being supported.

Inventor has complied with all the requirements of the Statement of Work or ERIP assistance is terminated. 


\section{INDEX TO RECOMMENDED INVENTIONS}

DOE

No.

0001 No DOE Support

0002 Other Assistance

0003 Complete

0004 Complete

0005 Complete

0006 Complete

0007 Complete

0008 Complete

0009 Complete

0010 Complete

0011 Complete

0012 Complete

0013 Complete

0014 Complete

0015 Complete

0016 Complete

0017 Complete

0018 Complete

0019 Complete

0020 Complete

0021 Complete

0022 No DOE Support

0023 No DOE Support

0024 Complete

0025 Complete

0026 Complete

0027 Complete

0028 Other Assistance

0029 Complete

0030 Complete

0031 Complete

0032 Complete

0033 Complete

0034 Complete

0035 No DOE Support

0036 Complete

0037 No DOE Support

0038 Complete

0039 No DOE Support

0040 No DOE Support

0041 No DOE Support

0042 Complete

0043 Complete
TITLE

Demand Metering System for Electric Energy

Fuel Miser

Hydrogen Generation from Producer Gas by Oxidation-Reduction of Tin

Power Conversion of Energy Fluctuations

Diesel Engine Conversion System for Gasoline Engines

Micro-Carburetor

Hydraulically Powered Waste Disposal Device

Inertial Storage Transmission

Heat/Electric Power Conversion via Charged Aerosols

Scrap Metal Preheating Method and Apparatus

Solar Collector

High Frequency Energy Saving Device

Anti-Pollution System

Aerodynamic Lift Translator

Estacron

Method and Apparatus for Vacuum Drying of Commodities

Osmotic-Hydro Power Generation

The Control of the Analysis of Low Carbon Aluminum Steels Using Oxygen Sensors and Iron-Aluminum Alloy

Phenol Methylene Foam Rigid Board Insulation

Thermal Shade

Waste Oil Utilization System

Fuel Burner Attachment

Microgas Dispersions

Can and Bottle Crushing Apparatus

Sulfur Removal from Producer Gas-High Temperature

Compact Energy Reservoir

Waste Heat Utilization for Commercial Cooking Equipment

Ultraflo

Tuned Sphere Stable Ocean Platforms

Method of Removing Sulfur Dioxide from Flue Gases

Ceramic Rotors and Vanes

Wood Gas Reactor

Temperature Indicating Device

Delphic Thermogenic Paint (Heat Film)

Utilization of Solar Energy by Solar Pond System

Computerstat

Hotwater Engine

Reduction Volatilizations

Lawler Steam Generator and Lawler System of Thermal Oil Recovery Improved Equipment and Process for Production of Blue Water Gas Fabrication of Photovoltaic Devices by Solid Phase Growth of Semi-conductors from Metal Layers

Flue Baffle Assembly

Thermal Gradient Utilization Cycle 
0044 Complete

0045 Complete

0046 Complete

0047 Complete

0048 No DOE Support

0049 No DOE Support

0050 Complete

0051 No DOE Support

0052 No DOE Support

0053 Complete

0054 Complete

0055 No DOE Support

0056 Complete

0057 Complete

0058 Complete

0059 No DOE Support

0060 Complete

0061 Complete

0062 Complete

0063 Complete

0064 Complete

0065 Complete

0066 Complete

0067 Complete

0068 Other Assistance

0069 Complete

0070 Complete

0071 No DOE Support

0072 No DOE Support

0073 Complete

0074 Complete

0075 Complete

0076 Complete

0077 Complete

0078 No DOE Support

0079 Complete

0080 No DOE Support

0081 Complete

0082 Complete

0083 Complete

0084 No DOE Support

0085 Complete

0086 Complete

0087 Complete
New Working Fluids for Increasing the Cycle Efficiencies of Thermal

Bulk Cure Tobacco Barn with Improvements

Thexon Dehydration

Wastewater Aeration Power Control Device

Howald Combustor

Automatic Control System for Water Heaters

Scotsman Fuel Energizer

Thermal Efficiency Construction

Air Wedge

High Efficiency Water Heater

Optimizer

Electrically Heated Sucker-Rod

Flexaflo-The Wet Fuel Dryer

X-5 Smoke Eliminator

A Multiple Spark System Using Inductive Storage

The Volumetric Gas Turbine

Electric Transport Refrigerator

Fuel Preparation Process

Tapered Plate Annular Matrix

Fluorobulb

The Mahalla Process--A Hydrometallurgical Method for Extracting Copper

WattVendor

Heat Extractor

Windmill Using Hydraulic System for Energy Transfer and Speed Control

Under Compressioon and Over Compression Free Helical Screw Rotary Compressor

Ionic Fuel Control System for the Internal Combustion Engine Air Cooled Compressor Heat Recovery and Heat Circulation System plus Ambient Air Filter and Air Cleaner

Knight Guard

Utilization of Waste Gas for Boilers and Furnaces in Refineries and Petrochemical Plants

INTECH

A Solid Electrolyte Galvanic Solar Energy Conversion Cell

Coke Quenching Steam Generator

The Ross Furnace

Variable Heat Refrigeration System

System for High Efficiency Power Generation from Low Temperature Sources

Oil Well Bit Insert (Tooth), Cutting Article, Ablative

Improved Unfired Refractory Brick

Flash Polymerization

Cool Air Induction

Vertical Solar Louvers

Kinetic Energy Type Pumping System

Dielectric Windowshade

Coke Desulfurization

Recovering Uranium From Coal in Situ 
INDEX TO RECOMMENDED INVENTIONS(cont.)

DOE

No.

0088 Complete

0089 Complete

0090 No DOE Support

0091 Complete

0092 No DOE Support

0093 Complete

0094 Complete

0095 No DOE Support

0096 Complete

0097 Complete

0098 Complete

0099 Complete

0100 Complete

0101 Complete

0102 Complete

0103 Complete

0104 Complete

0105 Complete

0106 No DOE Support

0107 Complete

0108 Complete

0109 Complete

0110 Complete

0111 Complete

0112 Complete

0113 Complete

0114 No DOE Support

0115 Complete

0116 No DOE Support

0117 Complete

0118 Complete

0119 No DOE Support

0120 Complete

0121 No DOE Support

0122 Complete

0123 Complete

0124 No DOE Support

0125 Complete

0126 Complete

0127 Complete

0128 Complete
TITLE

System-100

Continuous Casting Process and Apparatus

Grain Dryer

Mine Brattice

Tri-Water, A Combination Air Conditioning and Fire Protection System for a Building.

Shelander-Burrows Process for Recovery of Metallic Values from Smelter Emissions

Lantz Converter

Omni-Horizontal Axis-Wind Turbine

Leavell, Vibrationless, Low Noise, High Efficiency, Pneumatic Percussion Tools and Air Compressor Systems

Water Drying System

Process Development to Conserve Energy and Material---(in the manufacture of)---Bearings

Light Weight Composite Trailer Tubes

Solaroll

Controlled Combustion Engine

Method of Burning Residual Fuel Oil in Distillate Fuel Oil Burners

Low Voltage Ionic Fluorescent Light Bulb

Low Continuous Energy Mass Separation System

High Frequency Furnace

Deep Shaft Hydro-Electric Power

Waste Products Reclamation Process

Processing Recovery of Aluminum

Hydrostatic Meat Tenderizer

Improved Windpower Generating System

Haspert Mining System

Pump

Wallace Mold Additive System

New Energy-Saving Tire for Motor Vehicles

Refrigeration System

Model 5000 ASEPAK System

"Solarspan" Prism Trap

Energy Adaptive Control of Precision Grinding

Air Ratio Controller (AERTROL)

Vapor Heat Transfer Commercial Griddle

Solar Space Heating for both Retrofit and New Construction

Lean Limit Controller

Comminution of Ores by a Low-Energy Process

Solar Collector

The Turbulator Burner System

Vaclaim

Process and Apparatus to Produce Crude Oil from Tar Sands

Continuous Distillation Apparatus and Method 
INDEX TO RECOMMENDED INVENTIONS (cont.)

DOE

No.

STATUS

0129 Complete

0130 No DOE Support

0131 Complete

0132 No DOE Support

0133 Complete

0134 Complete

0135 Complete

0136 Complete

0137 Complete

0138 No DOE Support

0139 No DOE Support

0140 Complete

0141 Complete

0142 Complete

0143 Complete

0144 No DOE Support

0145 Complete

0146 Complete

0147 No DOE Support

0148 Complete

0149 Complete

0150 Complete

0151 No DOE Support

0152 Complete

0153 No DOE Support

0154 No DOE Support

0155 Complete

0156 Complete

0157 Complete

0158 Complete

0159 Complete

0160 Complete

0161 Complete

0162 Complete

0163 Complete

0164 Complete

0165 Complete

0166 Complete
TITLE

Super U System - Snap Strap

Furnace Input Capacity Trimming Switch

Valve Deactuator for Internal Combustion Engines

Process for Reclaiming and Upgrading Thin-Walled Malleable Waste Material

AUTOTHERM Car Comfort System

Expanded Polystyrene Bead Insulation System

Point Focus Parabolic Solar Collector

Windamper

A Portable Pollution Free Automobile Incinerator

Phantom Tube

Transformer With Heat Dissipator

Counter Flow Dual Tube Heat Exchanger

New Hydrostatic Transmission

Process for Heatless Production of Hollow Items

Oil Well Pump Jack

SpaCirc Space Circulation Fan

Solar Conversion by Concentration Cells with Hydrides

Line Integral Method of Magneto-Electric Exploration

Railroad Switch Heater

Reclaimation of $\mathrm{Oil}$ and High-Grade Iron Concentrates from Steel Mill Wastes

SCOTCH - (Simple, Cost-Effective, Optimum Temperature Control for Housing)

The Use of Solid Waste Material from a Lubricating Oil and/or Vegetable Oil Refining Operation.

Film Type Storm Window

Vehicle Exhaust Gas Warm-up System

A New Equipment Design Concept for Storage of Hot Foods

Rotating Horsehead for Pumping Units

Slip Mining

Direct-Current Electrical Heat-Treatment of Continuous Metal Sheets in a Protective Atmosphere.

Magnaseal Method and Means for Sealing Steel Ingot Casting Molds to Stools.

Energy Conservative Electric Cable System

Non-Tubing Type Lift Device, Described as the NTT Rabbit

High Efficiency Absorption Refrigeration Cycle

duPont Connell Energy Coal Gasification Process

Tubular Pneumatic Conveyor Pipeline

Thermotropic Plastic Films

Elastomer Energy Recovery Elements and Vehicle Component Applications

Process for Recovering Hydrogen and Elemental Sulfur from Hydrogen Sulfide and/or Mercaptans-Containing Hydrogen

Borehole Angle Control 


\section{INDEX TO RECOMMENDED INVENTIONS (cont.)}

DOE

No.

0167 Complete

0168 Complete

0169 No DOE Support

0170 No DOE Support

0171 Complete

0172 Complete

0173 Complete

0174 No DOE Support

0175 Complete

0176 No DOE Support

0177 Complete

0178 Complete

0179 Complete

0180 Complete

0181 Complete

0182 Complete

0183 Complete

0184 No DOE Support

0185 No DOE Support

0186 No DOE Support

0187 No DOE Support

0188 Complete

0189 Complete

0190 Complete

0191 Complete

0192 Complete

0193 Complete

0194 Complete

0195 Complete

0196 Complete

0197 Complete

0198 No DOE Support

0199 Complete

0200 Complete

0201 Complete

0202 Complete

0203 Complete

0204 No DOE Support

\author{
TITLE
}

Vaned Pipe for Pipeline Transport of Solids

The Hot Water Saver

MIRAFOUNT

Fog System - Low Energy Freeze Protection for Agriculture

A Method of Preserving Fruits and Vegetables without

Refrigeration

GEM Electrostatic Filtration System

Thermal Ice Cap

Skate on Plastic Ice Skating System

A Low-Energy Carpet Backing System

Self-Contained, Water Proof, Stoker Fired, Fully Automatic, Portable Solid Fuel Furnaces

The Solar I Option

Process and Apparatus for Producing Cellulated Vitreous Refractory Material

Development and Commercialization of Low Cost, Non-Metallic, Solar Systems

Adjustable Solar Concentrator (ASC)

The Karlson Ozone Sterilizer

Improved Seal for Geothermal Drill Bit

Increased Vapor Generator Feature. Reheat Vapor Generator

Coasting Fuel Shutoff

Insulated Garage Door

Oil Recovery by In-Situ Exfoliation Drive

Variable Field Induction Motor

Remote Controlled Underground Mining System for Horizontal or Pitching Seams

Pump Jack

Oxygen-Conducting Material and Oxygen-Sensing Method

Rotary Heat Pump Air Conditioner, Heater and Ventilator for Automotive, Mobile and Stationary Use.

Closed Cycle Dehumidification Clothes Dryer

Engine Heating Device

Radiant Energy Power Source for Jet Aircraft

Proportional Current Battery

Manufacturing and Using Nitrogen Fertilizer Solutions on a Farm Frequency Regulator and Protective Devices for Synchronous Generators

The Thermatreat system

Rotary Coal Combustor and Heat Exchangers

Removal of Sulfur Dioxide from the Stack Gas of Combusters Burning High Sulfur Fuel

Hydraulic, Variable, Engine Valve Actuation System

Wobbling Type Distillation Apparatus

Microwave Methods and Apparatus for Paving and Paving Maintenance The Induction Propeller 
INDEX TO RECOMMENDED INVENTIONS(cont.)

DOE

No.

0205 No DOE Support

0206 Complete

0207 Complete

0208 Complete

0209 Complete

0210 Complete

0211 Complete

0212 Other Assistance

0213 Complete

0214 Complete

0215 Complete

0216 Complete

0217 Complete

0218 Other Assistance

0219 Complete

0220 Complete

0221 Other Assistance

0222 Other Assistance

0223 Complete

0224 Complete

0225 Complete

0226 No DOE Support

0227 Complete

0228 Complete

0229 No DOE Support

0230 Complete

0231 Complete

0232 Complete

0233 No DOE Support

0234 Complete

0235 Complete

0236 Complete

0237 Complete

0238 Complete

0239 Complete

0240 No DOE Support

0241 Complete
TITLE

Energy Efficient Solid State Multiple Operator Metallic Arc Welding System

Method and Apparatus for High Efficiency Operation of Electromechanical Energy Conversion

Glass Sheet Manufacturing Method and Apparatus

CNG Automotive Fuel Cylinders/Gas Transport Modules

Reclaiming Process for Resin Treated Fiberglass

Ultra High Speed Drilling Device for Use in Hard Rock Formations

Shock Mounted Stratapax Bit

Water Warden

The Kaunitz Process for Welding Pipe

Convertible Flat/Drop Trailer

Slag Waste Heat Boiler

Method and Assembly for Mounting a Semiconductor Element

Jointless Advanced Composite Material Tape for Operating Lift

Pumps in Oil Wells

Behemoth

Method for Making Acelaldehyde from Ethanol

Deep Throat Resistance Welder

Strainercycle

Louver Trombe Solar Storage Unit

Minimizing Subsidence Effects during Production of Coal In Situ

Haile Alternate Fuel Grain Dryer

ROVAC High Efficiency Low Pressure Air Conditioning System

An Electronic Anemometer System for Locating Air-Infiltration

Heat Leaks in Buildings

CRM Pipe

EGD Fog Dispersal System

Contoured Finger Follower Variable Valve-Timing Mechanism for Internal Combustion Engines

Absorption Heat Pump Augmented Separation Process

Natural Gas from Deep-Brine Solutions

Method of Separating Lignin and Making Epoxide-Lignin

Mounted Steerable Ripper for Deep Soil Ripping and Subsoil Operations

Geodesic Solar Paraboloid

Single Stage Anaerobic Digestion Process

Steam Turbine Packing Ring

Hicks Alter-Brake System/Electric Charging Apparatus for Ground Vehicles

Industrial and Residential Clothes Dryer Automatic Shut-Off at Dryness

Electrochemical Separation and Concentration of Sulfur-Containing Gases from Gas Mixtures

All Steam Heated Sadiron for Commercial Use

Polysulfide Oil Field Corrosion Control System 
INDEX TO RECOMMENDED INVENTIONS(cont.)

DOE

No. STATUS

0242

Complete

0243 Complete

0244 Complete

0245 Complete

0246 No DOE Support

0247 Complete

0248 Complete

0249 Complete

0250 Complete

0251 Complete

0252 Complete

0253 Complete

0254 Complete

0255 No DOE Support

0256 Other Assistance

0257 Complete

0258 Complete

0259 Complete

0260 Complete

0261 Other Assistance

0262 Complete

0263 No DOE Support

0264 Complete

0265 Complete

0266 Other Assistance

0267 Complete

0268 Complete

0269 No DOE Support

0270 Complete

0271 Complete

0272 Complete

0273 No DOE Support

0274 Complete

0275 Complete

0276 Complete

0277 No DOE Support

0278 Complete
New Petersburg Beam Trawl

An Electronic/Pneumatic Ejector System for Producing an Aluminum Rich Concentrate from Municipal Waste

CHARLIE - Trademark - Federally Registered 1123957

Improved Oil Well Pumping Unit

Maximum Cruise Performance

Energy Conservation by Improved Control of Bulk Power Transfers on Interconnected Systems

Dyna-Bite Traction Intensifier, Model Agri, for Agricultural Tractors or the Like

Subsurface Flow Control (Gas Wells) and High Gas-Oil-Ratio Oil Wells

A System to Adapt Diesel Engines to the Use of Crude Oils

Process and Apparatus for Reducing the Energy Required to Separate Liquids by Distillation

Thermal Bank

High Performance Heat Pump

"Turbo-Glo" Immersion Furnace

Method and Apparatus for Scrubbing Gas - Scrubbing Apparatus

Method and Apparatus for Irrigating Container Grown Plants

Method and Apparatus for Melting Snow

Corrosion Protection Process for Bore Hole Tool

Hydrostatic Support Sleeve and Rod - Gas Release Probe

Method and Apparatus for Handling and Dry Quenching Coke

A New Apparatus for Making Asphalt Concrete

Energy Saving Pump and Pumping System

Method for Reconditioning Rivetless Chain Links

Desulfurization of Coal

Flozone method and Apparatus for Direct Application of Treatment Liquid to Growing Vegetation

Energy Conversion Method

Integrated Gasification of Coal, Municipal Solid Wastes and Sludge

Apparatus for Enhancing Chemical Reactions

Refrigerant Accumulator and Charging Apparatus

Method of Energy Recovery for Wastewater Treatment

Hydrogen Storage System

V-Plus System

Open Cycle Latent Heat Engine

Flexible Lighting - Fluorescent Lighting Operating at Radio Frequency

Low Head - High Volume Pump

Gas Concentration Cells as Converters of Heat into Electrical Energy

Electronic Conveyor Control Apparatus

Complete System for Large Solar Water Heating and Storage 
INDEX TO RECOMMENDED INVENTIONS(cont.)

DOE

No.

0279 Complete

0280 Complete

0281 Complete

0282 Complete

0283 Complete

0284 Complete

0285 Award

0286 No DOE Support

0287 Complete

0288 No DOE Support

0289 Complete

0290 Complete

0291 Complete

0292 Complete

0293 Complete

0294 Complete

0295 Complete

0296 Complete

0297 Complete

0298 Complete

0299 Complete

0300 Complete

\author{
TITLE
}

Method and Means for Preventing Frost Damage to Crops

Down Hole and Above Ground Resistance Heating for Paraffin

Elimination

Sun Synchronous Solar Powered Refrigerator

Insulated Siding

Aluminum Roofing Chips

Atomized Oil-Injected Rotary Screw Compressors

Novel Fluid Ring (F/R) Seal Systems for Railroad Axle Bearing Systems

Use of Pulse-Jet for Atomization of Coal/Water Mixture

Automatic Variable Pitch Marine Propeller

Dickinson Pure Air Combustion (DIPAC) and Modified DIPAC (MODIPAC)

An Earthquake Barrier

Low Energy Ice Making Apparatus

Selective Zone Isolation for HVAC System

Roof Construction Having Membrane and Photo Cells

"Therm-A-Valve" - Insulated Valve Coverings

Highway Power Patcher

Improved Method of Electroplating Aluminum for Corrosion Resistance

Shower Bath Economizer

Series (Two-Wire) V-Controller

Three Tenths Degree Kelvin Closed Cycle Refrigeration System Process for Using Cocurrent Contacting Distillation Column Casing Stabbing Apparatus 


\subsection{Brief Descriptions of Recommended Inventions}

The following presents brief descriptions of each of the inventions recommended by the Office of Technology Evaluation and Assessment at NIST to the Energy Related Inventions Program office at DOE. Each description includes a brief description of the invention, a summary of the invention status, significant dates, status, and summary of development. The name of the inventor, primary contact for information, and DOE staff coordinator are also provided. The address of the contact is provided if an award has been made. The descriptions are presented in DOE number sequence. Section 3 presents four cross reference lists for locating specific invention descriptions. These lists provide cross reference between DOE No. and Inventor name, DOE No. and Contact name, DOE No. and Inventor state, and Doe No, and invention classification. 
DOE No: 0001

DOE Coord: G. K. Ellis

Title: Demand Metering System for Electric Energy

Description: The invention provides a means whereby a consumer's electric meter can be adjusted by the electric company to run at a faster rate at times of greater loads upon the utility system - load leveling.

Inventor: Willard Graves

State : MD

Status: No DOE Support
Contact:

Murray G Lowenthal

Status Date: 07/07/77 OERI No.: 000019

Patent Status : Patent Number: 3683343

Development Stage : Concept Development

Technical Category: Miscellaneous

Recv. by NIST : 05/23/75

Recom. by NIST : 02/12/76

Summary: No area of appropriate DOE support could be identified.

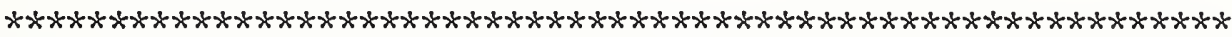

DOE No: 0002

DOE Coord: G. K. Ellis

Title: Fuel Miser

Description: The device is an attachment which can be used to retrofit a room thermostat with a synchronous motor-driven clock timer and an auxiliary heating element to enable it to have a temperature set-back cycle.

Inventor: Rita Paleschuck State : NY

Status: Other Assistance
Contact:

Rita Paleschuck

$$
\text { Status Date: 07/15/76 OERI No.: } 000100
$$

Patent Status : Not Applied For

Development Stage : Production \& Marketing

Technical Category: Buildings, Structures \& Components

Recv. by NIST : 07/14/75

Recom. by NIST : 02/19/76

Summary:

No research and development required, since the device is on the market. A generic brochure was written and published on the "need for automatic temperature setback." Extensive distribution was accomplished through DOE's Office of Public Affair's "supermarket handout" program and General Services Administration's Consumer Information Center. 
DOE No: 0003

DOE Coord: J.Aellen

Title: Hydrogen Generation from Producer Gas by Oxidation- Reduction of Tin

Description: A new approach to the generation of tonnage hydrogen from carbonaceous fuels. Two reactions:/ steam with tin, whereby hydrogen is produced, and the reduction of the tin oxide produced in the first reaction back to tin.

Inventor: Donald C Erickson

State : MD
Contact:

Donald C Erickson

Director of Research

Energy Concepts Co.

1704 South Harbor Lane

Annapolis MD 21401

$301-266-6521$

Status: Complete

Status Date: 03/18/81

OERI No.: 000003

$\begin{array}{ll}\text { Patent Status } & \text { Patent Applied } \\ \text { Development Stage } & \text { Laboratory Test }\end{array}$

Technical Category: Other Natural Sources

Recv. by NIST : 05/07/75

Recom. by NIST : $05 / 21 / 76$

Award Date : $07 / 12 / 78$

Contract Period: 07/12/78

Award Amount: $\$ 80,820$ Grant No: FGO1-78IR10103

$-03 / 18 / 81$

Summary: A grant was awarded and completed for the grantee to identify the optimum operating conditions, and to do -an economic study. Results showed efficiency less than predicted - which in turn, leads to marginal economics. There is a possibility for improvement with more $\mathrm{R} \& \mathrm{D}$. Inventor seeking licensee.

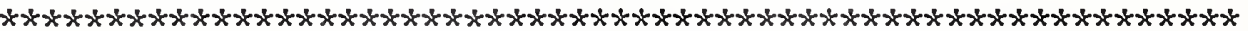

DOE No: 0004

DOE Coord: G.K.Ellis

Title: $\quad$ Power Conversion of Energy Fluctuations

Description: A solid state device is claimed that can transfer thermal energy into usable electrical power with high efficiency, by cascading large numbers of such circuits.

Inventor: Joseph C Yater

State : MA

Status: Complete

Patent Status

Development Stage:

Technical Category:

Recv. by NIST

Recom. by NIST $: 06 / 04 / 76$

Contract Period: 06/04/76
Contact:

Joseph C Yater

Autumn Lane

Lincoln MA 01773

$617-259-8544$
OERI No.: 000230

Summary:

Status Date: 06/15/77

Patent Applied For

Concept Development

Direct Solar

Award Amount: $\$ 40,400$ Grant No:

- 06/15/77 A grant was awarded to define an adequate development plan. The plan was incompatible with present state-of-art of micro- device manufacturing. 
DOE No: 0005

DOE Coord: G. K. Ellis

Title: Diesel Engine Conversion System for Gasoline Engines

Description: The system is proposed for converting a standard gasoline auto engine into a diesel engine

Inventor: George C Austin State : $\mathrm{CA}$

Status: Complete

Patent Status

Development Stage : Engineering Design

Technical Category: Combustion Engines \& Components

Recv. by NIST : 06/30/75

Recom. by NIST : 08/12/76

Award Date: : 11/20/77

Contract Period: 11/20/77

Award Amount: $\$ 18,000$ Grant No: EM78-G-01-4263

$-11 / 20 / 78$

\author{
Contact: \\ - George C Austin \\ Austin Tool Company \\ 2239 North Loma Ave. \\ South E1 Monte CA 91605 \\ $213-442-7338$
}

Status Date: 11/20/78

OERI No.: 000088

Summary: A grant was awarded for a marketing study was awarded, and completed. Significant interest by those surveyed was expressed in the Austin diesei conversion, if they were having their engine rebuilt.

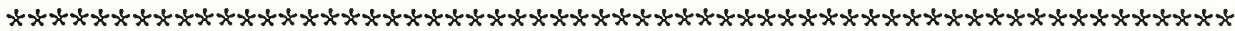

DOE No: 0006

DOE Coord: D. G. Mello

Title: Micro-Carburetor

Description: A new kind of carburetor which is claimed to be fuel-saving and pollution-reducing.

Inventor: Albert B Csonka

State : NY

Status: Complete

Patent Status

Development Stage : Engineering Design

Technical Category: Combustion Engines \& Components

Recv. by NIST : 09/15/75

Recom. by NIST : $08 / 17 / 76$

Award Date : $09 / 15 / 77$

Contract Period: 09/15/77
Award Amount: $\$ 193,500$ Grant No:

- $12 / 17 / 80$

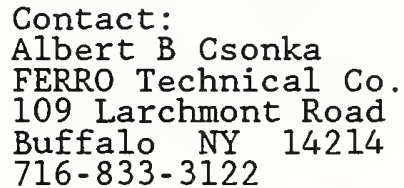

$716-833-3122$

Summary: A grant was awarded to build a working micro-carburetor, sized to fit a late model, standard 350 cubic inch V-8 engine. Contract is being administered by Office of Transportation Programs, DOE. Carburetor was tested by NASA's Jet Propulsion Lab and report \#JPL 81-75, August, 1981 shows improvements ranging from 9 to $18 \%$ over standard carburetor. 
DOE No: 0007

DOE Coord: G. K. Ellis

Title: Hydraulically Powered Waste Disposal Device

Description: The device is to replace conventional food waste disposal units which are powered by electric motors.

Inventor: David Virley

State : CA
Contact:

Len Speiber

Wastemate Corporation

4830 Viewridge Avenue

San Diego CA 92123

- 619-292-3122

Status: Complete

Status Date: 08/20/79

OERI No.: 000387

\begin{abstract}
Patent Status : Patent Number: 3700178
Development Stage : Production \& Marketing

Technical Category: Miscellaneous
\end{abstract}

Recv. by NIST: 11/10/75

Recom. by NIST : $08 / 26 / 76$

Award Date : 08/20/78

Contract Period: 08/20/78

Award Amount: $\$ 28,000$ Grant No: EM78-G-01-5034

- 08/20/79

Summary:

A grant was awarded and completed for the grantee to prepare a qualified business plan to assist in acquiring the necessary capital funding. The company went public and raised $\$ 1.5$ million which was used mainly to buy production tools. The company is now in production. Follow-on financing desired by grantee.

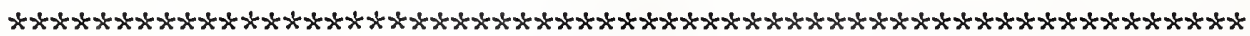

DOE No: 0008

DOE Coord: D.G.Mello

Title:

Inertial Storage Transmission

Description: The device is a system for improving the efficiency and reducing the fuel consumption of a motor vehicle, utilizing a regenerative hydraulic system to store the kinetic energy from deceleration for use in accelerating the vehicle.

Inventor: Vincent E Carman

State : OR

Status: Complete

Patent Status

Development Stage: Prototype Test

Technical Category: Transportation Systems, Vehicles \& Components

Recv. by NIST : 11/12/75

Recom. by NIST : 09/03/76

Award Date $\quad 07 / 21 / 81$

Contract Period: 07/21/81

Award Amount: $\$ 49,541$ Grant No: FG01-81CS15069

- $08 / 31 / 82$

Summary:

A grant was awarded for final preparation of vehicle to present to EPA for testing. Olsen Corporation has tested the device. Ownership changed recently and financing is at a reputed level of $\$ 3.2$ million with 7 employees. Product is available for distribution. Engineering details available from company. 
DOE No: 0009

DOE Coord: D. G. Mello

Title: Heat/Electric Power Conversion via Charged Aerosols

Description: This device is to convert thermal energy to electric energy without the use of moving parts.

Inventor: Alvin M Marks

State : NY
Contact:

Alvin M Marks

Marks Polarized Corp.

153-16 Tenth Avenue

Whitestone NY 11358

212-767-9600

Status: Complete

Status Date: 05/09/79

OERI No.: 000151

Patent Status : Patent Applied For

Development Stage : Laboratory Test

Technical Category: Miscellaneous

Recv. by NIST : 08/04/75

Recom. by NIST : $09 / 13 / 76$

Award Date : $03 / 01 / 78$

Contract Period: 03/01/78

Award Amount: $\$ 50,000$ Grant No: EU78-G016225

- $08 / 31 / 78$

Summary:

A grant was awarded to construct and test an Electro Gas Dynamics Generator, and then use this device to investigate the condensation charging of a steam jet. This project was followed by a three year project funded by another DOE program, to build and test a lokw laboratory model of the device, of which the first year funding was $\$ 199,077$. (The company's work force averages 25 people.)

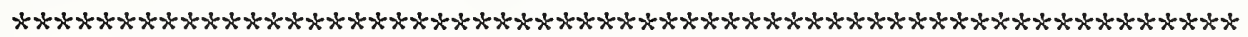

DOE No: 0010

DOE Coord: G. K. Ellis

Title:

Scrap Metal Preheating Method and Apparatus

Description: The device provides a means of extracting waste heat from hot ingots and billets and utilizing this waste heat to preheat scrap steel prior to placing it in an electric-arc furnace.

Inventor: Harrison Robert Woolworth State : WA

Contact:

Harrison Robert Woolworth

International Preheater

P.O. Box \#88218

- Tukwila Branch

Seattle WA 98188

206-852-1992

Status: Complete

Status Date: $10 / 23 / 78$

OERI No.: 000421

Patent Status

Development Stage : Production Engineering

Technical Category: Industrial Processes

Recv. by NIST

Recom. by NIST : $09 / 29 / 76$

Award Date : $12 / 23 / 77$

Contract Period: 12/23/77

Award Amount: $\$ 170,000$ Grant No: EM78-G-01-1797

- $12 / 23 / 78$

Summary:

A grant was awarded to design and fabricate hardware; and to operate a system utilizing waste heat for preheating scrap steel, in a working specialty steel mill. A 208 or more energy saving was demonstrated. Steel company interest has developed. Inventor obtained a $\$ 360,000$ SBA guaranteed loan, has built an operating unit costing $\$ 500,000$ at a steel pant in Knoxville, Tennessee, and has several additional $\$ 500,000$ units on order. The company employs three people. 
DOE No: 0011

DOE Coord: D. G. Mello

\section{Title: Solar Collector}

Description: This is a composite extruded aluminum section -- incorporating a cylindrical absorption tube that carries the working fluid. The collector surface is in the form of an Archimedes Spiral and a parabolic curve to maximize the collection angle and eliminate the need to reposition the collector.

Inventor: Ronald H Smith

State : CA

Status: Complete

Status Date: 11/19/80

Contact:

Ronald $\dot{H}$ Smith

150 Green Street

San Francisco CA 94111

$415-398-6813$

Patent Status : Not Applied For

Development Stage : Production Engineering

Technical Category: Direct Solar

Recv. by NIST : 09/09/75

Recom. by NIST : 09/29/76

Award Date : 05/17/78

Contract Period: 05/17/78

Award Amount: $\$ 46,884$ Grant No: EM78-G019214

- $11 / 19 / 80$

Summary:

A grant was awarded to Solergy, Inc., to initiate a series of marketing studies to determine the attitudes of Western U.S. manufacturers, distributors and designers, regarding prospects for successful installation of passive solar systems in new buildings. Survey results were used by Solergy to aid their marketing and manufacturing plans. Company is now out of business.

DOE No: 0012

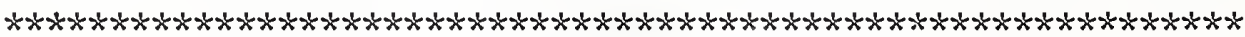

Title:

DOE Coord: G.K.E11is Description: This invention consists of a high-frequency generator, to excite one of allowing the system to operate at substantially higher efficiency.

Inventor: Frank R Summa

State : NY

Status: Complete

Patent Status

Development Stage : Engineering Design

Technical Category: Buildings, Structures \& Components

Recv. by NIST : 10/28/75

Recom. by NIST : 09/30/76

Award Date : $12 / 31 / 80$

Contract Period: 12/31/80

Award Amount: $\$ 30,000$ Grant No:

- $12 / 31 / 82$
Contact:

Thomas j Russo

100 Forest Avenue

Staten Island NY 10310

212-273-0248

Status Date: $12 / 31 / 82$

OERI No.: 000448

Summary: A grant was awarded to engage the services of Niesi-Fitzmaurice and Associates, Inc., to conduct a marketing study and prepare a preliminary business plan for the purpose of commercializing the technology. 
DOE No: $0013 \quad$ DOE Coord: P.M.Hayes

Title: Anti-Pollution System

Description: This device utilizes a high speed turbine to refine exhaust gases and recirculate the unburned portions of that gas to the engine.

Inventor: Ranendra $\mathrm{K}$ Bose

State : VA

Status: Complete

Status Date: 01/03/79

Contact:

Ranendra $\mathrm{K}$ Bose

$14346 \mathrm{Jacob}$ Lane

Centreville VA 22020

- 703-266-2379

Patent Status : Patent Number: 3861142

Development Stage : Limited Production/Marketing

Technical Category: Transportation Systems, Vehicles \& Components

Recv. by NIST : 06/03/75

Recom. by NIST : $09 / 30 / 76$

Award Date : 04/04/78

Contract Period: 04/04/78

Award Amount: $\$ 40,000$ Grant No: EM77-G014222

$-01 / 03 / 79$

Summary: A grant was awarded, and a prototype was built and tested. Project goals were met. Final Report was accepted. Inventor plans to seek private assistance for commercialization.

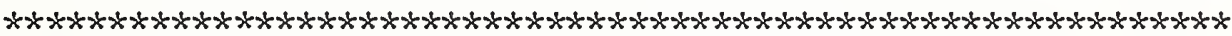

DOE No: 0014

DOE Coord: G K Ellis

Title:

Aerodynamic Lift Translator

Description: This device is a wind-activated power generating system intended to provide large power outputs in regions where the prevailing wind direction does not vary appreciably during the year. The device also has application in low-head hydro.

Inventor: Daniel J Schneider

State : TX

Status: Complete

Status Date: 01/11/79

Contact:

Daniel j schneider

Route \#1, Box \#81

Justin TX 76247

$817-430-0174$

Patent Status Development Stage : Production Engineering

Technical Category: Other Natural Sources

Recv. by NIST : 08/15/75

Recom. by NIST : 09/30/76

Award Date : $01 / 11 / 78$

Contract Period: 01/11/78

Award Amount: $\$ 50,000$ Grant No: EG-77-G01-7114

- $01 / 11 / 79$

Summary: A grant was awarded to develop performance and cost data for the "Schneider Aerodynamic Power Generator". The inventor is currently pursuing the hydro application, and asked for program assistance in obtaining venture capital. The translator still requires technical development. 
DOE No: 0015

DOE Coord: D.Mello

Title: Estacron

Description: Estacron consists of an aggregate of Portland cement, fly ash, stack dust, and polyethylene. It has significant potential as a light-weight and energy-conservative construction material.

Inventor: Dante A Raponi

State: NC
Contact:

James L Bullock

Suite \#403, Minges Building

P. O. Box \#7151

Greenville NC 27834

919-752-1138
Status: Complete

Patent Status

Development Stage $\vdots$ Laboratory Test

Technical Category: Buildings, Structures \& Components
Recv. by NIST : 10/28/75

Recom. by NIST : $09 / 30 / 76$

Award Date : 09/28/79

Contract Period: 09/28/79
A grant was awarded to conduct an application engineering and economic analysis of the material, Estacron, in order to assess its material characteristics and to recommend product applications. Results appear indeterminate. Inventor seeks funding for pilot plant design.

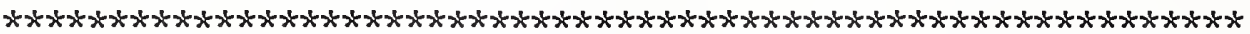

DOE No: 0016

DOE Coord: G. K. Ellis

Title:

Method and Apparatus for Vacuum Drying of Commodities

Description: This invention describes a new method of drying commodities, primarily applicable to such grains as corn, rice, and soybeans, by alternately exposing the commodities to dry heated air and to a vacuum.

Inventor: John $\mathrm{W}$ Bruce

State : SD

\section{Contact:}

John W Bruce

West Highway, \#16

Mitche11 SD' 57301

605-996-8335

Status: Complete

Status Date: 03/30/81

OERI No. : 000486

Patent Status : Patent Number: 3914874

Development Stage : Engineering Design

Technical Category: Industrial Processes

Recv. by NIST : 10/10/75

Recom. by NIST : $11 / 30 / 76$

Award Date $\vdots 03 / 30 / 80$

Contract Period: 03/30/80

Award Amount: \$ 52,917 Grant No: FG01-78IR04211

- $03 / 30 / 81$

Summary:

A grant was awarded to design, fabricate, and demonstrate a device for efficiently drying agriculture commodities. The Montana Energy and MHD Development Institute is managing the technical aspects of the program. In addition, the inventor received $\$ 32,000$ to dry whey from a private sector source. Results from all tests appear indeterminate. Inventor is interested in selling or licensing patent rights and has ceased work on the technology. 
DOE No: 0017

DOE Coord: D. G. Mello

Title: Osmotic-Hydro Power Generation

Description: The invention uses a reverse osmosis to produce high pressure liquid that can subsequently be passed through a hydraulic turbine to produce electric power.

Inventor: David W Doyle State : VA
Contact:

David W. Doyle, V.P.

Intertechnology Corp.

100 Main Street

Warrenton VA 22186
Status: Complete

Patent Status

Development Stage

Technical Category:
Status Date: 05/01/78

OERI No.: 000619

Recv. by NIST : 01/21/76

Recom. by NIST : $01 / 14 / 77$

Award Date : $08 / 11 / 77$

Contract Period: 08/11/77

Award Amount: $\$ 48,950$ Grant No: EG77-G014066

$-05 / 01 / 78$

Summary:

A grant was awarded for research and development of membranes suitable for use in a "Osmo-Hydro Power" system. Studies included membrane long-term effects, polarization dilution, and concentration. The research was judged as high quality by the cognizant DOE program office.

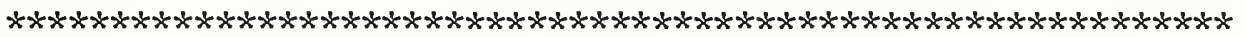

DOE No: 0018

DOE Coord: G.K.Ellis

Title:

The Control of the Analysis of Low Carbon Aluminum Steels Using Oxygen Sensors and Iron-Aluminum Alloy

Description: The production of Al "killed" steel is intended to be controlled by the use of $\mathrm{Fe}-\mathrm{A} I$ alloys instead of $\mathrm{Al}$ and by the use of oxygen probes to control the amounts of Al or oxygen in the melt.

Inventor: G R Fitterer State : PA

Status: Complete

Patent Status

Development Stage

Technical Category:

Industrial Processes

Recv. by NIST : $08 / 01 / 75$

Recom. by NIST : $01 / 31 / 77$

Award Date : $09 / 14 / 77$

Contract Period: 09/14/77

Award Amount: \$99,600 Grant No: EC77-G-01-5034

\section{Contact:}

G R Fitterer

P.0. Box \#206

Oakmont PA 15139

412-828-0233

Summary:

A grant was awarded for a system to conserve energy by monitoring and controlling the amount of oxygen in a low carbon aluminum killed steel melt. The system was highly successiul. On basis of the success, the steel company involved has initiated a research effort to apply the technology to other ferro melts. The technology is reported to have saved a steel company, doing $\$ 18 \mathrm{million} / \mathrm{yr}$ business from bankruptcy. 
DOE No: 0019

DOE Coord: P.M.Hayes

Title:

Phenol Methylene Foam Rigid Board Insulation

Description: This invention is a urea-formaldehyde phenol methylene modified form of insulating board material. Properties are similar to others on the market except for its fire retardancy and the low toxicity of its combustion products.

Inventor: Walter J Hasselman, Jr State : NY

\section{Contact:}

Clair $\mathrm{H}$ Reinbergen, Pres.

C. P. Chemical Co., Inc.

25 Home Street

White Plains NY 10606

914-428-2517
Status: Complete

\section{Patent Status}

Development Stage

Technical Category:
Status Date: 09/12/79

OERI No.: 000205

Recv. by NIST : 08/18/75

Recom. by NIST : 02/04/77

Award Date : 09/13/78

Contract Period: 09/13/78

Award Amount: $\$ 29,900$ Grant No: EU78-G-01-6603 - $09 / 12 / 79$

Summary: A grant was awarded to study physical properties of proprietary insulating material, and to determine the optimum ratios of base chemicals. The result was a product which maximizes insulating properties while minimizing costs. EPA temporary ban of formaldehyde led to a new product that eliminates formaldehyde without sacrificing performance. Additional testing on fire properties revealed a double five-hour rating over competitive products. The products are available for sale.

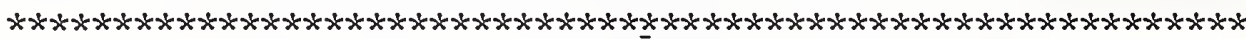

DOE No: 0020

DOE Coord: D. G. Mello

Title:

Thermal Shade

Description: The device is a multi-layer window shade to be fitted to conventional windows and to retract into a small space -- uses reflective surface coatings and with dead air spaces between the layers to reduce heat transfer.

Inventor: Thomas $\mathrm{P}$ Hopper

State : NH

Status: Complete

Patent Status

Development Stage :

Technical Category:

Recv. by NIST

Recom by NIST: $02 / 26 / 76$

Award Date : $05 / 17 / 78$

Contract Period: 05/17/78

Summary:
Contact:

Thomas $\mathrm{P}$ Hopper

103 Old Loudon Road

Concord NH 03301

603-225-7554

Status Date: 01/06/79

OERI No.: 000839

\section{Patent Applied For}

Production Engineering

Buildings, Structures \& Components
Award Amount: $\$ 50,707$ Grant No: EM78-G014268

- 01/06/79

A grant was awarded for the investigations and research of sheet material, seal configurations, and assemblies with third party testing. In addition, marketing assistance was supplied by MIT Innovation Center. Product is now being market tested. It is avai-lable for licensing. Last reported sales of $\$ 20,000$ per month with 40 people working 2 shifts. Similar devices are being sold by other companies. 
DOE No: 0021

DOE Coord: G. K. Ellis

Title:

Waste Oil Utilization System

Description: This invention would utilize existing emulsification machinery to add a mixture of used lubricating oil and water to fuel oil used in large power plant boilers. Key point is the use of existing additives in fuef oil to prevent boiler tube deposits.

Inventor: Robert $S$ Norris

State : MA
- Contact:

Robert $\dot{S}$ Norris

Energy Conservation Systems

Ten Starboard Way

Box \#472

West Dennis MA 02670

$617-398-3430$
Status: Complete

Patent Status

Development Stage :

Technical Category:
Status Date: 03/30/81

OERI No.: 000613

Recv. by NIST : 08/25/75

Recom. by NIST : 02/28/77

Award Date $\vdots 03 / 30 / 80$

Contract Period: 03/30/80

Award Amount: $\$ 50,000$ Grant No: EM78-G-01-4261

- $03 / 30 / 81$

Summary: A grant was awarded for the purpose of a market survey for use of waste automotive crankcase lubricating oil as a fuel additive to prevent boiler tube deposits, augment energy availability, and minimize environmental pollution. Utility plants, the prime potential user, were found to have little incentive to purchase the cheaper additive. Product available for licensing.

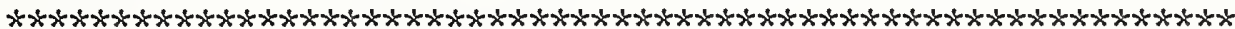

DOE No: 0022

DOE Coord: D. G. Mello

Title:

Fuel Burner Attachment

Description: Device to reduce oil consumption by introducing air to oil stream of the burner.

Inventor: Herbert G Lehmann State : CT

Status: No DOE Support
Contact:

Herbert G Lehmann

Status Date: 09/19/77 OERI No.: 000537

Patent Status : Not Applied For

Development Stage : Laboratory Test

Technical Category: Buildings, Structures \& Components

Recv. by NIST : $12 / 29 / 75$

Recom. by NIST : 02/28/77

Summary: The inventor had his device tested without DOE funding by a private contractor and advised DOE that these tests demonstrated his device to be unsuccessful and that he is withdrawing his device from DOE consideration. 
DOE No: 0023

DOE Coord: D. G. Mello

\section{Title: Microgas Dispersions}

Description: Device consists of a motor, pump, bubble machine, and valves, uses \#2 fuel oil, compressed air, surfactant, to maintain bubbles. Resulting mixture burns like natural gas, which burner can use interchangeably, thereby allowing industrial burners to switch fuels. Can also use small amounts of coal dust in the mixture.

Inventor: International MGD Companies Contact:

State : MI James E Luber

Status: No DOE Support Status Date: 10/24/78 OERI No.: 000951

Patent Status : Patent Number: 3900420

Development Stage : Laboratory Test

Technical Category: Other Natural Sources

Recv. by NIST : $12 / 22 / 75$

Recom. by NIST : $03 / 28 / 77$

Summary: Brookhaven National Laboratory agreed to test the burner but advised on June 17, 1977, that they were unable to contact the inventor. An attorney representing the company stated in a letter dated November 10, 1977, that he wished to delay all actions until January 1978 pending resolution of patent related negotiations. On October 24, 1978, DOE advised inventor that support was terminated due to lack of response to repeated inquiries.

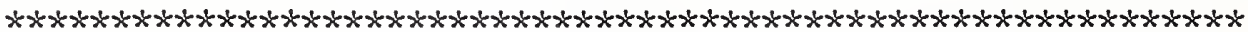

DOE No: 0024

DOE Coord: G. K. Ellis

Title: Can and Bottle Crushing Apparatus

Description: The invention consists of a portable trailer-mounted device for crushing cans and bottles thereby increasing the density of the scrap, making handling more efficient.

Inventor: Drew $W$ Morris

Contact:

Country : $\quad$ Drew W Morris

Status: Complete Status Date: 05/07/81 OERI No.: 000819

Patent Status : Patent Applied For

Development Stage : Production Engineering

Technical Category: Industrial Processes

Recv. by NIST : 03/22/76

Recom. by NIST : 03/30/77

Award Date : 05/07/80

Contract Period: 05/07/80

Award Amount: $\$ 35,000$ Grant No: EC77-G-01-5090

- $05 / 07 / 81$

Summary: A grant was awarded to construct and operate five mobile can-and-bottle crushers, and assemble data on the machine's efficiency and reliability. No final report has been received. DOE unable to locate the inventor. 
DOE No: 0025

DOE Coord: J.Aellen

\section{Title:}

Sulfur Removal from Producer Gas-High Temperature

Description: The concept envisions the removal of hydrogen sulfide from a high temperature "reducing gas" stream using two scrubbing stages in series, a molten carbonate salt bath and a molten copper bath, each complete with a continuous regeneration cycle.

Inventor: Donald C Erickson

State : MD
Contact:

Donald C Erickson

- Energy Concepts Co.

1704 South Harbor Lane

Annapolis MD 21401

$301-266-6521$
Status: Complete

Patent Status

Development Stage: Not Applied For

Technical Category: Industrial Processes

Recv. by NIST

Recom. by NIST

Award Date

:07/09/81

Contract Period: 07/09/81

Summary:
Status Date: 07/09/83

OERI No.: 000002
Award Amount: $\$ 91,032$ Grant No: FG01-81CS15059 - 07/09/83

An award was granted to conduct a research program to establish the technical and economic teasibility of a hot fuel gas desulfurization. Inventor has been successful in generating $\$ 4$ million follow-on financing on this and DOE \#3. This project has been completed.

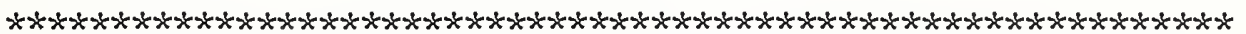

DOE No: 0026

$$
\text { DOE Coord: D. G. Mello }
$$

Title:

Compact Energy Reservoir

Description: A room-heating convector which stores energy in eutectic salts and radiates the heat to the room under thermostatic control.

Inventor: Seymour Jarmul

State : NY
Contact:

Seymour Jarmul

96 Windsor Gate

North Hills NY 11040

$516-365-9886$

Status: Complete

Status Date: 10/26/79

OERI No.: 000782

Patent Status : Not Applied For

Development Stage : Prototype Test

Technical Category: Miscellaneous

Recv. by NIST : $03 / 17 / 76$

Recom. by NIST : 04/12/77

Award Date $\vdots 08 / 02 / 78$

Contract Period: 08/02/78

Award Amount: $\$ 20,740$ Grant No: EU78-G016499

Summary:

A grant was awarded for a 9 month project to design, construct and functionally test a prototype CER suitable for heating a $395 \mathrm{sq}$.ft. room in a well-insulated house similar to Solar One at the University of Delaware. DOE decided it was not necessary to subsequently subject the device to quantitative tests. A qualitative assessment was given to the inventor for his consideration. 
DOE No: 0027

DOE Coord: D. G. Mello

Title: Waste Heat Utilization for Commercial Cooking Equipment

Description: Waste heat utilization for commercial cooking equipment to recover some of the energy in such a way as to avoid interaction with grease vapors.

Inventor: $\mathrm{R} J \mathrm{~J}$ Jones

State : CA
Contact:

$\mathrm{R} J$ Jones

2772 Salmon Drive

Los Alamitos CA 90720

213-721-2641

Status: Complete

Status Date: $03 / 25 / 80$

OERI No.: 001205

Patent Status : Patent Number: 4084745

Development Stage : Limited Production/Marketing

Technical Category: Buildings, Structures \& Components

Recv. by NIST :08/13/76

Recom. by NIST : 04/14/77

Award Date : $02 / 01 / 78$

Contract Period: 02/01/78

Award Amount: $\$ 65,000$ Grant No: EM78-G031852

$-03 / 25 / 80$

Summary: A grant was awarded to fabricate two production-ready Hydrocoils: one for water, one for air. Calspan Corporation conducted a series of tests. Research facility of American Gas Association evaluated and provided a comprehensive engineering report. Results of Fall'78 AGA tests proved that unit operates as expected. At last report, inventor had sold three products. Technology is available for licensing.

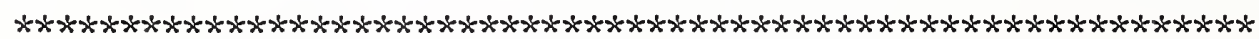

DOE No: 0028

DOE Coord: D. G. Meilo

Title: U1traflo

Description: Ultraflo, a hot water energy-saving system for buildings, is a water delivery system controlling temperature and flow by switches, low voltage current, and solenoid valves.

Inventor: Gilbert $W$ Didion

State : $\mathrm{OH}$

Status: Other Assistance
Contact:

Gilbert $W$ Didion

Status Date: 10/24/78

OERI No.: 000161

Patent Status : Patent Number: 3668884

Development Stage : Limited Production/Marketing

Technical Category: Buildings, Structures \& Components

Recv. by NIST : 06/30/75

Recom. by NIST : 04/27/77

Summary: The invention was tested in California under DOE mission program auspices. The same program provided the inventor with an opportunity for publicizing the technology in a marketing project in Denver in 1977. Inventor has obtained $\$ 160,000$ in private financing and an additional $\$ 200,000$ from Federal contracts. Product is now being marketed with limited success. 
DOE No: 0029

DOE Coord: D. G. Mello

Title: $\quad$ Tuned Sphere Stable Ocean Platforms

Description: This invention presents a unique design approach for an ocean platform, by which the body's natural tendency to roll with wave excitation is diminished or offset.

Inventor: Kenneth E Mayo

State : $\mathrm{NH}$
Contact:

Kenneth E Mayo

Tuned Sphere Int1., Inc

- 111 Lock Street

Nashua NH 03060
Status: Complete

Patent Status

Development Stage

Technical Category
Status Date: 02/06/79

OERI No.: 000800

Recv. by NIS

Recom. by NIST

Award Date

Contract Period

$12 / 18 / 75$
$05 / 10 / 77$
$09 / 30 / 77$
$09 / 30 / 77$

Patent Number: 3837308 and others

Prototype Test

Fossil Fuels

Summary:

An award was granted to test vessel models, list pertinent parametric data, produce motion picture evidence of vessel stability, and provide reduced graphical data. Completion date was extended to August 1978, at no cost to allow for extension of tank tests and subsequent data reduction. Final report has been received and accepted. Company obtained an additional $\$ 200,000$ from $\mathrm{R} \& \mathrm{D}$ sales.

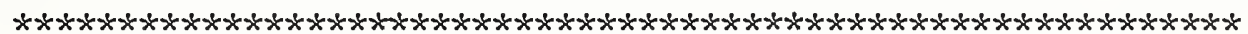

DOE No: 0030

DOE Coord: G. K. Ellis

Title:

Method of Removing Sulfur Dioxide from Flue Gases

Description: Embodies the scrubbing of flue gases with an aqueous solution of metal salt.

Inventor: Leopold Pesse1

State : PA
Contact:

Ken Walmer

AEL-EMTEC Corp.

P.O. Box \#507

Lansdale PA 19446

215-822-2929

Status Date: 03/01/83

OERI No.: 000482

Status: Complete

Patent Status

Development Stage : Laboratory Test

Technical Category: Industrial Processes

Recv. by NIST : 12/08/75

Recom. by NIST : 05/17/77

Award Date : 03/01/82

Contract Period: 03/01/82

Award Amount: $\$ 94,150$ Grant No:

- $03 / 01 / 83$

Summary:

A grant of $\$ 94,150$ was awarded to 1$)$ conduct a laboratory-scale testing program to further clarify the basic chemical reactions of the process in controlled but realistic environments, and 2) to provide background material for an economic analysis of the process. The results appear promising. Now, with the death of the inventor, technology is available for licensing or outright sale. 
DOE No: 0031

DOE Coord: G.K.Ellis

Title: Ceramic Rotors and Vanes

Description: Technique for fabricating turbine rotors that will operate at high temperatures, thereby making it possible to operate at higher efficiencies.

Inventor: James C Withers State : VA

Status: Complete

Patent Status

Development Stage : Engineering Design

Technical Category: Combustion Engines \& Components

Recv. by NIST: $09 / 19 / 75$

Recom. by NIST: $05 / 24 / 77$

Award Date : 05/24/78

Contract Period: 05/24/78

Award Amount: $\$ 131,250$ Grant No: FG01-85CE15214

- $02 / 01 / 85$

Contact:

Richard E Engdahl

Deposits and Composites, Inc.

318 Victory Drive

Herndon VA 22070

$703-471-9310$

Summary:

A grant ( $\$ 62,500$ for each of two years) was awarded for the grantee to conduct a research program designed to improve the material properties of his Chemical Vapor Deposition (CVD) material for use in energy-related applications. A variety of Chemical Vapor Deposition products are resulting. Entrepreneur is interested in licensing and/or forming and financing $R$ \& $D$ imited partnerships. DOE inventions program is assisting by identifying financial resources. An additional $\$ 6,250$ was awarded on April 15, 1985 .

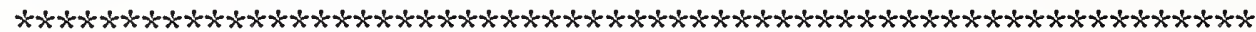

DOE No: 0032

DOE Coord: D.G.Mello

Title:

Wood Gas Reactor

Description: The device produces a fuel gas from wood suitable for use in existing gas or oil-fired combustion equipment.

Inventor: Robert A Caughey

State : NH

\author{
Contact: \\ John C Calhoun, President \\ Forest Fuels, Inc. \\ P.O. Box \#207 \\ Antrim NH 03440 \\ $603-876-3353$
}

Status: Complete

Status Date: 03/16/81

OERI No.: 001174

Patent Status : Patent Applied For

Development Stage : Prototype Development

Technical Category: Fossil Fuels

Recv. by NIST : 08/09/76

Recom. by NIST : 05/26/77

Award Date : 05/24/79

Contract Period: 05/24/79

Award Amount: $\$ 49,405$ Grant No: FG01-79IR10171

- $03 / 16 / 81$

Summary: A grant of $\$ 49,405$ was awarded and completed, to design and build a gasifier system to produce gaseous fuel from biomass. The unit is being used to demonstrate the practical use of alternate fuels in existing industrial boiler installations, and is in demonstration service at Forest Fuel Technical Center in Antrim, NH. About 30 units sold at $\$ 100,000$ to $\$ 200,000$ each as of Nov, 1982. The business is reported to be successful and employs twenty-five. 
DOE No: 0033

DOE Coord: D. G. Mello

Title: Temperature Indicating Device

Description: Device to identify malfunction of steam trap.

Inventor: Joseph B Vogt

State : MI

Contact:

Joseph B Vogt

5391 Ostrum Road

Attica MI 48412

313-724-0106
Status: Complete

Patent Status

Development Stage: Patent Applied For

Technical Category: Bulldings, Structures \& Components

Recv. by NIST : 04/19/76

Recom. by NIST : $05 / 31 / 77$

Award Date : $08 / 24 / 79$

Contract Period: 08/24/79

Award Amount: $\$ 10,135$ Grant No: FG01-79IRI0272

- $08 / 23 / 80$

Summary:

A one year grant of $\$ 10,135$ was àwarded to conduct an engineering development project to test and improve the operation of the inventor's temperature monitoring device. Inventor determined that there is no market for his product.

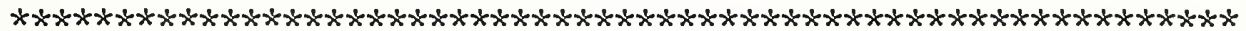

DOE No: 0034

DOE Coord: P.M. Hayes

Title: Delphic Thermogenic Paint (Heat Film)

Description: A thin conductive paint containing crystalline graphite and pigments bonded to a surface such as Mylar with parallel bussbar connections to $120 / 220 \mathrm{v}$ AC to be used as radiant heating.

Inventor: Hal Ellis

State : FL

\author{
Contact: \\ Alex DeFonso \\ Jerry Woolman \\ 4261 Howard Avenue \\ Kensington MD 20795 \\ $301-595-5252$
}

Status: Complete

Status Date: 03/31/83

OERI No.: 001588

Patent Status

Development Stage : Production \& Marketing

Technical Category: Buildings, Structures \& Components

Recv. by NIST : 11/11/76

Recom. by NIST : 06/16/77

Award Date: :09/30/82

Contract Period: 09/30/82

Award Amount: $\$ 25,000$ Grant No: FG01-82CE15147

$03 / 31 / 83$

Summary:

A grant of $\$ 25,000$ was awarded to verify the claim that radiant heating allows air temperature to be significantly lower than by convection heating, thus reducing building heat consumption with no loss in occupant comfort. The company developed new applications for the technology including thermal targets and decoys for the U S Air Force. Total product sales were $\$ 4.1$ million in 1986. 
DOE No: 0035 DOE Coord: D. G. Mello

Title: Utilization of Solar Energy by Solar Pond System

Description: The proposal is for a solar pond demonstration plant.

Inventor: Gulab Chand Jain

Country: India

Contact:

Gulab Chand Jain

Status: No DOE Support Status Date: 12/12/77 OERI No.: 000336

Patent Status : Not Applied For

Development Stage : Concept Development

Technical Category: Direct Solar

Recv. by NIST : 10/23/75

Recom. by NIST : 06/23/77

Summary: Program has declined support of this invention because the inventor's proposal does not respond to several significant problems which are inherent in the system.

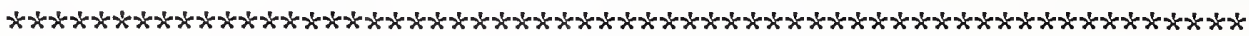

DOE No: 0036

DOE Coord: D. G. Mello

Title:

Computerstat

Description: Computerstat is a computerized thermostat set-back device that appears to be more energy-conserving than a conventional clock-thermostat.

Inventor: Richard P Gingras

State : CT

Contact:

Richard P Gingras

41 Kenoria Avenue

Danbury CT 06810

$203-792-8877$

Status: Complete

Status Date: 09/01/79

OERI No.: 001283

Patent Status : Patent Applied For

Development Stage : Engineering Design

Technical Category: Buildings, Structures \& Components

Recv. by NIST : 08/04/76

Recom. by NIST : $06 / 24 / 77$

Award Date : $02 / 24 / 78$

Contract Period: 02/24/78

Award Amount: $\$ 65,000$ Grant No: EM78-G014208

- $09 / 01 / 79$

Summary: $\quad$ Program office awarded a grant of $\$ 65,000$ to build, test, and demonstrate the energy saving potential of a microprocessor controlled thermostat designed for use in residential and small commercial buildings. Grant also included the design of a computer program to simulate operation in a small commercial building. Company subsequently has gone bankrupt. Concept is now advertised by several companies. 
DOE No: 0037

DOE Coord: G.K.Ellis

Title:

Hotwater Engine

Description: The proposal is for the production of mechanical power from low grade heat.

Inventor: Lawrence E Bissell

State : CA

Status: No DOE Support
Contact:

Lawrence E Bissell

Status Date: 10/31/77 OERI No.: 000565

\section{Patent Status : Patent Applied For}

Development Stage : Concept Development

Technical Category: Miscellaneous

Recv. by NIST : 01/02/76

Recom. by NIST : 08/05/77

Summary: The DOE program office recommended that the inventor be assisted by providing a specialized, highly sophisticated computer analysis of his device. ERIP requested a proposal to this effect, in October, 1977. To date there has been no response from the inventor indicating the type of device he would like tested, nor giving any specification or goals for the development.

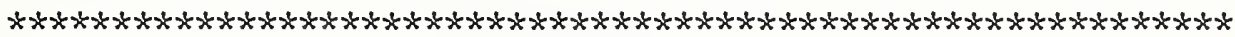

DOE No: 0038

DOE Coord: D. G. Mello

Title:

Reduction Volatilizations

Description: The purpose of this invention is to produce volatile gases, 1iquids, and combustible coke, by passing pulverized coal through a eutectic molten metal bath of lead and sodium.

Inventor: John McCallum

State : $\mathrm{OH}$

Status: Complete

Patent Status

Development Stage : Prototype Development

Technical Category: Industrial Processes

Recv. by NIST : 01/02/76

Recom. by NIST : $08 / 11 / 77$

Award Date $\vdots 08 / 28 / 78$

Contract Period: $08 / 28 / 78$

Award Amount: $\$ 49,740$ Grant No: EU78-G016594

Summary:

A grant of $\$ 49,740$ was awarded and completed for a 5 month experiment program to study chemical reactions of the process, measure all variables, outine plan for design of prototype plant and examine economic feasibility or large scale production. Ohio State University was the sub-contractor. Final report suggests that process is not economically feasible at this time. 
DOE No: 0039

DOE Coord: G. K. Ellis

Title: Lawler Steam Generator and Lawler System of Thermal Oil Recovery

Description: A small, high pressure, high temperature, mobile steam generator which can be economically operated at an oil well installation.

Inventor: James $\mathrm{H}$ Lawler

State : CA

Status: No DOE Support
Contact:

James H Lawler

Status Date: $02 / 01 / 79$
OERI No.: 000219

Patent Status : Patent Number: 3543732

Development Stage : Engineering Design

Technical Category: Fossil Fuels

Recv. by NIST : 08/29/75

Recom. by NIST : 08/18/77

Summary: On Feb. 1, 1979, the inventor was advised that DOE would not support his invention as it represented no advance in the state-of-the-art, and because having sold his equipment, he no longer had it available for test.

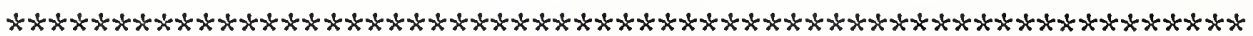

DOE No: 0040

DOE Coord: G. K. Ellis

Title:

Improved Equipment and Process for Production of Blue Water Gas

Description: The main features of the invention are to use automatic valves for controlling the blue gas process, a square reactor bed with a rotating grate which will give positive ash removal - all of which permits a faster cycling between the "run" and the "blow" of the process.

Inventor: Roland P Soule

State : NY

Status: No DOE Support
Contact:

Roland $\dot{P}$ Soule

Status Date: 06/12/81

OERI No.: 000734

Patent Status : Not Applied For

Development Stage : Concept Development

Technical Category: Other Natural Sources

Recv. by NIST : 03/08/76

Recom. by NIST : 08/18/77

Summary: No feasible method of DOE support could be identified. Various options were considered, and several tentative expressions of interest from others were made known to the inventor. He declined each of them. In his mid-eighties, he was not interested in personally pursuing the development. Nor was he interested in dealing with a small company. Also, he disagreed upon the need for establishing economic and technical feasibility. 
DOE No: 0041

DOE Coord: D. G. Mello

Title: Fabrication of Photovoltaic Devices by Solid Phase Growth of Semi-conductors from Metal Layers

Description: The purpose of the invention is to provide a more efficient and economical process for fabricating solar cells.

Inventor: William F Armitage, Jr. Contact:

State : MA William F Armitage Jr

Status: No DOE Support Status Date: 11/07/78 OERI No.: 000580

Patent Status : Not Applied For

Development Stage : Concept Development

Technical Category: Direct Solar

Recv. by NIST : $01 / 12 / 76$

Recom. by NIST : $08 / 30 / 77$

Summary: Inventor failed to respond to repeated requests for a proposal.

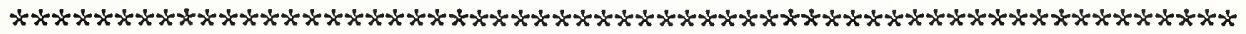

DOE No: 0042

DOE Coord: P.M.Hayes

Title: Flue Baffle Assembly

Description: The invention is a baffle device to be inserted in hot air passage of old, solid fuel-burning furnaces that have been converted to oil. The device increases heat transfer and reduces fuel gas temperature, thereby saving fuel.

Inventor: Everett Millard

State : IL

Status: Complete

Patent Status

Technical Category: Buildings, Structures \& Components

Recv. by NIST : 09/03/75

Recom. by NIST : 09/23/77

Award Date : $06 / 29 / 79$

Contract Period: 06/29/79

Award Amount: $\$ 30,000$ Grant No: FG01-79IR10277

Award Amount
$-\quad 09 / 08 / 80$

Contact:

Everett Millard

4030 Irving Park Road

Chicago IL 60641

$312-797-4030$

Summary: A grant of $\$ 30,000$ was awarded and completed, to perform a six-task study and survey of existing coal fired heating systems that have been converted to oil and which may be modified profitably to accept the inventor's energy-saving flue baffle device. The survey failed to show a sufficient number of heating systems to warrant commercialization of the baffle. However, a secondary business developed as a result of the survey, in which the inventor measures flue gases that form the basis for optimizing air/fuel ratio to save energy. 
DOE No: 0043

DOE Coord: J. Aellen

Title: Thermal Gradient Utilization Cycle

Description: The invention describes a new kind of power plant cycle using low grade, low temperature energy which does not need copious amounts of water for its operation.

Inventor: Sidney A Parker

State : TX
Contact:

Sidney A Parker

- 5820 Diamond Oaks Dr., S

Fort Worth TX 76117 '

$817-834-5081$
Status: Complete

Patent Status

Development Stage

Technical Category

Recv. by NIST: 07/23/76

Recom. by NIST : 09/30/77

Award Date : 09/16/78

Contract Period: 09/16/78
Status Date: 08/04/80

OERI No.: 001263

Summary:

A grant of $\$ 40,000$ for one year was given to Mr. Parker, with support from Texas A\&M, assessing the technical and economic feasibility of the thermal gradient utilization cycle when applied to selected energy conversion systems. Final report has been received. Inventor will make final report available to others in the trade and DOE.

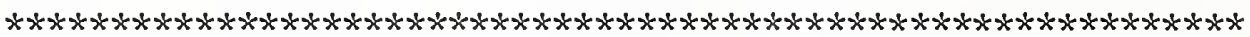

DOE No: 0044

DOE Coord: D.G.Mello

Title:

New Working Fluids for Increasing the Cycle Efficiencies of Thermal

Description: The invention is a new type of absorption refrigerator.

Inventor: Leon Lazare

State : CT

Status: Complete

Patent Status

Development Stage : Engineering Design

Technical Category: Miscellaneous

Recv. by NIST : 08/24/76

Recom. by NIST : 09/30/77

Award Date : 05/16/78

Contract Period: 05/16/78

Summary:
A grant of $\$ 75,000$ was awarded to research a dual- solvent system for heat pump application, and to determine phase relationships and thermodynamic properties of certain specific three-component systems. Grant complete. Equipment failed to confirm theoretical predictions but yielded results which led to another invention which was subsequently funded by DOE. 
DOE No: 0045

DOE Coord: D. G. Mello

Title:

Bulk Cure Tobacco Barn with Improvements

Description: The tobacco curing barn is a trailer-like structure that is fitted with a roof-top solar collector, a recouperator formed by the double roof structure, and the entire structure well insulated on all external walls and floor.

Inventor: Joe W Fowler

State : NC
Contact:

Joe W Fowler

Carolina Thermal Company

Iron Works Road

Route \#2, Box \#39

- Reidsvilie NC 27320

919-342-0352

Status: Complete

Status Date: 06/01/79

OERI No.: 001739

Patent Status

Development Stage : Limited Production/Marketing

Technical Category: Industrial Processes

Recv. by NIST : 01/19/77

Recom. by NIST : $09 / 20 / 77$

Award Date : $05 / 31 / 78$

Contract Period: 05/31/78

Award Amount: $\$ 54,980$ Grant No: EM78-G014254

- 06/01/79

Summary:

A grant of $\$ 54,980$ was awarded to manufacture, install on-site, and demonstrate a new type tobacco curing barn. Test data confirm this type barn yields significant energy savings compared to earlier designs and present industry standards. Final report has been received and accepted as meeting all the requirements of the grant. The business was not successful because, the inventor claims, of institutional barriers.

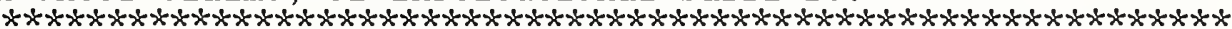

DOE No: 0046

DOE Coord: G. K. E1lis

Title:

Thexon Dehydration

Description: The process uses mechanical methods to reduce a liquid, containing the product to be dried, to a very fine spray of droplets, which are then carried to an air stream at ambient temperature, pressure and humidity so that some unidentified phenomenon, possibly surface evaporation, can cause crystallization.

Inventor: David J Secunda

State : NJ

Status: Complete

Patent Status

Development Stage

Technical Category:
Contact:

David J Secunda

90 Prospect Hill Avenue

Summit NJ 07901

201-277-4475

Recv. by NIST : 02/04/76

Recom. by NIST : $09 / 23 / 77$

Award Date $: 08 / 01 / 79$

Contract Period: 08/01/79

Award Amount: $\$ 47,660$ Grant No: FG01-79IR10023

Status Date: 08/01/80 OERI No.: 000679

Summary:

A grant of $\$ 47,660$ was awarded for the grantee to contract with TRW to make exploratory holograms and do some limited analysis, in order to assess the nature of the phenomena. The work has been completed, and the phenomenon found to be evaporation, but which occurs at room temperature without the deliberate addition of any external heat. Inventor is not presently pursuing the development of this technology and would be interested in considering licensing opportunities. 
DOE No: 0047

DOE Coord: G.K.E1lis

Title:

Wastewater Aeration Power Control Device

Description: An on-line respirometer to measure the oxygen demand of microorganisms in waste water, and to regulate the power required for supplying the oxygen needed to keep the organisms alive.

Inventor: Robert M Arthur

State : WI

Status: Complete

Patent Status

Development Stage:

Technical Category:
Contact:

Robert $M$ Arthur

548 Prairie Road

Fond du Lac WI 54935

414-922-6970

Recv. by NIST : 02/07/77

Recom. by NIST : 10/25/77

Award Date $\vdots 06 / 26 / 80$

Contract Period: 06/26/80

Award Amount: $\$ 58,200$ Grant No: EU78-G-01-6418

Status Date: 06/26/81

OERI No.: 001773

Summary:

A grant of $\$ 58,200$ was awarded and inventor was successful in developing a low-cost, less sophisticated model of an energy-saving on-line respirometer for use in wastewater treatment plants. Grantee has about $\$ 2.5 \mathrm{M}$ out in proposals. Response has been slow from municipalities but good from industry. At last account, inventor was doing $\$ 0.5 \mathrm{million} / \mathrm{yr}$ business; in $5-7$ years, inventor estimates $\$ 25$ million.

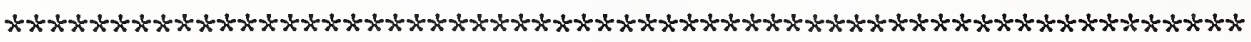

DOE No: 0048

DOE Coord: D. G. Me11o

Title:

Howald Combustor

Description: A fuel nozzle and chamber that pre-mixes air and fuel for more efficient, and less polluting combustion in aviation and automotive gas turbines.

Inventor: Werner E Howald

State : $\mathrm{OH}$

Status: No DOE Support
Contact:

Werner $\dot{E}$ Howald

Status Date: 02/08/79 OERI No.: 000197

Patent Status : Not Applied For

Development Stage: Laboratory Test

Technical Category: Combustion Engines \& Components

Recv. by NIST : 07/10/75

Recom. by NIST : 11/09/77

Summary:

MIT Innovation Center provided inventor with technical review and analysis of support possibilities. MIT determined that the combustor designs were engineering improvement, not patentable. The scale of laboratory testing required to develop jet-engine combustors is beyond the scope of this program and is not being pursued in any DOE laboratory. Inventor was referred to private consulting firm which specializes in combustor design. 
DOE No: 0049

DOE Coord: D. G. Mello

Title:

Automatic Control System for Water Heaters

Description: Invention is a valve to shut off water heater energy source, and to shut off cold water input in the event of a burst tank. It may also be applicable to solar systems.

Inventor: Wayne S Boals

State : $\mathrm{CA}$

Status: No DOE Support

Patent Status

Development Stage

Technical Category:

Recv. by NIST : $07 / 22 / 76$

Recom. by NIST : 10/31/77

Summary:

DOE determined that the device offered little or no direct energy saving potential. A manufacturer of valves declined an offer of the technology citing marketing studies indicating poor sales potential. Program office stated that solar heating system application was ineffective as conservation device. Development of similar devices is now being pursued by others.

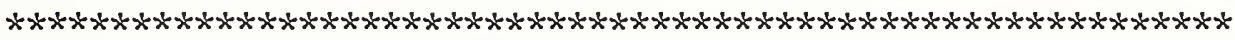

DOE No: 0050

DOE Coord: P.M.Hayes

Title:

Scotsman Fuel Energizer

Description: An accessory screen to atomize fuel in carbureted internal combustion engines.

Inventor: John $\mathrm{T}$ Benton

State : IL
Contact:

Robert Cameron

Scotsman Automotive Corp.

855 Sterling Avenue, Suite \#8

Palatine IL 60067

312-991-5770
Status: Complete

Patent Status

Development Stage

Technical Category:
Recv. by NIST

Recom. by NIST

Award Date

Contract Period:

$07 / 02 / 75$
$\vdots 1 / 23 / 77$
$07 / 11 / 78$
$07 / 11 / 78$
Status Date: 01/10/79

OERI No. : 000094

Summary:

A grant of $\$ 74,579$ was awarded to the grantee to determine the principles of operation and to measure overall fuel saving performance of the device. DOE determined, based upon the findings and conclusions of the Inspector General, the grant to be fraudulently obtained and that all funds must be returned to DOE. Grantee has been notified. 
DOE No: 0051

DOE Coord: J.Aellen

Title:

Thermal Efficiency Construction

Description: A method for building on energy-efficient residence, incorporating a counterflow heat exchanger double- wall
features. Copyright plans sold under license.

Inventor: Richard B Bentley

Contact:

State: NY

Richard B Bentley

Status: No DOE Support

Status Date: 07/31/78

OERI No.: 001116

Patent Status : Not Applied For

Development Stage : Concept Development

Technical Category: Buildings, Structures \& Components

Recv. by NIST : 03/19/76

Recom. by NIST : $12 / 20 / 77$

Summary: In July $\cdot 78$ inventor advised DOE of his intention to prepare a proposal. Nothing has been received to date. Inventor reported he had applied for a grant under the Appropriate Technology Program. DOE support cannot be considered without a proposal from the inventor, or his or her agent.

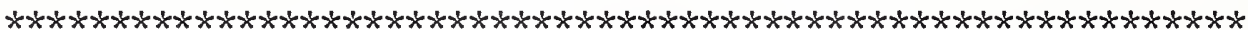

DOE No: 0052

DOE Coord: G. K. Ellis

Title:

Air Wedge

Description: The device is an aerodynamic drag device for use with trucks, mounted on the front face of the trailer or the cargo box.

Inventor: Robert G Landry

Contact:

State : ME

Sherman R Jenney

Status: No DOE Support

Status Date: $11 / 28 / 79$

OERI No.: 000172

Patent Status : Patent Number: 3740320

Development Stage : Concept Development

Technical Category: Transportation Systems, Vehicles \& Components

Recv. by NIST : 08/13/75

Recom. by NIST : $12 / 21 / 77$

Summary: On November 28, 1979, the inventor was advised that there is no basis for DOE support because there are devices already installed on trucks on the highway, which accomplish the same purpose. 
DOE No: 0053

DOE Coord: G.K.Ellis

Title:

High Efficiency Water Heater

Description: A direct contact, gas-fired hot water heater that can extract the latent heat of the water vapor formed during combustion.

Inventor: Harry E Wood
State
Contact:

Harry E Wood

6465 Oakland Drive

New Orleans LA 70118

$504-488-7853$
Status: Complete

Patent Status

Development Stage

Technical Category:
Status Date: 03/01/79

OERI No.: 002070

Recv. by NIST : 04/15/77

Recom. by NIST : $12 / 23 / 77$

Award Date : $03 / 01 / 78$

Contract Period: 03/01/78

Award Amount: $\$ 72,600$ Grant No: EM78-G-01-4255

- $03 / 01 / 79$

Summary:

A grant of $\$ 72,600$ was awarded to install a direct contact gas fired hot water heater in a new 210-unit apartment building, and measure the system characteristics, efficiency and reliability. The results of this DOE support, and some free publicity on a national CBS program shortly thereafter, have materially assisted the inventor in marketing the technology. At last account, Kemco Co., Milwaukee, exclusive licensee, had sold 67 units (altogether saving 0.5 billion cu-ft gas/year), 48 in the last year, at $\$ 30,000$ each, with 30 more on order.

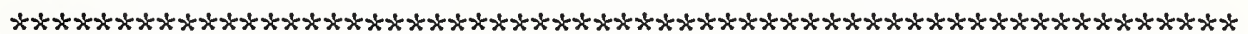

DOE No: 0054

DOE Coord: D. G. Mello

Title: $\quad$ Optimizer

Description: A closed-loop electronic ignition for automobile engines. Spark advance is optimized for maximum power output, and minimum fuel consumption.

Inventor: Paul H Schweitzer

State : PA

\section{Contact:}

Edward Perry Sikes, Jr.

Optimizer Control Corp.

Suite \#104, 201 Burnside Pkwy

Burnsville MN 55337

612-894-3610

Status: Complete

Status Date: 06/15/81

OERI No.: 001355

Patent Status

Development Stage : Working Model

Technical Category: Combustion Engines \& Components

Recv. by NIST : 08/25/76

Recom. by NIST : $01 / 11 / 78$

Award Date $\quad 09 / 01 / 78$

Contract Period: 09/01/78

Award Amount: $\$ 88,895$ Grant No: EU78-G016602

- $06 / 18 / 81$

Summary:

A grant of $\$ 88,895$ for one-year program was awarded and completed to design, develop, fabricate and test a pirot model of the Optimizer. Pennsylvania State University sub-contracted electronic design tasks and analytical evaluation. First progress report indicated that prototype performed as predicted. Penn. State Univ. has been assigned greater role in development of instrumentation and additional test units. Final results showed insufficient improvement to warrant further development. 
DOE No: 0055

DOE Coord: J.Aellen

Title:

Electrically Heated Sucker-Rod

Description: An electric heater is the sucker rod used to drive a pump at the bottom of an oil well, intended to prevent paraffin from congealing and restricting flow, thus avoiding consequent costly maintenance cleanout.

Inventor: Richard D \& Chester Palone

State: AR

Contact:

Richard D Palone

Status: No DOE Support

Status Date: 12/29/80

OERI No.: 002523

Patent Status : Patent Number: 3859503

Development Stage : Concept Development

Technical Category: Fossil Fuels

Recv. by NIST : 07/22/77

Recom. by NIST : $01 / 30 / 78$

Summary: This invention received a favorable review within DOE. During the last contact with the inventor, he said he had located an interested subcontractor and would soon be submitting a proposal requesting a DOE grant. Then, on December 29 th, 1980 he advised that he no longer needed a grant.

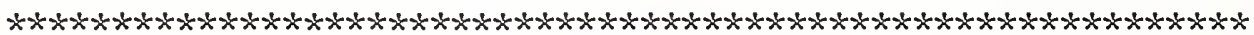

DOE No: 0056

DOE Coord: G.K.E1lis

Title:

Flexaflo-The Wet Fuel Dryer

Description: A dryer/boiler using sugar cane waste (bagasse) for fuel; exhaust gases from process are used to "pre- dry" fuel prior to entering boiler.

Inventor: William P Boulet

State: LA
Contact:

Jay Dornier

Quality Industries

P. 0. Box \#406

Thibodoux LA 70301

504-447-4021
Status: Complete

Status Date: 12/29/80

OERI No.: 002238

Patent Status : Patent Number: 3976018

Development Stage : Prototype Test

Technical Category: Industrial Processes

Recv. by NIST : 05/24/77

Recom. by NIST : 03/31/78

Award Date : $12 / 29 / 79$

Contract Period: 12/29/79

Award Amount: $\$ 111,220$ Grant No: EU78-G-01-6593

$-12 / 29 / 80$

Summary:

A grant of $\$ 111,220$ was awarded to Quality Industries to modify design of existing bagasse dryer in sugar cane refinery to control airborne bagacillio to enable bagasse to replace oil-gas as alternate fuel for dryer. Results indeterminate due to poor industry economic conditions which tended to interfere with fair appraisal. Further testing needed to prove concept. Quality is interested in forming and financing $R \& D$ limited partnership in another industry with the same technology. 
DOE No: 0057

DOE Coord: G.K.E11is

\section{Title:}

\section{X-5 Smoke Eliminator}

Description: A two-stage combustion chamber suitable for adapting existing incinerators to meet current EPA pollution requirement.

Inventor: Robert $\mathrm{H}$ Wieken

State : MN

\section{Contact:}

Robert $\mathrm{H}$ Wieken

411 Betty Lane, West

- Saint Paul MN' 55118

$612-457-8227$

Status: Complete

Status Date: 04/01/81

OERI No.: 000274

Patent Status : Patent Number: 3812297

Development Stage : Prototype Development

Technical Category: Buildings, Structures \& Components

Recv. by NIST : 07/23/75

Recom. by NIST : $03 / 31 / 78$

Award Date : $04 / 01 / 79$

Contract Period: 04/01/79

Award Amount: $\$ 55,000$ Grant No: FG01-79IR10097

- $04 / 01 / 81$

Summary:

A grant of $\$ 55,000$ was awarded for the grantee to convert the X-5 Smoke Eliminator from its existing use as a gas burner to the burning of all grades of fuel oil.

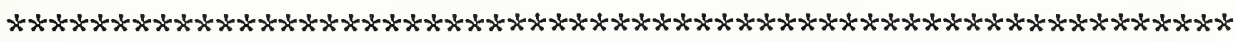

DOE No: 0058

DOE Coord: D. G. Mello

Title:

A Multiple Spark System Using Inductive Storage

Description: Multiple spark system using a gated series of spark discharges on a single plug, to improve the fuel economy of a spark-ignition engine, by reducing the mistire rate.

Inventor: Charles M Kirk

State : FL
Contact:

Charles M Kirk

1965 Arrowhead Lane, NE

Saint Petersburg Fi 33703

813-525-7878

Status: Complete

Status Date: 02/26/79

OERI No.: 001922

\section{Patent Status}

Development Stage : Prototype Test

Technical Category: Transportation Systems, Vehicles \& Components

Recv. by NIST : 03/10/77

Recom. by NIST : $03 / 31 / 78$

Award Date $\quad 02 / 26 / 78$

Contract Period: 02/26/78

Award Amount: $\$ 59,079$ Grant No: FG01-78IR10025

Award Amount:
$-\quad 02 / 26 / 79$

Sunnary:

A grant of $\$ 59,079$ was awarded to manufacture ten (10) prototype "MSS" units. Three units were installed on selected vehicles and dynamometer tested at University of Florida. ERIP assistance completed. 
DOE No: 0059

DOE Coord: G.K.Ellis

Title:

The Volumetric Gas Turbine Description: A positive displacement, modified Brayton cycle engine, for use primarily in
automobiles.

Inventor: Bernard Zimmern

Country: France

Status: No DOE Support

Ptatent Status

Development Stage

Technical Category:

\section{Not Applied For}

Concept Development

Recv. by NIST : $11 / 15 / 76$

Recom. by NIST : $04 / 12 / 78$

Summary:

The inventor was interested in a large grant in the vicinity of $\$ 1$ million, an amount greater than the program could justify or provide. The inventor was advised that no support would be forthcoming.
Contact:

Bernard Zimmern

Status Date: 09/24/82 OERI No.: 001680

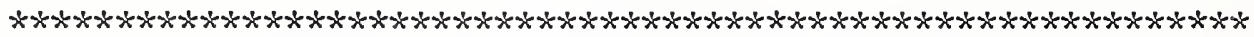

DOE No: 0060

DOE Coord: D. G. Mello

Title:

Electric Transport Refrigerator

Description: Prime mover engine of Refrigerated Truck is modified to function as an A.C. Generator as well as being an engine. Electricity produced, powers sealed refrigerator on trailer, replacing present diesel-powered refrigeration unit.

Inventor: William $\mathrm{H}$ Cone

State : IA

Status: Complete

Patent Status

Development Stage :

Technical Category:
Contact:

William $\mathrm{H}$ Cone

Coneco, Inc.

1151 Meadow Lane, A3

Waterloo IA
$319-233-8224$

Recv. by NIST : $12 / 13 / 76$

Recom. by NIST : $04 / 28 / 78$

Award Date : $09 / 25 / 78$

Contract Period: 09/25/78

Award Amount: $\$ 50,000$ Grant No: EU78-G016601

Status Date: 04/09/80

OERI No.: 001654

Summary:

A grant of $\$ 50,000$ was awarded for one-year design, development, and testing of invention. Iowa State University was sub-contractor for electronic design tasks. Inventor procured a diesel engine for test and modification. Grantee completed all tasks except in-service demonstration. Technical problems with invention design prevented performance of last task. Inventor plans to seek private funds for continuation of project. 
DOE No: 0061

DOE Coord: D.G.Me11o

Title:

Fuel Preparation Process

Description: A method for separating mineral matter from coal using a flotation process.

Inventor: Willing B Foulke

State : DE
Contact:

Murry S. Laskey

2401 Pennsylvania Avenue

Suite \#1010

Wilmington DE 19806

302-652-0115

Status: Complete

Status Date: 06/17/83

OERI No.: 001088

Patent Status

Development Stage
Technical Category

Patent Number: 3932145

Concept Development

Industrial Processes

Recv. by NIST : 06/14/76

Recom. by NIST : 04/26/78

Award Date : 06/17/81

Contract Period: 06/17/81

Award Amount: $\$ 96,421$ Grant No: FG01-81CS15041

$-06 / 14 / 82$

Summary:

A grant of $\$ 96,421$ was awarded for an experimental program on a laboratory scale basis with Research Triangle Institute as the contractor for the purpose of assessing the technical feasibility of the Foulke process. Grant complete, and the results appear promising. Inventor seeks licensing or other opportunities with industry.

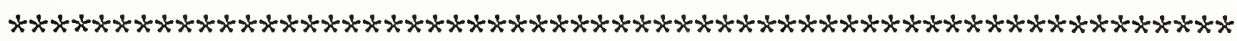

DOE No: 0062

DOE Coord: G.K.Ellis

Title:

Tapered Plate Annular Matrix

Description: A compact heat tank exchanger that offers significant improvement over conventional shell-and- tank exchangers, especially for very high pressure applications.

Inventor: Thaddeus Papis

State : CA

Status: Complete

Patent Status

Development Stage : Production Engineering

Technical Category: Miscellaneous

Recv. by NIST : 05/28/76

Recom. by NIST : $04 / 28 / 78$

Award Date $\vdots 07 / 22 / 79$

Contract Period: 07/22/79

Award Amount: $\$ 79,800$ Grant No: FG01-79IR10172

Summary:

A grant of $\$ 79,800$ was awarded and completed for the inventor to analyze the potential uses, energy- related benefits, production techniques, and comparative economics of the heat exchanger. The study culminated in the definition of, and a plan for, a hardware demonstration program. The final report is being circulated among potential sources of private sector support for the hardware phase. 
DOE No: 0063

DOE Coord: J.Aellen

Title: Fluorobulb

Description: Fluorescent bulb designed to directly replace an incandescent bulb. 20 watt bulb and ballast can be easily separated. Built on Edison screwbase.

Inventor: Thomas LoGiudice

State : NY

Status: Complete

Patent Status

Development Stage

Technical Category:
Contact:

Thomas LoGiudice

520 East $72 d$ Street

New York NY 10021

$212-737-6703$

Recv. by NIST : $08 / 13 / 76$

Recom. by NIST : $05 / 03 / 78$

Award Date : $04 / 11 / 79$

Contract Period: 04/11/79

Award Amount: $\$ 49,500$ Grant No: FG01-79IR10093

Status Date: 08/18/81

OERI No.: 001330

Summary:

A grant of $\$ 49,500$ was awarded and completed for research and product development. Grantee produced ten prototype bulbs, investigated problems of uniform coating, and produced certified data regarding lamp efficiency, luminous efficiency and accurate cost data for predicting production quantity costs. Data suggests that lamp is not likely to be manufactured at a competitive price.

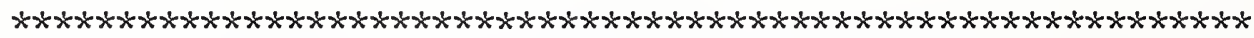

DOE No: 0064

DOE Coord: G. K. Ellis

Title:

The Mahalla Process--A Hydrometallurgical Method for Extracting Copper

Description: A hydrometallurgical process for refining copper that eliminates the electrofining step.

Inventor: Shalom Mahalla

State : AZ
- Contact:

Lester Hendrickson

Arizona State U.

School of Engineering

Tempe AZ 85281

$602-965-3764$
Status: Complete

Patent Status

Development Stage :

Technical Category:

Recv. by NIST

Recom. by NIST

Award Date

Contract Period: 09/01/78
Status Date: 09/01/79

OERI No.: 002543

Summary: A grant of $\$ 88,933$ was awarded and the work completed, to develop and optimize the process variables on a laboratory scale. With the copper industry depressed, the technology is being adapted for industrial toxic waste recovery. At last account, Hendrickson sought $\$ 500,000$ to build a pilot plant having enough flexibility to be adaptable to the processing of feed sources from various industrial plant wastes. 
DOE No: 0065

DOE Coord: J.Aellen

Title: WattVendor

Description: A coin operated device for dispensing electricity.

Inventor: Lee A Henningsen

State : PA
Contact:

Lee A Henningsen

Firetrol, Inc.

1617 Cascade Street

Erie PA 16502

$814-459-1770$

Status: Complete

Status Date: 09/10/79

OERI No.: 000741

Patent Status
Development Stage : Not Applied For

Technical Category: Miscellaneous

Recv. by NIST : 02/18/76

Recom. by NIST : 05/12/78

Award Date : 09/14/79

Contract Period: 09/14/79

Award Amount: $\$ 55,800$ Grant No: FG01-79IR10266 $-\quad 12 / 31 / 80$

Summary:

A grant of $\$ 55,800$ was awarded and completed, to manufacture and install sufficient units to completely convert Hillman Ferry Campground (TVA operated) from free to metered electric service. TVA will record user reactions, electric usage before and after, and operate units in one year demonstration program.

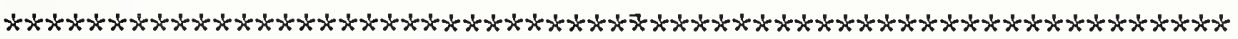

DOE No: 0066

DOE Coord: D.G.Mello

Title:

Description:

Heat Extractor

A system for recovering "Waste Heat" from industrial combustion processes by using water in direct contact with combustion products and an auxiliary heat exchanger.

Inventor: Philip Zacuto

State : NY

Status: Complete

Status Date: 09/29/78

Contact:

Daniel Ben-Shmuel

Heat Extractor Corporation

P.O. Box \#455

Johnstown NY 12095

$518-568-2288$

Patent Status

Development Stage : Prototype Test

Technical Category: Industrial Processes

Recv. by NIST : 06/20/77

Recom. by NIST : $05 / 26 / 78$

Award Date : 09/29/78

Contract Period: 09/29/78

Award Amount: $\$ 125,000$ Grant No: EU78-G016677

Summary:

A grant of $\$ 125,000$ was awarded and completed to install, operate and test, a heat extractor in an operating paper mill with Mohawk Paper Mills, Inc. Included were funds to adapt the heat extractor for coal-fired boilers. The work is complete. Results confirm significant fuel savings. As of January, 1985, inventor had sold the industrial unit to a Pittsburgh firm and the residential one to Armitron. The unit is re-engineered and being marketed through Heat Extractor, Inc., Melrose, MA (800-633-3324) 
DOE No: 0067

DOE Coord: G. K. Ellis

Title: Windmill Using Hydraulic System for Energy Transfer and Speed Control

Description: A windmill design based on a hydraulic system for wind energy, particularly suited for low to medium speed winds.

Inventor: James A Browning State : NH

Status: Complete

Patent Status

Development Stage : Prototype Development

Technical Category: Other Natural Sources

Recv. by NIST : 02/05/76

Recom. by NIST : $06 / 20 / 78$

Award Date : $12 / 07 / 79$

Contract Period: 12/07/79

Award Amount: $\$ 39,000$ Grant No: FG01-80IR10320

- $12 / 01 / 84$
Contact:

James A Browning

Browning Engineering Corp.

P.O. Box \#863

Hanover $\mathrm{NH} 03755$

$603-298-8400$

Status Date: 12/01/84

OERI No.: 000799
A grant of $\$ 39,000$ was awarded to complete the construction of the grantee's 70-ft diameter hydraulic windmill, and then to test it. Accidents and delays in receipt of materials have delayed the project.

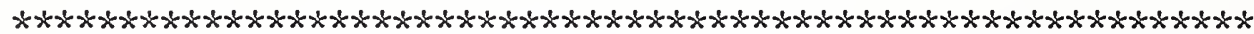

DOE No: 0068

DOE Coord: D.G.Mello

Title: Under Compression and Over Compression Free Helical Screw Rotary Compressor

Description: A compressor for use in medium-to-large sized heat pump-air conditioning systems.

Inventor: Leroy M Bissett

State : VA

Status: Other Assistance
- Contact:

Charlie Baziel

Status Date: 10/01/79

OERI No.: 000631

Patent Status : Patent Number: 3936239

Development Stage : Prototype Development

Technical Category: Buildings, Structures \& Components

Recv. by NIST : $01 / 22 / 76$

Recom. by NIST : 06/28/78

Summary: As a result of the NBS recommendation and in consideration of an unsolicited proposal from the grantee, the CE program within DOE funded a $\$ 300,000$ two-year contract, which has now been completed. Results show good energy savings, but further work is required to develop a commercial prototype of a marketable size. 
DOE No: 0069

Title:

Description:

Inventor:

State
Enoch J Durbin NJ

DOE Coord: G. K. Ellis

Ionic Fuel Control System for the Internal Combustion Engine

A system for controlling the air-fuel ratio of a gasoline internal combustion engine to maintain lean operation, improved fuel economy, and good performance.

Contact:

Enoch J Durbin

Instrumentation \& Control Lab.

Aero Lab., Forrestal Campus

Princeton University

Princeton NJ 08540

$609-452-5154$

Status: Complete

Status Date: 07/01/80

OERI No.: 000844

Patent Status

Patent Number: 3470741

Development Stage: Prototype Development

Technical Category: Combustion Engines \& Components

Recv. by NIST : $03 / 25 / 76$

Recom. by NIST : 06/29/78

Award Date : 07/01/79

Contract Period: 07/01/79

Award Amount: $\$ 87,051$ Grant No: FG01-79IR10022

$-07 / 01 / 80$

Summary:

A grant of $\$ 87,051$ was awarded to develop the Ionic Fuel Control System and to assess its commercial feasibility. A successful prototype was developed. Despite much work, the inventor's only success with an automotive company was Chrysler's successful bid on a military contract which incorporated the technology. Adaptation of the device gives wind action in three directions, which could also be critical in determining velocities of STOL aircraft, where there have been a number of landing crashes for lack of this information.

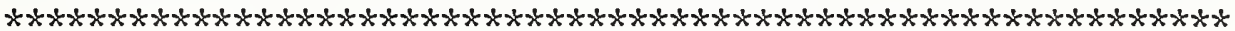

DOE No: 0070

Title:
DOE Coord: J. Aellen

Air Cooled Compressor Heat Recovery and Heat Circulation System plus Ambient Air Filter and Air Cleaner

Description: A heat recovery system for large compressors.

Inventor: Kenneth A Stofen

State : WI
Contact:

Kenneth A Stofen

3642 Country Lane

Racine WI 53405

414-554-7987

Status: Complete

Status Date: $08 / 08 / 80$

OERI No. : 002847

Patent Status

Development Stage $\vdots$ Limited Production/Marketing

Technical Category: Miscellaneous

Recv. by NIST : $10 / 21 / 77$

Recom. by NIST : 06/28/78

Award Date

Contract Period:

Award Amount: $\$ 53,000$ Grant No: FG01-79IR10026

Summary:

A grant of $\$ 53,000$ was awarded to design and build ecology cabinets; and then assemble, operate, and test air cooled compressor systems in environments with particulate-laden and high temperature air. Sold 31 units to various size companies. Expanding his product to include 5 through $2000 \mathrm{HP}$ compressors. Secured GSA contract two years in a row. A new company named Air Systems Inc at 937 Hays Ave., Racine, WI 53405 has been formed to build the units. Trying to expand market through more distributors. 
DOE No: 0071

DOE Coord: D. G. Mello

Title:

Knight Guard

Description: A system for remote controlling the lighting in a building by means of low frequency radio signals.

Inventor: Arleigh Wangler

State : CA

Status: No DOE Support

Patent Status

Development Stage:

Patent Applied For

Limited Production/Marketing

Buildings, Structures \& Components

Recv. by NIST : 08/10/77

Recom. by NIST : 06/29/78

Summary: Inventor is investigating law enforcement agencies' interest.
Contact:

Arleigh Wangler

Status Date: 09/01/78 OERI No.: 002538

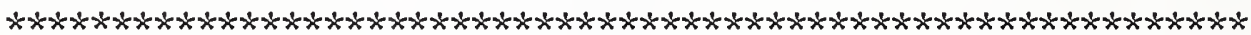

DOE No: 0072

DOE Coord: G. K. Ellis

Title: Utilization of Waste Gas for Boilers and Furnaces in Refineries and Petrochemical Plants

Description: System exploits the relationship between specific gravity of the flare gas and its BTU content, to compute BTU per hour and subsequently control the fuel-air ratio of boilers.

$\begin{array}{ll}\text { Inventor: } & \text { Joe Agar } \\ \text { State } & \text { TX }\end{array}$

- Contact:

Basil W Balls

Status: No DOE Support Status Date: 08/08/80 OERI No.: 000733

Patent Status : Not Applied For

Development Stage: Laboratory Test

Technical Category: Industrial Processes

Recv. by NIST : 03/08/76

Recom. by NIST : 06/28/78

Summary:

A procurement request for a grant was initiated on April 20, 1979. Shortly thereafter, Mr. Agar sold the company and the new manager indicated that the earlier proposal was not in accord with the company's new goals. Then, on Dec 28 1979, the company advised by telephone that they were not interested in pursuing the development at all, since it did not coincide with their company s new goals. Formal notification was received in an August 5, 1980 letter. 
DOE No: 0073

DOE Coord: G. K. Ellis

Title:

Description:

\section{INTECH}

A system which uses light-weight aggregate insulation to provide the form-work for the concrete structural members of a building, with pre-finished exterior and interior surfaces.
Inventor: Melvin $\mathrm{H}$ Sachs

State : MI
Contact:

Melvin $\mathrm{H}$ Sachs

ISTECH, INC

29200 Vassar Ave

Livonia MI 48152

313-478-0606
Status: Complete

Patent Status Development Stage
Technical Category:
Status Date: 06/22/79

OERI No.: 001323

Recv. by NIST : 08/09/76

Recom. by NIST : 08/10/78

Award Date : $06 / 22 / 78$

Contract Period: 06/22/78

Patent Number: 3800015 and others

Production \& Marketing

Buildings, Structures \& Components

Summary:

A grant of $\$ 87,230$ was awarded for the purpose of contracting with Underwriters Laboratories, Inc. to perform fire tests, and to contract with Lev Zetlin Consultants for structural testing and analysis. This invention won the "outstanding individual inventor" award from the Dvorkovitz Technology Show of 1980 . At last account, Sachs was looking for $\$ 2$ million private sector money to design machinery for mass production. Some designs have been sold and built.

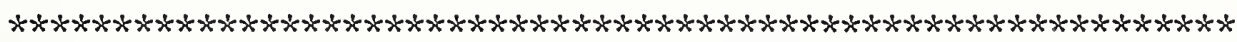

DOE No: 0074

DOE Coord: D. G. Mello

Title:

A Solid Electrolyte Galvanic Solar Energy Conversion Cell

Description: A high-temperature, high voltage (1.51V) fuel cell utilizing a unique calcium stabilized zirconia solid electrolyte. Device promises high efficiency, minimum environmental problems and wide application. It can also simultaneously produce chemical feedstock.

Inventor: $G R$ Fitterer

State : PA
Contact:

G. R. Fitterer, President

Scientific Appiications, Inc.

825 Twelfth Street

Oakmont PA 15139

412-828-0233

Status: Complete

Status Date: $10 / 30 / 80$

OERI No.: 002560

Patent Status : Patent Applied For

Development Stage $\vdots$ Limited Production/Marketing

Technical Category: Direct Solar

Recv. by NIST : 09/19/77

Recom. by NIST : 08/29/78

Award Date $\vdots 08 / 24 / 79$

Contract Period: 08/24/79

Award Amount: $\$ 50,000$ Grant No: FG01-79IR10264 - $10 / 30 / 80$

Summary:

A grant of $\$ 50,000$ was awarded to conduct a two-part research project to investigate the characteristics of his Fuel Cell. Part one is a study of the primary cell and its voltage characteristics. Part two is research leading to selection of the best electrolyte. Results indicate that although workable, advantages over existing fuel cells are not significant. 
DOE No: 0075

DOE Coord: G.K. Ellis

Title:

Coke Quenching Steam Generator Description: The steam generator is a direct contact heat exchanger for generation of
process steam from hot coke. Objective: to build new coke ovens.

Inventor: Richard Jablin

State : NC

Status: Complete

Patent Status

Development Stage
Technical Category

Recv. by NIST : 06/06/77

Recom. by NIST : 08/29/78

Award Date : 05/14/79

Contract Period: 05/14/79

Summary:

A grant of $\$ 119,400$ was awarded to complete a program of laboratory and pilot plant scale development. The work was successful, with steam quality adequate for process steam, and coke quality superior to the only competing process. Inventor seeks limited partnership arrangement, and anticipates a $\$ 10$ million/year business.

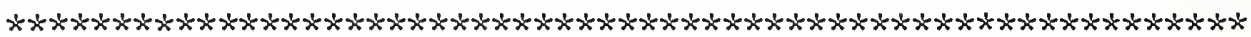

DOE No: 0076

DOE Coord: G.K.E1lis

Title:

The Ross Furnace

Description: A new gas burner design for use in high temperature industrial process

Inventor: Donald R Ross

State : TX

Status: Complete

Status Date: 05/05/81

Contact:

Donald $\dot{R}$ Ross

3344 South Grove

Fort Worth TX 76110

817-921-9671

Patent Status : Patent Applied For

Development Stage : Prototype Test

Technical Category: Industrial Processes

Recv. by NIST : 04/18/77

Recom. by NIST : 09/18/78

Award Date $\quad 05 / 05 / 80$

Contract Period: 05/05/80

Award Amount: $\$ 82,000$ Grant No:

$-05 / 05 / 81$

Summary:

A grant of $\$ 82,000$ was awarded to build, assemble, operate and test two systems; one for a tilted furnace and one for a rotary furnace. The work was completed satisfactorily. 
DOE No: 0077

DOE Coord: J. Aellen

\section{Title:}

Variable Heat Refrigeration System

Description: An improved vapor degreasing system incorporating a heat pump to conserve energy, retain solvents, and reduce hazards associated with solvent vapors.

Inventor: James W McCord

State : KY
Contact:

James W McCord

Corpane Industries, Inc.

250 Production Court

Bluegrass Industrial Park

Louisville KY 40299

- 502-491-4433
Status: Complete

\section{Patent Status}

Development Stage:

Technical Category:

Recv. by NIST : 08/09/76

Recom. by NIST : $09 / 25 / 78$

Award Date $\quad 09 / 23 / 80$

Contract Period: 09/23/80

Summary:
Award Amount: $\$ 97,400$ Grant No: FG01-80CS15026
Status Date: 09/23/80 OERI No.: 001173
: Patent Applied For

Working Model

An award of $\$ 97,400$ was granted to design and construct demonstration models of the variable heat refrigeration system.

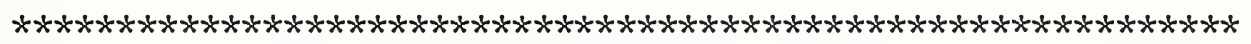

DOE No: 0078

DOE Coord: G. K. Ellis

Title:

System for High Efficiency Power Generation from Low Temperature Sources

Description: Concept for reducing the heat sink temperature in power plant operation and other applications; ice would be generated during cold weather and used to reduce the heat sink temperature during warmer weather.

Inventor: Robert McNeill

State : CA

Status: No DOE Support

Patent Status

Cot Applied For

: Concept Development

Technical Category: Other Natural Sources

Recv. by NIST : 06/30/76

Recom. by NIST : 09/28/78

Summary: Inventor advised DOE that he is no longer interested in pursuing the invention because of other interests. 
DOE No: 0079

DOE Coord: G. K. Ellis

Title: Oil Well Bit Insert (Tooth), Cutting Article, Ablative

Description: A new composite bit insert to replace the tungsten carbide inserts now commonly used in the rotary cone cutter bits for oil and gas well drillings. It is claimed to have sharper edges, more resistant to wear, and to be stronger.

Inventor: Marvin L Wahrman

State : CA

Contact:

Marvin i Wahrman

47 Red Rock

Irvine $\mathrm{CA} 92714$

$714-979-1280$

Status: Complete

Status Date: 01/29/81

OERI No.: 001732

Patent Status : Patent Applied For

Technical Category: Fossil Fuels

Recv. by NIST : $01 / 21 / 77$

Recom. by NIST : $08 / 25 / 78$

Award Date : $01 / 29 / 80$

Contract Period: 01/29/80

Award Amount: $\$ 57,150$ Grant No: FG01-79IR10288

$-\quad 01 / 29 / 81$

Summary:

A grant of $\$ 57,150$ was awarded to prove the technical feasibility and to address the repeatability and controllability of the manufacturing process for these bits. A bit was developed which cuts 3-4 times faster and lasts longer than conventional ones. At last account, company had 4 employees and had expanded to produce saw blades.

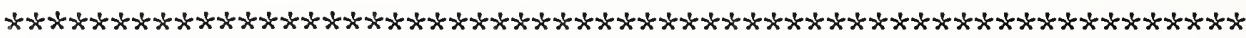

DOE No: 0080

DOE Coord: J.Aellen

Title:

Improved Unfired Refractory Brick

Description: Chemically bonded, unfired brick for ladles handling molten steel, consisting of $90 \%$ silica and containing $10 \%$ clay with minor amounts of hardening agent and Gulac.

Inventor: Patsie C Campana

State : $\mathrm{OH}$

Status: No DOE Support
Contact:

Patsie C Campana

Status Date: 03/23/82

\section{Patent Status : Not Applied For}

Development Stage : Limited Production/Marketing

Technical Category: Industrial Processes

Recv. by NIST : 03/18/77

Recom. by NIST $: 09 / 28 / 78$

Summary: A proposal has been received from the inventor for several million dollars to build a production facility. The inventor was advised the program was unable to fund capital equipment, and potential alternatives of business plan and marketing study were described. The inventor has indicated no interest except on the basis of a large grant for capital equipment. 
DOE No: 0081

DOE Coord: D. G. Mello

\section{Title: $\quad$ Flash Polymerization} Description: A process utilizing pulsed xenon arc discharge lamps for polymerizing
thermosetting resins.

Inventor: ${ }_{\text {MA }}^{C}$ Richard Panico
Contact:

C Richard Panico

Xenon Corporation

66 Industrial Way

Wilmington MA O1887

$617-658-8940$
Status: Complete

Patent Status

Development Stage:

Technical Category:
Status Date: 02/03/81

OERI No.: 002526
Recv. by NIST : 07/26/77

Recom. by NIST : 09/29/78

Award Date : 09/29/79

Contract Period: 09/29/79
Award Amount: \$ 99,990 Grant No: FG01-79IR1030 - 02/02/81

Summary:

A grant of $\$ 99,990$ was awarded and completed, to conduct a 3-part investigation of the energy-saving and market penetration potential for this curing machine. A $\$ 500,000$ contract for automotive parts curing was captured as a result of DOE- supported Development work. Several venture capitalists have expressed considerable interest. Sale of the company has been discussed.

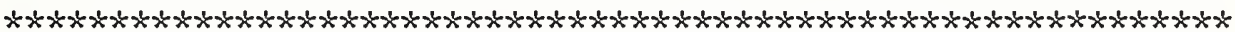

DOE No: 0082

Title:

DOE Coord: D. G. Mello

Cool Air Induction

Description: Modification kit for engines used for powering irrigation pumps. Uses cool well water in air cooler placed between commercial supercharger and the engine.

Inventor: Robert L U1lrich

State : NM

\section{Contact:}

Robert I Ullrich

U11rich Eng. \& Mfg., Inc.

1717 East Second Street

Roswe11 NM 88201

$505-662-1821$

Status: Complete

Status Date: 09/24/79

OERI No.: 003061

\section{Patent Status}

Development Stage : Limited Production/Marketing

Technical Category: Industrial Processes

Recv. by NIST : $11 / 23 / 77$

Recom. by NIST : $10 / 27 / 78$

Award Date : $09 / 24 / 79$

Contract Period: 09/24/79

Award Amount: $\$ 68,402$ Grant No: FG01-79IR10284 - $04 / 30 / 80$

Summary:

A two-phase grant in the amount of $\$ 99,282$ was requested. The first phase was awarded $(\$ 68,402)$ and provided for analysis of existing operating data, a survey of the potential market, development and comparison of alternate strategies and a preparation of a formal business plan. Product is available for licensing. 
DOE No: 0083

DOE Coord: P.M.Hayes

Title:

Vertical Solar Louvers

Description: Massive rectangular columns oriented in NE-SW direction, located indoors behind a glazed southern exposure. Aesthetic improvement over conventional TROMBE wall should lead to increased acceptance of passive solar heating.

Inventor: Charles James Bier

Contact:

State : VA

Charles James Bier

Route \#2, Box \#35

Ferrum VA 24088

Status: Complete

Status Date: $02 / 28 / 84$

OERI No.: 002821

Patent Status

Not Applied For

Development Stage $\vdots$ Concept Development

Technical Category: Buildings, Structures \& Components

Recv. by NIST : 10/17/77

Recom. by NIST : $10 / 27 / 78$

Award Date : $08 / 31 / 82$

Contract Period: 08/31/82

Award Amount: $\$ 26,510$ Grant No: FG01-82CE15135

Summary:

A grant of $\$ 26,510$ was awarded for inventor to prepare instrumentation strategy, and computer design guide. Final semi-technical journals to encourage the passive solar concept.

test plan, report was in several

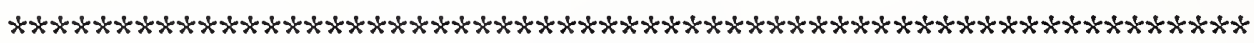

DOE No: 0084

DOE Coord: G.K.Ellis

Title:

Kinetic Energy Type Pumping System Description: Simplified pumping system utilizes the kinetic energy of a circulating fluid
to reduce the bottom- hole pressure and to lift the down-hole fluid.

Inventor: Kenneth $\mathrm{W}$ Odil

State : TX

Status: No DOE Support
Contact:

Kenneth $\mathrm{W}$ Odil

Status Date: 09/24/82

OERI No.: 002032

\section{Patent Status : Patent Number: 3123009 \\ Development Stage : Prototype Test \\ Technical Category: Industrial Processes}

Recv. by NIST : 04/11/77

Recom. by NIST : 10/30/78

Summary:

A proposal was received from the inventor which was unacceptable because it was considerably beyond the level of support funds that could be justified. The inventor then endeavored to find a cost sharing arrangement with an interested private industry. A 5/13/82 check with him indicated that due to other business interests, Mr. Odil temporarily at least, is not interested in pursuing his invention. 
DOE No: 0085

DOE Coord: D.G.Mello

Title: Dielectric Windowshade

Description: A method by which an applied voltage causes a reflective aluminized mylar film to unroll and press flat against a window.

Inventor: Charles G Kalt State : MA

Status: Complete

Patent Status : Patent Number: 398935

Technical Category: Buildings, Structures \& Components

Recv. by NIST : 04/12/78

Recom. by NIST $\vdots 10 / 31 / 78$

Award Date: $08 / 18 / 81$

Contract Period: 08/18/81
Award Amount: $\$ 99,500$ Grant No: FG01-81CS15076 - $11 / 18 / 82$
Contact:

Charles G Kalt

29 Hawthorne Road

Williamstown MA 01267

413-664-6371

Summary: A grant of $\$ 99,500$ was awarded and completed, to design, build and test, a demonstration model of the Dielectric Windowshade. A unique product resulted. Test-marketing for commercial greenhouses has been completed.

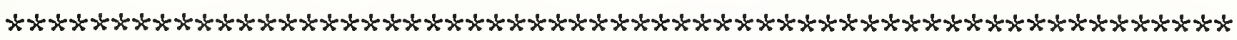

DOE No: 0086

DOE Coord: G. K. Ellis

Title: $\quad$ Coke Desulfurization

Description: Method to remove sulfur from high sulfur coal during the coking process, which makes it possible to use high sulfur coals in the manufacture of metallurgical coke. Process can pay for itself with the sulfur by-product.

Inventor: Douglas MacGregor

State : UT
Contact:

Howard Bovars

Diamond Energy Corporation

1012 North Beck Street

Sale Lake City UT 84103

$801-359-3718$
Status: Complete

Patent Status

Development Stage:

Technical Category:
Status Date: 03/23/81

OERI No.: 002726

Recv. by NIST : 09/21/77

Recom. by NIST $\vdots 11 / 27 / 78$

Award Date : $12 / 07 / 79$

Contract Period: 12/07/79

Award Amount: $\$ 82,500$ Grant No: FG01-80IRl0305

Summary :

A grant of $\$ 82,500$ was awarded for Diamond West Corporation, exclusive licensee, to perform sufficient additional technical, engineering and application investigation, to ready the technology for the marketplace. Licensee, with the help of the inventor, unable to duplicate results of initial experiment. But, Diamond West took a new approach and developed a successful process. $\$ 1.5$ million private monies invested to date, and doubling that is anticipated. At last account, Diamond West had tentative plans for joint venture to build a calciner for sale to coke industry. 
DOE No: 0087

DOE Coord: J. Aellen

Title:

Recovering Uranium From Coal in Situ

Description: A method for recovering uranium from the sites of depleted coal deposits that have been mined by in situ gasification.

Inventor: Ruel Carlton Terry

State : OK

Contact:

Ruel Carlton Terry

2235 Northwest 55 th Street

Oklahoma City OK 73112

405-840-9586

Status: Complete

Status Date: 02/06/80

OERI No.: 002224

Patent Status

Development Stage
Technical Category

Patent Number: 4113313

Laboratory Test

Industrial Processes

Recv. by NIST : 05/17/77

Recom. by NIST : $11 / 29 / 78$

Award Date : $02 / 01 / 80$

Contract Period: 02/01/80

Award Amount: $\$ 85,240$ Grant No: FG01-80IR10301

$-\quad 08 / 01 / 81$

Summary:

A grant of $\$ 85,240$ was awarded to reduce two of the uncertainties related to eventual commercialization of the process. The first uncertainty concerns potential sites and the second uncertainty relates to technical feasibility. DOE Livermore Lab believes this method has good commercial possibilities, but uranium price must rise to make it commercially feasible.

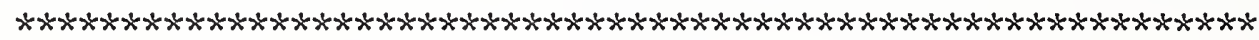

DOE No: 0088

DOE Coord: D. G. Mello

Title: $\quad$ System-100

Description: A strategy (control system) for regulating centrifugal and reciprocating equipment used in natural gas compressor stations.

Inventor: Alex Rutshein, et al

State : IA

Contact:

Lawrence Ladin

c/o Compressor Controls Corp.

P. O. Box \#1936

Des Moines IA 50306

515-244-1180

Status: Complete

Status Date: 08/12/80

OERI No.: 001818

Patent Status

Development Stage : Concept Development

Technical Category: Fossil Fuels

Recv. by NIST : 02/10/77

Recom. by NIST : $11 / 30 / 78$

Award Date : $08 / 26 / 80$

Contract Period: 08/26/80

Award Amount: $\$ 50,000$ Grant No: FG01-80CS15012

$-08 / 15 / 81$

Summary: A grant of $\$ 50,000$ was awarded to develop a microprocessor-based strategy control system for control of compressors in gas transmission pipelines. Two pipelines have purchased product. Potential is easily $\$ 1$ million annual savings. Product has gone on to win industry award for significant invention. 
DOE No: 0089

Title:

Description:
DOE Coord: D.G.Mello

Continuous Casting Process and Apparatus

A continuous horizontal casting process for steel billets, slabs, and tubing, which achieves a very high quality product at twice the speed of existing continuous casting processes.
Inventor: Henry E Allen

State : CT
Contact:

Henry E Allen

Techmet Corporation

Fifteen Valley Drive

$203-629-4633$

Status: Complete

Status Date: 07/31/84

OERI No. : 002648

Patent Status : Patent Number: 3517725

Development Stage : Prototype Development

Technical Category: Industrial Processes

Recv. by NIST : 08/22/77

Recom. by NIST : $11 / 30 / 78$

Award Date : $07 / 29 / 82$

Contract Period: 07/29/82

Award Amount: $\$ 115,000$ Grant No: FG01-82CE15101

$-07 / 31 / 84$

Summary:

A grant of $\$ 115,000$ was awarded to build and test a device for continuous casting of 4 -inch bars of steel. The work on this project is complete. The project was generally successful. Lack of interest due to unfavorable economic conditions in steel industry however, prevents its commercialization.

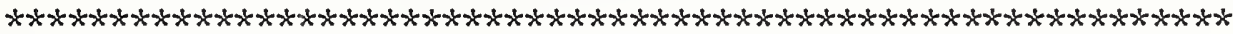

DOE No: 0090

DOE Coord: J.Aellen

Title:

Grain Dryer

Description: A device to be added to a grain combine, to utilize the exhaust energy from the combine engine for drying the grain in the combine hopper tank.

Inventor: Clinton Van Winkle

State : NE

Status: No DOE Support
Contact:

Clinton Van Winkle

Status Date: / / OERI No.: 003790

Patent Status : Patent Number: 4003139

Development Stage : Prototype Development

Technical Category: Industrial Processes

Recv. by NIST : $03 / 16 / 78$

Recom. by NIST $: 12 / 18 / 78$

Summary: Inventor not responsive. No basis for consideration of DOE grant support. 
DOE No: 0091

DOE Coord: D.G.Mello

Title: Mine Brattice

Description: A reusable brattice for use in coal mining. Quick, and inexpensive to install - seals better than present stoppings. Improved air seal saves power and improves safety.

Inventor: James Allen Bagby

State : KY

Contact:

Rees Kinney, Atty.

Bagby Brattices, Inc.

P.8. Box \#569

Greenville KY 42345

$502-338-5619$

Status: Complete

Status Date: 09/20/79

OERI No.: 003210

Patent Status
Development Stage : Patent Number: 3972272

Technical Category: Fossil Fuels

Recv. by NIST : $12 / 20 / 77$

Recom. by NIST : $12 / 19 / 78$

Award Date : $09 / 29 / 79$

Contract Period: 09/29/79

Award Amount: $\$ 62,664$ Grant No: FG01-79IR10302

Summary:

A grant of $\$ 62,664$ was awarded and completed to fabricate 25 prototype brattices and install them in Peabody Coal underground coal mine in Southern Illinois. Data were collected and possibly detrimental effects of natural subsidence on the performances of the brattices was measured and found to be minimal. Product advanced rapidly, with sales organization formed and 1982 sales of $\$ 150,000$. Product is accepted in the mining industries and is available for distribution. Corporation has doubled sales.

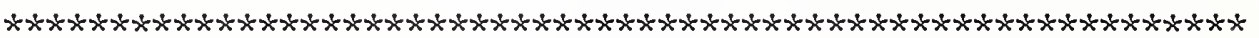

DOE No: 0092

DOE Coord: G.K.Ellis -

Title:

Tri-Water, A Combination Air Conditioning and Fire Protection System for a Building.

Description: Utilizes common plumbing system with water serving as heat source/sink for heat pumps as well as sprinkler system.

Inventor: John L Carroll

State : KY

Status: No DOE Support
Contact:

Roger Stamper

Status Date: 07/15/86

OERI No.: 001160

Patent Status : Patent Number: 3939914

Development Stage : Limited Production/Marketing

Technical Category: Buildings, Structures \& Components

Recv. by NIST : 03/22/76

Recom. by NIST : $12 / 28 / 78$

Summary: Inventor has licensed the technology to American Air Filter Co Inc. A grant was declined on the belief that it would compromise the inventor's patent position. At last account, American Air had installed $\$ 22$ million of the technology, including $\$ 2$ million for equipment and $\$ 20$ million for construction, representing 36 jobs. Another 30 were on the drawing board. 
DOE No: 0093

DOE Coord: G.K.Ellis

Title:

Shelander-Burrows Process for Recovery of Metallic Values from Smelter Emissions

Description: A solution/precipitation process for recovery of zinc, lead, and copper from the baghouse dust collected from smelter emissions.

Inventor: Edward $\mathrm{H}$ Shelander

State : GA
Contact:

Edward $\mathrm{H}$ Shelander

P.0. Box \#603

Brunswick GA 31520

912-265-8464
Status: Complete

Patent Status

Development Stage

Technical Category:

Recv. by NIST

Recom. by NIST

Award Date

Contract Period: $03 / 28 / 80$

A grant of $\$ 89,742$ was awarded, and has been completed to provide an engineering and economic analysis of the subject process. At last account, grantee was looking for several million dollars venture start-up capital.

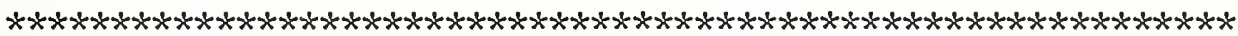

DOE No: 0094

DOE Coord: J. Aellen

Title:

Lantz Converter

Description: Unit for pyrolyzing municipal refuse that uses natural gas to bring converter up to pyrolyzing temperature and then switches to pyrolytic gases to maintain the process.

Inventor: William M FioRito

State : CA

Status: Complete

Status Date: $07 / 10 / 85$

Contact:

- William M FioRito

12650 Mantilla Road

San Diego CA 92128

$914-591-5080$

Patent Status

Development Stage

Technical Category:

Recv. by NIST

:03/02/78

Recom. by NIST : $01 / 30 / 79$

Award Date : $09 / 20 / 82$

Contract Period: 09/20/82

Award Amount: $\$ 134,000$ Grant No: FG01-82CE15126

- $09 / 17 / 83$

Summary:

A one year grant of $\$ 134,000$ was awarded to instrument the Lantz Converter under engineering- test conditions to determine significant operating and economic factors. 
DOE No: 0095

DOE Coord: D. G. Mello

Title:

Omni-Horizontal Axis-Wind Turbine

Description: A low cost, self starting, horizontal axis wind turbine with novel blade orientation. Operation is relatively insensitive to wind direction.

Inventor: Val o Bertoia

State : PA

Status: No DOE Support

Patent Status : Disclosure Document Program

Development Stage : Concept Development

Technical Category: Other Natural Sources

Recv. by NIST : 04/10/78

Recom. by NIST $\vdots 01 / 30 / 79$

Summary:

Inventor requested project be terminated for his convenience. Preliminary DOE review suggested that project would not be economically justifiable.
Contact:

Val o Bertoia

OERI No.: 003875

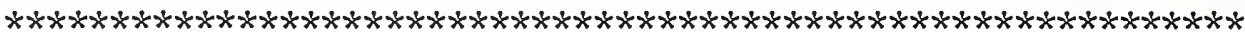

DOE No: 0096

Title:

Description:

\section{DOE Coord: J. Aellen}

Leavell, Vibrationless, Low Noise, High Efficiency, Pneumatic Percussion Tools and Air Compressor Systems

Pneumatic tools (paving breaker, etc.) reconfigured to obtain additional energy from high temperature compressed air. High temperature and low pressure requires larger displacement and therefore overall size to achieve same output power.

Inventor: Floyd R Anderson

State: AR

\author{
Contact: \\ Floyd R Anderson \\ Vast Research Company \\ Seven Tiffany Lane \\ Bella Vista AR 72712 \\ 501-855-9202
}

Status: Complete

Status Date: $07 / 28 / 80$

OERI No. : 001869

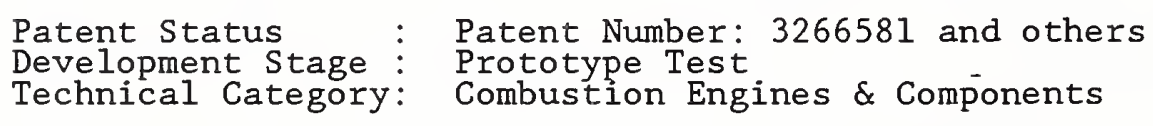

Recv. by NIST : $02 / 28 / 77$

Recom. by NIST : $02 / 28 / 79$

Award Date : $09 / 12 / 79$

Contract Period: 09/12/79

Award Amount: $\$ 76,675$ Grant No: FG01-80IR10305

Summary: A grant of $\$ 76,675$ was awarded to design, build, and test six pneumatic tools. Independent test evaluation by a third party did analyze energy input and output, rate of work, noise and vibration. Results have been compared with performance of conventional tools; all criteria show outstanding advantages of the Anderson system. Company has raised $\$ 3$ million in private investments and 130 units have been put into demonstration service. Product is available for distributor sales. 
DOE No: 0097

DOE Coord: J. Aellen

Title: Water Drying System

Description: A technique for removing wash water from manufactured parts by dipping parts into degreaser solvent and mechanically separating water by virtue of differences in liquid densities.

Inventor: James W McCord

State : KY

\author{
Contact: \\ James W McCord \\ Corpane Industries, Inc. \\ 250 Production Court \\ Bluegrass Industrial Park \\ Louisville KY 40299 \\ 502-491-4433
}

Status: Complete

Status Date: 09/10/80

OERI No.: 003679

Patent Status

Development Stage : Engineering Design

Technical Category: Industrial Processes

Recv. by NIST : 08/09/76

Recom. by NIST : $02 / 28 / 79$

Award Date : $09 / 10 / 80$

Contract Period: 09/10/80

Award Amount: $\$ 93,800$ Grant No: FG01-80CS15025 $06 / 10 / 82$

Summary:

A grant of $\$ 93,800$ was awarded to design and construct demonstration models of a system to degrease and dry metal parts prior to painting. Product is available for custom installation in production lines. The inventor has been successful in marketing his product.

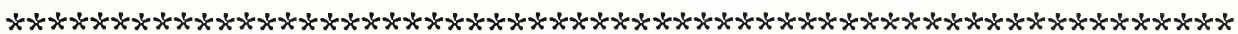

DOE No: 0098

DOE Coord: D.G.Mello

Title:

Process Development to Conserve Energy and Material- --(in the manufacture of) -.-Bearings

Description: A methodology for continuously casting a sheet of the desired bearing alloy, in the desired thickness, cutting it to the proper length, rolling it to the specified diameter, and welding it together.

Inventor: James L Chill

State : $\mathrm{OH}$
- Contact:

James L. Chill, President

Chillcast, Inc.

404 Executive Boulevard

Marion $\mathrm{OH} 43302$

$614-383-6337$

Status: Complete

Status Date: 06/30/83

OERI No. : 003547

Patent Status

Development Stage : Prototype Development

Technical Category: Industrial Processes

Recv. by NIST : 02/17/78

Recom. by NIST : 03/14/79

Award Date : $01 / 07 / 80$

Contract Period: 01/07/80

Award Amount: $\$ 123,994$ Grant No: FG01-80IR10321

$-06 / 30 / 83$

Summary:

A grant of $\$ 123,994$ was awarded for the grantee to work with Battelle Memorial Institute to optimize the rolling-pass and heat treatment schedules, establish and compare the performance characteristics of the prototype bearings with those made by current methods, evaluate cylindrical bearings with and without a seam weld, and investigate performance of prototypes containing only $3 \%$ tin. An entrepreneur is needed to market this invention successfully. 
DOE No: 0099

DOE Coord: D. G. Mello

Title:

Light Weight Composite Trailer Tubes

Description: A design and manufacturing method for manufacture of composite pressure vessels employed in highway transport of gaseous fuel.

Inventor: Oscar Weingart

State : CA

Status: Complete

Status Date: 01/14/80

Contact

Ed Morris, President

Struct. Comp Ind., Inc.

325 Enterprise Avenue

Pamona CA 91768

$714-594-7777$

Patent Status : Disclosure Document Program

Development Stage : Engineering Design

Technical Category: Transportation Systems, Vehicles \& Components

Recv. by NIST : 06/05/78

Recom. by NIST : $03 / 30 / 79$

Award Date : $01 / 14 / 80$

Contract Period: 01/14/80

Award Amount: $\$ 96,000$ Grant No: FG01-80IR10319

Summary:

A grant of $\$ 96,000$ was awarded to design, fabricate, and test a large scale section of a new light-weight composite trailer tube for highway transportation of compressed gases. Product requires sponsor for commercial introduction. Licensing is available. Prototype product sales total $\$ 50,000$.

DOE No: 0100

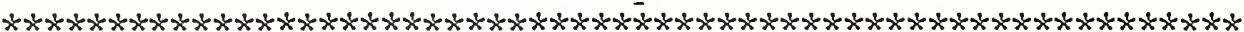

Title:

DOE Coord: J. Aellen

Description: A flexible rubber tubing solar collector for hot water and building heating systems. Collector is extrusion of ethylene-propylene-diamine rubber.

Inventor: Michael F Zinn

State: NY
Contact:

Michael F Zinn

Bio-Energy Systems, Inc.

Box \#191

Ellenvilie NY 12428

$914-647-6482$

Status: Complete

Status Date: $03 / 25 / 80$

OERI No.: 003236

Patent Status Not Applied For

Development Stage : Limited Production/Marketing

Technical Category: Direct Solar

Recv. by NIST: 12/05/77

Recom. by NIST : $03 / 30 / 79$

Award Date : 05/24/80

Contract Period: 05/24/80

Award Amount: $\$ 110,390$ Grant No: FG01-80CS15002

$-11 / 25 / 81$

Summary:

A grant of $\$ 110,390$ was awarded to test the product's performance in a variety of applications; in limited production/marketing stage when recommended. Sales for 1981 exceeded $\$ 4$ million through 400 distributors and dealers in the U.S and from licensees in five foreign countries. Company now publicly held, from $\$ 2.5$ million stock issue and employs 100 in three divisions. New products are developed and on the market. 
DOE No: 0101

Title:

Description:
DOE Coord: P.M.Hayes

Controlled Combustion Engine

A modified intake valve for spark ignition engines. Creates increased turbulence at low throttle settings to allow lean burning mixtures.
Inventor: Sharad M Dave

State : MI
Contact:

Sharad $M$ Dave

27689 Doreen

Farmington Hills MI 48024

. $313-478-5976$

Status: Complete

Status Date: $11 / 30 / 82$

OERI No.: 002114

Patent Status : Patent Number: 3762381

Development Stage : Concept Development

Technical Category: Combustion Engines \& Components

Recv. by NIST : $02 / 28 / 77$

Recom. by NIST : $04 / 20 / 79$

Award Date : $05 / 05 / 81$

Contract Period: 05/05/81

Award Amount: $\$ 85,000$ Grant No: FG01-81CS15040 $-11 / 30 / 82$

Summary:

An award of $\$ 85,000$ to modify a conventional engine was granted to provide variable valving in a variety of designs and test on an engine dynamometer both for efficiency and performance. The project is completed. Inventor is seeking licensing.

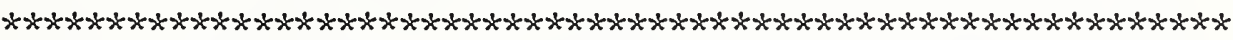

DOE No: 0102

DOE Coord: D.G.Mello

Title:

Method of Burning Residual Fuel Oil in Distillate Fuel Oil Burners

Description:

The invention is a method to convert standard distillate fuel oil burners to residual fuel oil, which is accomplished by heating that portion of the combustion air used to atomize the fuel oil.

Inventor: Frank C Bernhard

State : MO

Status: Complete

Patent Status

Development Stage
Technical Category

Recv. by NIST

Recom $12 / 19 / 77$

Recom. by NIST : $04 / 24 / 79$

Award Date : 02/21/80

Contract Period: 02/21/80
Contact:

Frank C Bernhard

11936 Claychester Drive

St. Louis MO 63131

$314-822-3484$

Status Date: 02/21/80

OERI No.: 003205

Summary:

Award Amount: $\$ 43,550$ Grant No: FG01-80CS15003

Patent Number: 3977823

Concept Development

Buildings, Structures \& Components

A grant of $\$ 43,550$ was awarded to design and build a packaged, self-contained fuel oil burning test stand that can burn residual fuel oil in any low-pressure, atomizing fuel oil burner. Test showed technical viability. Market presently very poor. 
DOE No: 0103

DOE Coord: P.M.Hayes

Title:

Low Voltage Ionic Fluorescent Light Bulb

Description: Fluorescent light bulb built on Edison base. Excited by array of gas discharge tubes. Uniform output, high efficiency, and long life are claimed.

Inventor: Edwin E Eckberg

State : ID
Conțact:

Edwin E Eckberg

Ecklux R \& D Vacuum Lab Inc

5504 Currier Road

Boise ID 83705

$208-343-7442$

Status: Complete

Status Date: 09/10/81

OERI No.: 001446

Patent Status : Patent Number: 3447098 and others

Development Stage : Engineering Design

Technical Category: Buildings, Structures \& Components

Recv. by NIST : 09/17/76

Recom. by NIST : $04 / 30 / 79$

Award Date : 03/12/80

Contract Period: 03/12/80

Award Amount: $\$ 73,554$ Grant No: FG01-80CS15007

- 09/10/81

Summary: A grant of $\$ 73,554$ was awarded to design, develop, fabricate and test a series of one, two and four-bulb configuration low-voltage fluorescent ionic light bulbs. The one-bulb version will be developed to a point suitable for semi-automatic machine production. The grant was completed. The inventor is deceased. An entrepreneur is needed to develop further and market this invention.

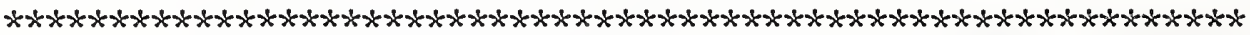

DOE No: 0104

DOE Coord: G. K. E11is

Title:

Low Continuous Energy Mass Separation System

Description: The invention is a combination of any two or all three separation techniques involving chromatography, electrophoresis, and centrifugation (common in all combinations) to provide a low-energy continuous separation of chemical species, either in the gas phase or liquid phase.

Inventor: Eskil L Karlson

State : PA

Status: Complete

Patent Status

Development Stage:

Technical Category:
Contact:

Eskil I Karlson

4634 State Street

Erie PA 16509

$814-871-7000$

Recv. by NIST : 05/11/77

Recom. by NIST : $04 / 30 / 79$

Award Date : 02/26/80

Contract Period: 02/26/80

Award Amount: $\$ 83,015$ Grant No: FG01-80CS15008

- $04 / 26 / 81$

Summary:

A grant was awarded to build and test two laboratory models. More development needed but the results encouraging with 90 percent separation each pass at several gal/min throughput. Inventor needs funding for $R \& D$ to build a production prototype, and alternate versions. Inventor seeking company interested in producing a unit to do genetic separations. Potential market at medical schools and labs, around 30,000 units at $\$ 2,000$ to $\$ 10,000$ per unit. 
DOE No: 0105

DOE Coord: J. Aellen

Title:

High Frequency Furnace

Description: A furnace for the melting of reactive metals and semi-conductors which must be obtained in high purity form. It employs high frequency heating in a manner that allows the metal being melted to form its own crucible.

Inventor: Allen D Zumbrunnen

State : UT
Contact:

Allen D Zumbrunnen

419 Sherman Avenue

Salt Lake City UT 84115

$801-466-2663$
Status: Complete

Patent Status

Development Stage :

Technical Category:

Recv. by NIST : $06 / 24 / 77$

Recom. by NIST : 04/30/79

Award Date : 09/30/81

Contract Period: 09/30/81

Status Date: 07/10/85

OERI No.: 002467

Summary:

A grant of $\$ 121,554$ was awarded to build and test a prototype high frequency induction furnace for the production of silicon for solar cells.

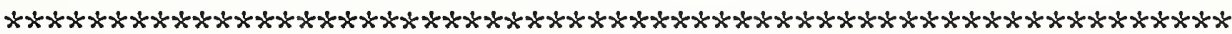

DOE No: 0106

DOE Coord: D. G. Melio

Title:

Deep Shaft Hydro-Electric Power

Description: A proposal to investigate the use of underground salt domes/caves as pumped storage of water for production of peak demand electricity.

Inventor: James L Ramer

State : MO

Status: No DOE Support
Contact:

James I Ramer

Patent Status : Not Applied For

Development Stage : Concept Definition

Technical Category: Miscellaneous

Recv. by NIST : 09/30/77

Recom. by NIST : 05/10/79

Summary:

Material submitted as proposal to DOE described a concept that related several known ideas and proposed to unite them into one large experiment. The work was not definitive or feasible enough to justify grant award by DOE. 
DOE No: 0107

DOE Coord: J.Aellen

Title: Waste Products Reclamation Process

Description:

This is a process for desulfurizing combustion gases, with a by-product "Linfans" which is claimed to have economic uses as a 1) construction material, 2) reagent for treating waste water, and 3) agent to react with sulphur dioxide in stack gas scrubbing processes.

Inventor: Ping-Wha Lin

State : IN

Status: Complete

Patent Status

Development Stage :

Technical Category:

Recv. by NIST

Recom. by NIST

Award Date $\quad 09 / 30 / 82$

Contract Period: 09/30/82
A grant of $\$ 129,888$ was awarded to define the operating parameters and optimize the variables. Final report shows considerable uses for the invention. Inventor attempting to find customers and suppliers, etc.

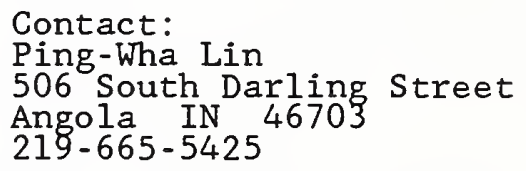

Contact:

Ping-Wha Lin

506 South Darling Street

Angola IN 46703

$219-665-5425$

Summary:

Status Date: 09/30/82

OERI No.: 001416

Patent Number: 3861930 and others

Laboratory Test

Industrial Processes

Award Amount: $\$ 129,888$ Grant No: FG01-81CS15143 $-12 / 31 / 83$

DOE No: 0108

DOE Coord: G. K. Ellis

Title: $\quad$ Processing Recovery of Aluminum

Description: The invention is a mechanical process, operated at room temperature, (except for the reduction step) for separating aluminum metal from the dross.

Inventor: Paul J Cromwell

State : NY

Status: Complete

Patent Status

Development Stage : Prototype Test

Technical Category:

Recv. by NIST: $12 / 27 / 78$

Recom. by NIST : $05 / 31 / 79$

Award Date : 06/11/80

Contract Period: 06/11/80

Award Amount: $\$ 158,029$ Grant No: FG01-80CS15009
Contact:

Robert j Cromwel1

120 Huntington Street

Chardon of 44024

$216-285-9306$

Status Date: 06/12/81

OERI No.: 004688

Summary: A grant of $\$ 158,029$ was used to develop a mechanical process for recovering aluminum from dross (i.e. waste). The inventor secured $\$ 1.5$ million in financing and opened a plant in Buffalo. The plant was closed down however, due to the depressed nature of the aluminum industry. Subsequently, the inventor patented a new process for melting aluminum beverage cans. 
DOE No: 0109

Title:

Description:

DOE Coord: D.G.Mello-

Hydrostatic Meat Tenderizer

The invention is a method for tenderizing low-grade, grass fed beef by subjecting the boned meat to a hydrostatic pressure of over 15,000 psi for several minutes.

Inventor: H. W. Kennick

State : $\mathrm{OR}$

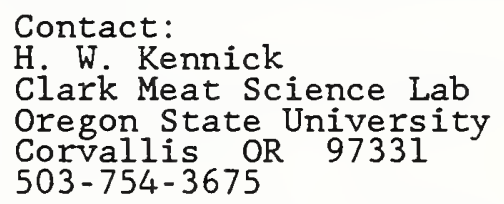

Contact:

H. W. Kennick

Clark Meat Science Lab

Oregon State University

$503-754-3675$
Status: Complete

Patent Status

Status Date: 06/24/80

OERI No. : 003321

Development Stage : Prototype Test

Technical Category: Miscellaneous

Recv. by NIST : 01/11/78

Recom. by NIST : 06/19/79

Award Date $\vdots 06 / 24 / 80$

Contract Period: 06/24/80

Award Amount: $\$ 86,000$ Grant No: FG01-80CS15013

$-03 / 01 / 83$

Summary:

A grant of $\$ 86,000$ was awarded to investigate and develop a feasible commercial process. The projects results show that the process is feasible and the product is at least as tender and tasty as traditionally processed grain-fed beef. Technical data are available for the cost of handing from the Oregon State University.

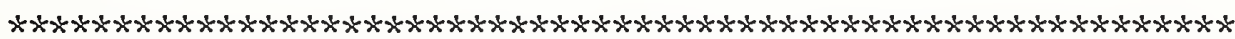

DOE No: 0110

DOE Coord: D.G.Mello

Title:

Improved Windpower Generating System

Description: Self-regulating, two-part windmill rotor with inner part for low-speed wind and outer part for high- speed wind.

Inventor: Karl H. Bergey

State: OK

Status: Complete

Patent Status

Development Stage $\vdots$ Prototype Development
Technical Category: Other Natural Sources

Recv. by NIST : 01/19/78

Recom. by NIST : 06/29/79

Award Date $\vdots 08 / 26 / 80$

Contract Period: 08/26/80

- 09/30/82
Contact:

Karl H. Bergey

Route \#1, Box \#151B

Norman OK 73069

405-364-3675

Summary:

Status Date: 08/27/80

OERI No. : 003425

Award Amount: $\$ 74,875$ Grant No: FG01-08CS15011

A 13 -month grant of $\$ 74,875$ was awarded for the development of an analytical program to characterize the operation of the Bergey windmill, design and test the prototype, and perform an economic analysis of the benefits of the design. Invention is available for wholesale and retail distribution. 
DOE No: 0111

DOE Coord: P.M.Hayes

Title:

Haspert Mining System

Description: The invention is intended for developing rectangular openings for mineral development. It is a mechanical apparatus that cuts linear grooves in rock using drag bits and then breaks the rock between the grooves primarily in the tension mode. Potential applications are in oil shale, rock and possibly coal.

Inventor: John C Haspert

State : CA
Contact:

John C. Haspert

P.O. Box \#1252

Arcadia CA 91006
Status: Complete

Patent Status

Development Stage

Technical Category:
Status Date: 09/11/81

OERI No.: 003688
Recv. by NIST : 03/27/78

Recom. by NIST : 06/29/79

Award Date $\vdots 03 / 27 / 80$

Contract Period: 03/27/80
Award Amount: $\$ 125,000$ Grant No: FG01-80CS15006

Summary:

A grant of $\$ 125,000$ was awarded to provide a complete set of preliminary design drawings for a prototype machine for "driving" a drift for the mining of oil shale and coal. The cutter produces uniformly sized material at lower costs than present methods. The work was completed and the inventor seeks licensing and/or venture capital.

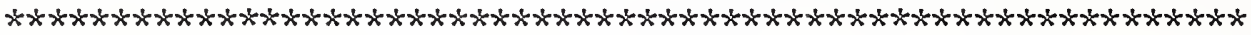

DOE No: 0112

DOE Coord: D.G.Mello

Title: Pump

Description: A conventional steam injector to serve as both feedwater pump and direct contact feedwater heater in conventional steam power plants.

Inventor: Paul Zanoni

State: CT
Contact:

Paul Zanoni

Boulder Engineering, Inc.

Fifty-Five Highland Street

Weathersfield CT 06109

203-569-0446

Status: Complete

Status Date: $11 \overline{j 07 / 85}$

OERI No.: 000548

Patent Status : Patent Number: 3314236

Development Stage : Concept Development

Technical Category: Fossil Fuels

Recv. by NIST : 12/29/75

Recom. by NIST : $07 / 26 / 79$

Award Date : 08/03/81

Contract Period: 08/03/81

Award Amount: $\$ 99,870$ Grant No: FG01-81CS15057

\section{- $11 / 07 / 85$}

Summary:

A grant of $\$ 99,870$ was awarded to design, build, and install system for field tests at Worchester Polytech in Massachusetts. System will operate in conjunction with existing steam power plant. The inventor complains that he is not getting proper cooperation from worcester Polytech, making it impossible to complete the project. The project was closed unfinished. 
DOE No: 0113

DOE Coord: P.M.Hayes

Title: Wallace Mold Additive System

Description: A device and method for feeding small pieces of metal scrap of known composition and at a fixed rate into a mold, while molten metal is being poured.

\section{Inventor: Henry J Wallace}

State : PA
Contact:

Henry J Wallace

570 Squaw Run Road

Pittsburgh PA 15238

412-963-0969

Status: Complete

Status Date: 09/21/83

OERI No.: 003865

Patent Status

Development Stage : Prototype Development

Technical Category: Industrial Processes

Recv. by NIST : 04/20/78

Recom. by NIST : $07 / 31 / 79$

Award Date : 09/22/82

Contract Period: 09/22/82

Award Amount: $\$ 89,000$ Grant No: FG01-82CE15093

$09 / 21 / 83$

Summary:

A grant of $\$ 89,000$ was awarded to build and test a feeding device to be installed on a mini-mill located in Florida. The grant work is completed. The Wallace injection system is patented in the U.S. and many other countries. The inventor is seeking licensing arrangement for his process through Blair- Knox Equipment Division of Blairnox, $\mathrm{Pa}$. 412-781-2700. Blair-Knox Equipment is licensed to supply apparatus for the Wallace Additive Injection System.

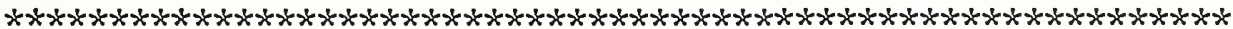

DOE No: 0114

DOE Coord: P.M.Hayes

Title:

New Energy-Saving Tire for Motor Vehicles

Description:

An automobile tire of innovative design intended to reduce rolling friction below that of equivalent radial tires. Special rims are required.

Inventor: Renato Monzini

Country : Milan, Italy

Status: No DOE Support
Contact:

Mario Bruno

Patent Status : Patent Number:

Development Stage : Prototype Development

Technical Category: Transportation Systems, Vehicles \& Components

Recv. by NIST : $04 / 20 / 78$

Recom. by NIST : $07 / 31 / 79$

Summary: DOE could find no basis for support. 
DOE No: 0115

DOE Coord: D. G. Mello

\section{Title: Refrigeration System}

Description: Device to be installed between the compressor and the air cooled condenser in a small refrigeration unit. It consists of a dryer-filter heat exchanger, a venturi-ejector, and connecting piping.

Inventor: ${ }_{\text {SE }}^{\text {Clyde G Phillips }}$

Contact:

Clyde G Phillips

- Rural Route \#2

Box \#148-G, Angola Beach

Lewes DE 19991

302-945-9093

Status: Complete

Status Date: $02 / 22 / 80$

OERI No.: 001188

Patent Status : Patent Number: 3783629

Development Stage : Laboratory Test

Technical Category: Miscellaneous

Recv. by NIST : 07/02/76

Recom. by NIST : $07 / 31 / 79$

Award Date $\vdots 12 / 07 / 79$

Contract Period: 12/07/79

Award Amount: $\$ 6,910$ Grant No: FG01-80IR10318

Summary:

The grantee installed his device in one large- capacity, and one smal1-capacity commercially available air conditioners and shipped them to an independent testing laboratory where the change in performance was documented. No energy savings were apparent.

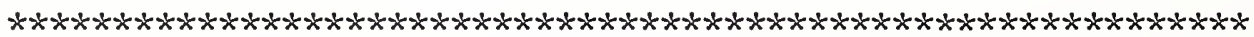

DOE No: 0116

DOE Coord: G. K. Ellis

Title:

Model 5000 ASEPAK System

Description: The inventions are for new methods for fabricating and aseptically filling sterile plastic bags with certain classes of food materials that have been previously sterilized by ultra-high temperature processes for very short periods of time.

Inventor: Roy J Weikert

Contact:

State : $\mathrm{OH}$

Roy J Weikert

Status: No DOE Support

Status Date: 10/04/80

OERI No.: 002946

Patent Status : Patent Number: 3813845 and others

Development Stage : Prototype Development

Technical Category: Industrial Processes

Recv. by NIST : 11/04/77

Recom. by NIST : $08 / 30 / 79$

Summary: Unable to identify suitable scope of work which was both agreeable to the inventor and supportable by DOE. 
DOE No: 0117

DOE Coord: J. Aellen

Title: "Solarspan" Prism Trap

Description: An all-plastic, black liquid, solar collector with provisions for freeze and overheat protection. Plastic can be molded to give good structural properties with thin sections.

Inventor: John Mattson

State : MA
Contact:

George E Mattson

361 Moraine Street

Brockton MA 02401

617-585-3598

Status: Complete Status Date: 09/30/80 OERI No.: 002189

\section{Patent Status : Patent Applied For}

Development Stage : Prototype Test

Technical Category: Direct Solar

Recv. by NIST : 03/28/77

Recom. by NIST : 09/20/79

Award Date : 09/30/80

Contract Period: 09/30/80

Award Amount: \$ 98,700 Grant No: FG01-80CS15024

- $10 / 30 / 81$

Summary: A grant of $\$ 98,700$ was awarded to design, test and construct, low-cost plastic solar water heating panels. The project was successful. Evaluation by the Oak Ridge National Laboratory comments that this invention "will save the solar program by showing all concerned that low costs can be achieved." Product is available for wholesale distribution.

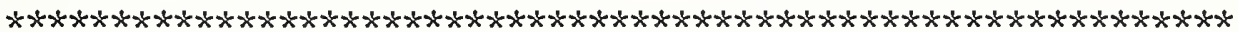

DOE No: 0118

DOE Coord: J.Aellen

Title:

Energy Adaptive Control of Precision Grinding

Description: An otherwise conventional, universal, external cylindrical grinder retrofitted with a computer control to save energy in removing metal.

Inventor: Roderick L Smith

State : IL
Status: Complete

Patent Status

Development Stage $\vdots$ Prototype Test

Technical Category:

Recv. by NIST : 04/24/78

Recom. by NIST : $09 / 27 / 79$

Award Date : 09/15/81

Contract Period: 09/15/81
A grant of $\$ 99,328$ was awarded to perform a complete engineering design and test of the invention prototype equipment. The technology has been licensed to the Caterpillar Tractor Company. 
DOE No: 0119

DOE Coord: G.K.Ellis

Title:

Air Ratio Controller (AERTROL)

Description: A controller that controls the running time of a blower in proportion to the rate of flow of liquid in forced aeration type sewage plants; developed specifically to serve many small package treatment plants with liquid flow of less that 100,000 gallons per day.

Inventor: Eldon L Asher

State : FL

Status: No DOE Support
Contact:

Otis W Smith

\section{Patent Status
Development Stage \\ Technical Category: Industrial Processes}

Recv. by NIST : 06/05/78

Recom. by NIST : 09/28/79

Summary: $\quad$ Proposal for marketing was rejected by DOE.

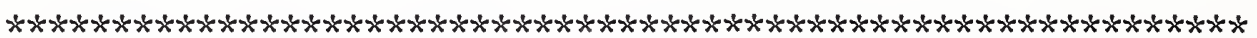

DOE No: 0120

DOE Coord: D.G.Mello

Title: Vapor Heat Transfer Commercial Griddle

Description: A griddle for restaurants with its surface heated by vapor condensation. This vapor is boiled with electric elements in a sump below the griddle surface. Vapor and condensed liquid are hermetically sealed.

Inventor: Robert Zartarian

State : NJ
Contact:

Robert Żartarian

Systech Industries

Six Hialeah Court

West Long Beach NJ 07764

$201-449-3700$

Status: Complete

Status Date: 10/30/86

OERI No.: 004562

Patent Status : Patent Applied For

Development Stage $\vdots$ Limited Production/Marketing

Technical Category: Miscellaneous

Recv. by NIST : 11/02/78

Recom. by NIST : $10 / 17 / 79$

Award Date $09 / 02 / 82$

Contract Period: 09/02/82

Award Amount: $\$ 72,603$ Grant No: FG01-82CE15124

Summary:

A 12 -month grant of $\$ 72,603$ was awarded for a two-phase, 7-task development project in which the grantee performed $R \& D$ tasks relating to product improvement and safety, as well as market development. Marketing plans depend on future financial assistance from the private sector. 
DOE No: 0121

DOE Coord: J. Aellen

Title:

Solar Space Heating for both Retrofit and New Construction

Description: Passive solar collector using air as the transfer fluid. Designed for vertical south wall of a structure.

Inventor: James B Whitmore

State : MI

Status: No DOE Support

\author{
Contact: \\ James $B$ Whitmore \\ Status Date: / / \\ OERI No.: 004843
}

\section{Patent Status : Not Applied For}

Development Stage : Limited Production/Marketing

Technical Category: Direct Solar

Recv. by NIST : 02/08/79

Recom. by NIST : 10/25/79

Summary: Inventor is in commercial production. Over 6000 installations, costing $\$ 30$ million, have been made.

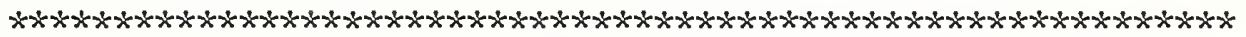

DOE No: 0122

DOE Coord: J. Aellen-

Title: Lean Limit Controller

Description: A device to apply adaptive control to air-fuel metering in internal combustion engines.

Inventor: Ervin Leshner

State : NJ

Status: Complete

Patent Status

Development Stage : Prototype Test

Technical Category: Combustion Engines \& Components

Recv. by NIST : $01 / 12 / 78$

Recom. by NIST : $11 / 23 / 79$

Award Date : $09 / 24 / 80$

Contract Period: 09/24/80

Award Amount: $\$ 99,500$ Grant No: FG01-80CS15022

- $12 / 24 / 81$
Contact:

Fuel Injection Development Cor

256 South Van Pelt

Philadelphia PA 19103

215-735-8704

Status Date: 09/24/80

OERI No.: 004035

Summary:

An grant of $\$ 99,500$ was awarded to design and test a lean limit control device for an internal combustion engine. Device is workable but engineering estimates show it will not be cost effective. 
DOE No: 0123

DOE Coord: G.K. Ellis

Title: Comminution of Ores by a Low-Energy Process

Description: Heating, with microwaves to differentially expand and fracture the sulphur containing elements of ore and porphory rock, intended as a preliminary stage in the processing of ore before the grinding stage.

Inventor: J Paul Pemsler

State : MA
Contact:

J. Paul Pemsler, President

Castle Technology Corp.

P. 0 . Box \#403

Lexington MA 02133

$617-861-1274$
Status: Complete

Patent Status Development Stage:

Technical Category:
Status Date: 11/25/81

OERI No.: 004573

Recv. by NIST : 11/06/78

Recom. by NIST : $11 / 29 / 79$

Award Date : $09 / 15 / 80$

Contract Period: 09/15/80

Award Amount: $\$ 90,394$ Grant No: FG01-80CS15020

Summary:

A grant of $\$ 90,394$ was awarded to explore the technical feasibility and determine the energy input for the process. The energy requirements to accomplish any practical degree of fracturing were found to be beyond the range of equipment that was available for this project.

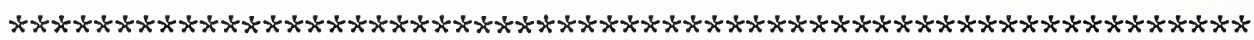

DOE No: 0124

DOE Coord: J.Aellen

Title:

Solar Collector

Description:

This solar collector is a two foot square module constructed entirely of a non-porous ceramic which has been fired at high temperatures so that it is vitrified.

Inventor: Charlton Sadler

State : FL

Status: No DOE Support
Contact:

- Charlton Sadler

Status Date: 06/02/82 OERI No.: 004352

Patent Status : Patent Number: 4170983 and others

Development Stage : Working Mode1

Technical Category: Direct Solar

Recv. by NIST : 08/30/78

Recom. by NIST : 11/30/79

Summary: Unable to agree with the inventor upon an acceptable statement of work. 
DOE No: 0125

DOE Coord: G.K.Ellis

Title :

The Turbulator Burner System

Description: Invention is a stirred heat exchanger (SHE) consisting of a heat exchanger with an annular cross section surrounding a region where the higher temperature fluid flows axially. Blades attached to an axial shaft stir the fluid at the surface of convective heat transfer. Offers possibility of enhanced heat transfer using dirty gases.

Inventor: Frank W Bailey

State : NJ
Contact:

Frank W Bailey

P.0. Box \#94

Fourth Avenue

Haskell NJ 07420

Status: Complete

Status Date: 09/30/81

OERI No.: 000707

Patent Status

Development Stage : Prototype Test

Technical Category: Buildings, Structures \& Components

Recv. by NIST : $02 / 11 / 76$

Recom. by NIST $12 / 31 / 79$

Award Date $\quad 09 / 11 / 80$

Contract Period: 09/11/80

Award Amount: $\$ 75,000$ Grant No: FG01-81CS15016

- 09/14/81

Summary:

A grant of $\$ 75,000$ was awarded to design, build, test, and evaluate both an externally and an internally stirred heat exchanger.

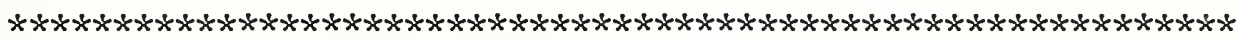

DOE No: 0126

DOE Coord: J. Aellen

Title:

Vaclaim Description: A system for use in metal casting foundries. Reclaims heat from metal castings
and energy from the binder in no-bake molds. Eliminates smoke and fumes from the foundry.

Inventor: Karl D Scheffer

State : NY

Contact:

Karl D Scheffer

121 Governor Drive

Scotia NY 12302

518-399-0016

Status: Complete

Status Date: 04/01/81

OERI No.: 004970

Patent Status : Not Applied For

Development Stage : Laboratory Test

Technical Category: Industrial Processes -

Recv. by NIST : 03/19/79

Recom. by NIST : $12 / 31 / 79$

Award Date : $04 / 01 / 81$

Contract Period: 04/01/81

Award Amount: $\$ 97,734$ Grant No: FG01-81CS15036

Summary:

A grant of $\$ 97,734$ was awarded for fabrication and testing heat recovery in vacuum metal casting process using no-bake molds. Inventor seeks license arrangements. 
DOE No: 0127

DOE Coord: D.G.Mello

Title: Process and Apparatus to Produce Crude Oil from Tar Sands

Description: Two-vesse1, fluidized bed system connected by heat pipes to transfer heat between the upper pyrolizer vessel and the lower combustor vessel in which char residue is burned. Clean sand comes out in the tailings and a usable grade of synthetic crude oil out the overhead.

Inventor: J D Seader

State : UT
Contact:

$J$ D Seader

Merrill Engineering Building

University of Utah

Sale Lake City UT 84112
$801-581-6348$
Status: Complete

Patent Status

Development Stage

Technical Category:

Recv. by NIST

: $03 / 26 / 79$

Recom. by NIST : $12 / 31 / 79$

Award Date : 09/16/82

Contract Period: 09/16/82
Status Date: 09/16/84

OERI No.: 005003

Summary:

A 12 -month grant of $\$ 49,949$ was awarded to the University of Utah to design, construct, and operate a device for the purpose of producing crude oil from tar sands. Goals to prove the design, optimize the variables (including the

DOE No: 0128

Title:

Description: New design for distilling column where the rectifying and stripping sections are side by side, and heat pipes transfer heat from the rectifying to the stripping section.

Inventor: J D Seader

State: UT product mix), and to prove the concept have been achieved.

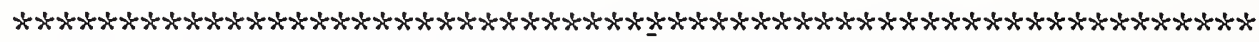

DOE Coord: D.G.Mello

Continuous Distillation Apparatus and Method

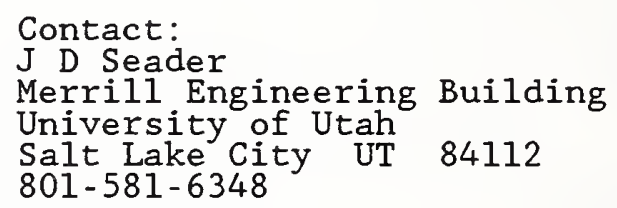

Award Amount: $\$ 49,949$ Grant No: FG01-82CE15136 
DOE No: 0129

DOE Coord: J. Aellen

Title: Super U System - Snap Strap

Description: Super U-Snap strap insulation system which is an innovative application technique.

Inventor: James E Kessler

State : MO

Contact:

James E Kessler

9913 Walnut Drive, \#201

Kansas City MO 64114

Status: Complete

Status Date: $11 / 28 / 80$

OERI No.: 004007

Patent Status : Patent Number: 4069636

Development Stage : Prototype Development

Technical Category: Buildings, Structures \& Components

Recv. by NIST : $05 / 24 / 78$

Recom. by NIST $\vdots 01 / 31 / 80$

Award Date : $11 / 28 / 80$

Contract Period: $11 / 28 / 80$

Award Amount: $\$ 84,642$ Grant No: FG01-81CS15209

- $11 / 28 / 81$

Summary:

A grant of $\$ 84,642$ was awarded to test market the Super U System. The project has created ten jobs, and sales have increased 100\% (to $\$ 300,000$ ). Product is available for franchise.

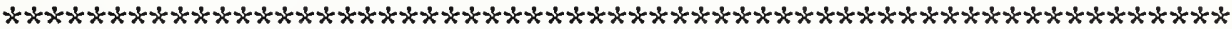

DOE No: 0130

DOE Coord: J.Aellen

Title:

Furnace Input Capacity Trimming Switch Description: A simple inexpensive device for gas and oil furnaces to reduce the flue gas
heat loss. During morning startup, when the room thermostat is calling for heat, the device will cycle the furnace on and off to minimize flue gas heat loss.

Inventor: Arnold R Post

State : MD

Status: No DOE Support
Contact:

Arnold R Post

Status Date: / / OERI No.: 004389

Patent Status : Disclosure Document Program

Development Stage : Laboratory Test

Technical Category: Buildings, Structures \& Components

Recv. by NIST : 09/11/78

Recom. by NIST : 02/26/80

Summary: Project terminated because inventor failed to respond. After repeated requests, inventor was finally informed that he had until August 30, 1981 to submit a preliminary proposal or his invention would no longer be considered for DOE support. Inventor failed to respond - project terminated. 
DOE No: 0131

DOE Coord: J. Aellen

Title: Valve Deactuator for Internal Combustion Engines

Description: A retrofit device that can provide variable displacement operation on existing gasoline engines by one cylinder at a time deactuating.

Inventor: Edgar R Jordon

State : MI

Status: Complete

Patent Status

Development Stage $\vdots$ Prototype Development

Recv. by NIST : 05/01/79

Recom. by NIST : $02 / 29 / 80$

Award Date : $09 / 25 / 80$

Contract Period: 09/25/80

Award Amount: $\$ 65,972$ Grant No: FG01-80CS15023
Contact:

N. John Beck

Fuel Injection Development Co

5141 Santa Fe Street

San Diego CA 92109

$619-270-6760$

Summary:

A grant of $\$ 65,972$ was awarded to develop and test a valve deactivator for internal combustion engines. The invention is available for sale or lease.

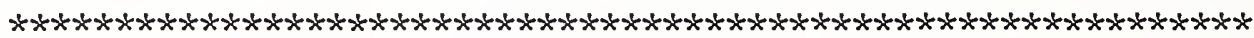

DOE No: 0132

DOE Coord: D.G.Mello

Title:

Process for Reclaiming and Upgrading Thin-Walled Malleable Waste Material

Description: A system for mechanically pelletizing ferrous and non-ferrous metals and some plastics, grading according to size, and then separating according to density by conventional gravity techniques.

Inventor: Michael Knezevich

State : IN

Status: No DOE Support

Patent Status : Patent Number: 4119453

Development Stage : Limited Production/Marketing

Technical Category: Industrial Processes

Recv. by NIST : $11 / 22 / 77$

Recom. by NIST : $03 / 25 / 80$

Summary: Other financial commitments prevent inventor from proceeding.
Contact:

Michael Knezevich

Status Date: / / OERI No.: 003045 
DOE No: 0133

DOE Coord: D.G.Me11o

Title:

AUTOTHERM Car Comfort System

Description: An auxiliary coolant circulator for an automobile which will provide heat to the vehicle operator for a period of time without requiring the engine to idle.

Inventor: F J Perhats

State : IL

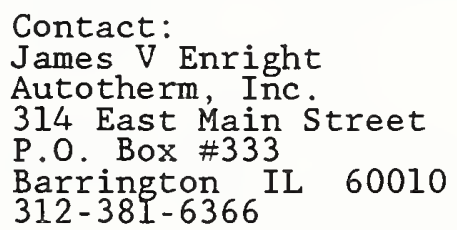

Status: Complete

Status Date: 06/19/83

OERI No.: 004641

Patent Status Patent Applied For

Development Stage : Limited Production/Marketing

Technical Category: Transportation Systems, Vehicles \& Components

Recv. by NIST : $07 / 27 / 78$

Recom. by NIST : $03 / 26 / 80$

Award Date : 06/19/81

Contract Period: 06/19/81

Award Amount: $\$ 71,034$ Grant No: FG01-81CS15050

- $06 / 19 / 83$

Summary:

A 24 -month grant of $\$ 71,034$ was awarded to perform the necessary research and development to ready the invention for the marketplace. A component, the pump, is on the market with sales of $\$ 36,000$. An additional $\$ 300,000$ in sales, supporting a 5-man operation, has come from Europe and Canada. Product is available for wholesale distribution. To date the company has sold 10K units at $\$ 160$ each, altogether saving 0.625 trillion Btu/Yr. They expect to sell 5-10K units/Yr. for the next 5 years.

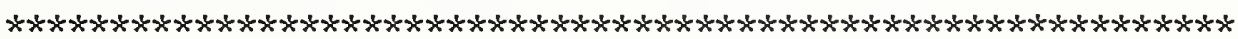

DOE No: 0134

DOE Coord: D.G.Mello

Title:

Expanded Polystyrene Bead Insulation System

Description: A means for retro-insulating housing walls, utilizing expanded polystyrene bead insulation coated with a flame-retardant adhesive and applied with a unique blower-mixer nozzle.

Inventor: John C Rupert

State : MN

Status: Complete

Patent Status

Development Stage

Technical Category: Buildings, Structures \& Components

Recv. by NIST : 05/30/79

Recom. by NIST : 03/31/80

Award Date $\vdots 09 / 26 / 80$

Contract Period: 09/26/80

Summary:

- $12 / 31 / 82$
Contact:

John C Rupert

1511 Grantham Street

Saint Paul MN 55108

612-645-0414
Award Amount: $\$ 80,844$ Grant No: FG01-80CS15027

A grant of $\$ 80,844$ was awarded to select an adhesive/flame retardant, test it at an independent laboratory, develop the blower system, develop a business plan, and demonstrate the technology. A final report is due. A first commercial sale grossed $\$ 14,000$, with total residential sales grossing $\$ 100,000$. Firm employs three individuals. 
DOE No: 0135

DOE Coord: D.G.Mello

Title:

Point Focus Parabolic Solar Collector

Description: It is a lightweight parabolic solar collector design which uses prestressed structural members and cables to achieve high rigidity at a low cost.

Inventor: M Hossein Khorsand

State : CA

Contact:

M Hossein Khorsand

33042 Commodore Court

San Juan Capistrano CA 92675

Status: Complete

Status Date: 06/22/84

OERI No.: 005216

Patent Status : Not Applied For

Development Stage : Working Model

Technical Category: Direct Solar

Recv. by NIST : 05/29/79

Recom. by NIST : 04/30/80

Award Date : 06/22/82

Contract Period: 06/22/82

Award Amount: $\$ 97,892$ Grant No: FG01-82CE15088

- $06 / 22 / 84$

Summary: A 24-month grant of $\$ 97,892$ was awarded to design, build and analyze a prototype point focus collector.

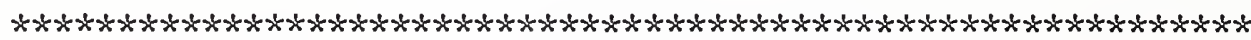

DOE No: 0136

DOE Coord: J. Aellen

Title: Windamper

Description: Wind damper for high voltage electric transmission line to prevent galloping in wind and ice storms

Inventor: Albert S Richardson, Jr.

State : MA

Contact:

Albert S Richardson, Jr.

83 Second Avenue

Burlington MA 01803

$617-862-7200$

Status: Complete

Status Date: 09/01/82

OERI No.: 003885

Patent Status

Development Stage : Limited Production/Marketing

Technical Category: Miscellaneous

Recv. by NIST : 04/25/78

Recom. by NIST : 05/08/80

Award Date : 09/01/82

Contract Period: 09/01/82

Award Amount: $\$ 76,000$ Grant No: FG01-82CE15102

Summary:

A 12-month grant of $\$ 76,000$ was awarded to extend the analysis of the windamper antigallop merits from single conductor to bundled conductor applications. To date, a total of 1400 units has been installed with a total market value of $\$ 130,000$. The invention is available for licensing, both domestic and foreign. 
DOE No: 0137

DOE Coord: J. Aellen

Title: A Portable Pollution Free Automobile Incinerator

Description: Portable automobile incinerator

Inventor: $\mathrm{H}$ Roy Weber

State : HI
Contact:

$\mathrm{H}$ Roy Weber

Box \#336

Kailua HI 96734

$808-262-6548$

Status: Complete

Status Date: 06/30/86

OERI No.: 005130

Patent Status

Development Stage : Prototype Development

Technical Category: Industrial Processes

Recv. by NIST : 05/17/79

Recom. by NIST : 05/08/80

Award Date $\vdots 06 / 20 / 81$

Contract Period: 06/20/81

Award Amount: $\$ 99,408$ Grant No: FG01-81CS15044

- $09 / 30 / 82$

Summary:

A 15 -month grant of $\$ 99,408$ was awarded to fabricate, construct and test, an incinerator to prove the invention is a viable method of reducing scrap cars into satisfactory condition for recycling into the iron and steel industry. The company filed bankruptcy before the grant was completed.

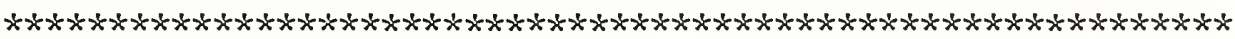

DOE No: 0138

DOE Coord: J. Aellen

Title:

Phantom Tube

Description: Phantom tube is a non light emitting, low energy device to be paired with a fluorescent tube in rapid or instant start fixtures. Device completes the electrical circuit to allow fixtures to operate on fewer lamps than original design specified, thus reducing electric power consumption. Product lifetime is virtually unlimited.

Inventor: Gerald R Seeman

State : CA

Status: No DOE Support
Contact:

Bernard Joseph Margowsky

Status Date: 12/31/81

OERI No. : 001994

Patent Status : Patent Number: 3956665

Development Stage : Limited Production/Marketing

Technical Category: Buildings, Structures \& Components

Recv. by NIST : 03/28/77

Recom. by NIST : 05/28/80

Summary: No appropriate DOE support can be identified. Product supports 5 employees and is on the market. The relatively slow sales of 1.5 million units/year appear adequate to support any needed market research the company might wish to initiate. 
DOE No: 0139

DOE Coord: D.G.Mello

Title: Transformer With Heat Dissipator

Description: An improved method for cooling dry-type transformers, thereby increasing their efficiency without increasing their weight and cost.

Inventor: Louis L Marton

State : CA

Status: No DOE Support
Contact:

Louis L Marton

Patent Status : Patent Number: 3659239 and others

Development Stage : Limited Production/Marketing

Technical Category: Miscellaneous

Recv. by NIST : 01/16/78

Recom. by NIST : 05/29/80

Summary: Inventor does not seek grant money but wishes us to exert legislative influence to require more efficient transformers in general. It does not appear that this service can be provided.

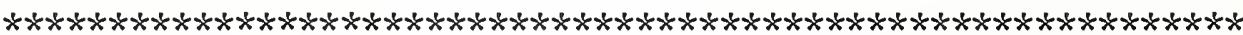

DOE No: 0140

DOE Coord: D.G.Mello

Title:

Counter Flow Dual Tube Heat Exchanger

Description: It is a simple plastic heat exchanger to preheat ventilating air for poultry or livestock barns.

Inventor: WE Mattson

State : $\mathbb{M N}$
Contact:

Tony Wilhelm

Wilhelm Engineering Company

707 Second Street, West

Ashland WI 54806

$715-682-8175$

Status: Complete

Status Date: 07/31/84

OERI No.: 003830

Patent Status : Not Applied For

Development Stage : Concept Definition

Technical Category: Industrial Processes

Recv. by NIST : 04/06/78

Recom. by NIST : 06/20/80

Award Date : 09/22/82

Contract Period: 09/22/82

Award Amount: $\$ 49,758$ Grant No: FG01-82CE15148

$-07 / 22 / 83$

Summary: A 10 -month grant of $\$ 49,758$ was -awarded to design, fabricate, instrument and operate, a prototype dual tube hear exchanger. The invention is available for licensing. It has proved to be cost effective. 
DOE No: 0141 DOE Coord: D.G.Mello

Title: New Hydrostatic Transmission

Description: A continuously variable hydraulic positive displacement transmission with lockup, overdrive, and regenerative braking for automotive and other vehicular uses.

Inventor: Samuel Shiber

State : IL
Contact:

Samuel Shiber

P. 0. Box \#371

- Mundelein IL 60060

Status: Complete

Status Date: 07/09/81

OERI No.: 003673

Patent Status

Development Stage : Concept Development

Technical Category: Transportation Systems, Vehicles \& Components

Recv. by NIST : 03/06/78

Recom. by NIST : $06 / 23 / 80$

Award Date : 07/09/81

Contract Period: 07/09/81

Award Amount: $\$ 95,000$ Grant No: FG01-81CS15064

- 07/09/83

Summary:

A grant of $\$ 95,000$ was awarded to design, build and test a Volkswagen Sirocco with a prototype hydrostatic transmission installed. Project was funded with 90 percent inventor-originated funds and 10 percent DOE funds. Inventor's share was 50 percent domestic and 50 percent foreign funded. Transmission is now available for licensing.

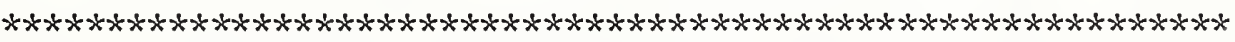

DOE No: 0142

DOE Coord: J. Aellen

Title: $\quad$ Process for Heatless Production of Hollow Items

Description: A metal casting method for hollow parts

Inventor: Anatol Michelson

State: FL

Status: Complete

Patent Status

Development Stage $\vdots$ Prototype Test

Technical Category: Industrial Processes

Recv. by NIST : 09/24/79

Recom. by NIST : $06 / 26 / 80$

Award Date $\vdots 06 / 30 / 81$

Contract Period: 06/30/81

Summary:

- $12 / 31 / 82$
Contact:

Anatol Michelson

3235 Pine Valley Drive

Sarasota FL 33579

$815-388-1252$

Award Amount: $\$ 108,920$ Grant No: FG01-81CS15055

An 18-month grant of $\$ 108,920$ was awarded to construct and test a working model to demonstrate the heatless production of hollow casting. The work has been completed. The invention has potential for greatly increasing productivity of the casting process. Inventor interested in licensing. 
DOE No: 0143

DOE Coord: J Aellen

Title:

Oil Well Pump Jack

Description: A new design for a pump that would replace the conventional beam pumps in pumping oil wells. It utilizes longer strokes than generally used by the beam pumps and has slower rates of acceleration/deceleration, reducing the power required to overcome the inertia of the sucker rods and other moving parts.

Inventor: Robert A Clay

State : CA

Status: Complete

Patent Status
Development Stage : Patent Applied For

Technical Category: Fossil Fuels

Recv. by NIST : 10/19/79

Recom. by NIST : $06 / 27 / 80$

Award Date $\quad 09 / 16 / 84$

Contract Period: 09/16/84

Summary:

A phase one grant of $\$ 52,500$ was made to perform engineering designs of the pump jack. Phase two will be funded upon availability of funds.
Contact:

Amar Amancharla

Alphatech Corporation

Houston TX 97052

$713-530-9060$
Award Amount: $\$ 52,500$ Grant No: FG01-84CE15188

- $03 / 06 / 85$

OERI No.: 005888

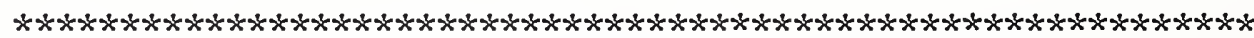

DOE No: 0144

DOE Coord: P.M.Hayes

Title: $\quad$ SpaCirc Space Circulation Fan

Description: The invention is a different type of ceiling fan designed for improved circulation and mixing of air throughout an air conditioned room. The increased air velocity allows the perception of comfort at higher temperatures and humidities.

Inventor: Robert C Saunders, Junior

State : MD

Contact:

Status: No DOE Support

Status Date: / /

OERI No.: 005852

Patent Status : Not Applied For

Development Stage: Concept Development

Technical Category: Buildings, Structures \& Components

Recv. by NIST : 10/09/79

Recom. by NIST : 07/23/80

Summary: Unable to reach agreement on work to be done. Inventor's interest has waned, due to several competitors now in the field and expected high costs of production of the Spacirc. No further action is anticipated. 
DOE No: 0145

DOE Coord: J. Aellen-

Title:

Solar Conversion by Concentration Cells with Hydrides

Description: The invention is a hydrogen concentration cell which converts solar energy to electricity by using heat to generate the gas pressure to drive the cell. (It is an electrochemical heat engine with sunlight furnishing the heat.)

Inventor: Robert E Salomon State : PA

\author{
Contact: \\ Robert E Salomon \\ Chemistry Department \\ Temple University \\ Philadelphia PA 19122 \\ $215-787-7125$
}

Status: Complete

Patent Status

Development Stage : Concept Development

Technical Category:

Recv. by NIST

Recom. by NIST

Award Date

Contract Period:

$12 / 26 / 79$

$07 / 29 / 80$

$07 / 01 / 81$

$07 / 01 / 81$
Award Amount: $\$ 67,868$ Grant No: FG01-81CS15043 $-\quad 09 / 30 / 83$

Summary:

A 17 -month grant of $\$ 67,868$ was awarded to build and test a laboratory model of the inventor's system, to determine efficiency and feasibility. Inventor requested an extension through $8 / 83$ to allow summer school student assistance to continue. Inventor interested in industry financial support, and eventual licensing. This project has been completed.

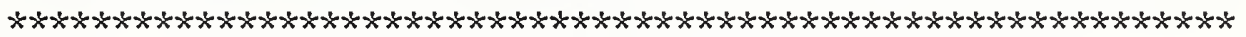

DOE No: 0146

DOE Coord: J.Aellen

Title:

Line Integral Method of Magneto-Electric Exploration

Description: A method of exploring for gas and oil deposits by plotting the intensity and polarities of local perturbations in the earth's magnetic field. These perturbations are caused by naturally occurring electrotelluric (ET) currents associated with the oil and gas.

Inventor: Sylvain J Pirson

State : TX

\author{
Contact: \\ Ronald $\dot{M}$ Hertzfeld \\ 5310 Harvest Hill \\ Suite \#285 \\ Dallas TX 75230 \\ 214-386-9311
}

Status: Complete

Patent Status

Development Stage

Technical Category:
Recv. by NIST : $01 / 25 / 79$

Recom. by NIST : $07 / 30 / 80$

Award Date: :08/13/82

Contract Period: 08/13/82
Status Date: 08/15/83

OERI No.: 004794

Summary: A grant of $\$ 74,689$ was awarded to make a priori predictions on at least 10 locations where wildcat wells are planned. Results show not only accuracy of prediction of dry/wet holes, but also predicted depth of drilling required. The inventor has sold about ten projects based on these results. Project has been completed. 
DOE No: 0147

DOE Coord: J. Aellen

Title:

Railroad Switch Heater

Description: The invention is an electric resistance heater for attachment to railroad switches. The heater can be activated to prevent ice and snow from clogging the area where the railroad switch is closed or opened.

Inventor: Henry Keep, Junior

State : CT

Status: No DOE Support

Patent Status

Development Stage

Technical Category:

\section{Patent Applied For}

Limited Production/Marketing

Transportation Systems, Vehicles \& Components

Recv. by NIST : 09/04/79

Recom. by NIST : 07/31/80

Summary:

Inventor advised that DOE would decline funding because the proposed testing of a commercially available device was outside this program's area of interest. Quantities of the device have been sold to Amtrak.
DOE No: 0148

Title:

Description:

Inventor: Leonard A Duval

State : $\mathrm{OH}$

Status: Complete

Status Date: 03/10/82

Contact:

Leonard A Duval

Colerapa Industries, Inc

Box $\# 172$

- Aurora OH 44202

$216-562-9822$

Patent Status : Patent Number: 3844943

Development Stage : Working Model

Technical Category: Industrial Processes

Recv. by NIST : $08 / 22 / 79$

Recom. by NIST : $08 / 15 / 80$

Award Date : $03 / 10 / 82$

Contract Period: 03/10/82

Award Amount: $\$ 99,000$ Grant No: FG01-82CE15084 - 09/09/82

Summary:

In FY 82, a 6-month grant of $\$ 99,000$ was awarded to test the Duval millscale deoiling process, using Duval's pilot plant with a design capacity of 2 tons $/ \mathrm{hr}$ of oily millscale. In FY 84 the inventor reported to NBS that he had achieved commercial success with the first plant being built in Aurora, Ohio. Others were planned for Chicago, Detroit, Pittsburgh and Hamilton, Ontario. An export license was signed with SPEICHIM in Paris that covers Europe, China and the USSR. Negotiations were underway with C. Itoh of Tokyo. Each plant will require $\$ 5$ milion capital and 35 employees. 
DOE No: 0149 DOE Coord: P.M.Hayes

Title: SCOTCH - (Simple, Cost-Effective, Optimum Temperature Control for Housing)

Description: A system to retrofit residential and other steam heating systems to allow zone heating.

Inventor: Ogden H Hammond

State : MA
Contact:

Ogden $\mathrm{H}$ Hammond

Monument Beach MA 02553

617-757-8400

Status: Complete

Status Date: 07/28/82

OERI No.: 005610

Patent Status : Not Applied For

Development Stage $\vdots$ Concept Development

Technical Category: Buildings, Structures \& Components

Recv. by NIST : 08/06/79

Recom. by NIST : 08/18/80

Award Date: :01/26/81

Contract Period: 01/26/81

Award Amount: $\$ 91^{-}, 962$ Grant No: FG01-81CS15038

$-07 / 28 / 82$

Summary: A grant of $\$ 91,962$ was awarded to design, build and test prototype installations in several residences in the Boston area where steam heated homes are numerous and winters severe. Grant is complete, the company made some sales, and is licensing the control system, which uses house wiring to convey signals.

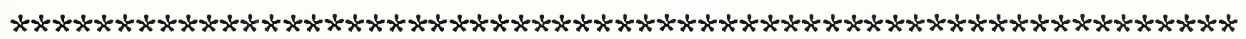

DOE No: 0150

DOE Coord: D.G.Mello

Title:

The Use of Solid Waste Material from a Lubricating Oil and/or Vegetable Oil Refining Operation.

Description: The invention involves the use of solid waste material from a lubricating oil and/or vegetable oil refining operation being used as a raw material for a Portland cement plant.

Inventor: Edward W Midlam

State : LA
Contact:

Edward W Midlam

230021 st Street

Lake Charles LA 70601

$318-436-6656$

Status Date: 08/06/81

OERI No.: 007141

Status: Complete

Patent Status

Development Stage : Production Engineering

Technical Category: Industrial Processes

Recv. by NIST : 06/16/80

Recom. by NIST : $09 / 30 / 80$

Award Date $\vdots 08 / 06 / 81$

Contract Period: 08/06/81

Award Amount: $\$ 64,200$ Grant No: FG01-81CS15073

$-06 / 30 / 83$

Summary :

A grant of $\$ 64,200$ was awarded to investigate one or more specific marketing opportunities. Unfavorable market conditions prevented inventor from pursuing the project further. 
DOE No: 0151

DOE Coord: J.Aellen -

Title:

Film Type Storm Window

Description: A plastic film type of storm window that is tensioned at the corners and sealed on the perimeter to produce a wrinkle free and air tight membrane for window insulation.

Inventor: Yao Tzu Li

State : MA

\author{
Contact: \\ Status Date: / / OERI No.: 005494
}

Status: No DOE Support

Patent Status : Patent Number: 4210191

Development Stage $\vdots$ Concept Development

Technical Category: Buildings, Structures \& Components

Recv. by NIST : 07/30/79

Recom. by NIST : 09/30/80

Summary: Inventor sold Product.

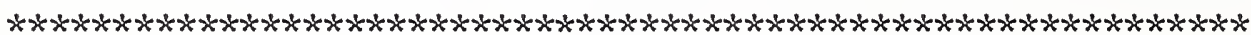

DOE No: 0152

DOE Coord: D.G.Mello

Title: Vehicle Exhaust Gas Warm-up System

Description: An accelerated warm-up system for an internal combustion engine which uses the hot exhaust gases to heat the cooling water. Engine cooling water is ducted to a heat exchanger/muffler in the exhaust system during the warm-up period.

Inventor: David S Majkrzak

State: ND

Contact:

David S Majkrzak

345 Cherry Court

West Fargo ND 58078

$701-282-5593$

Status: Complete

Status Date: 08/06/83

OERI No.: 006439

Patent Status : Not Applied For

Development Stage : Prototype Development

Technical Category: Transportation Systems, Vehicles \& Components

Recv. by NIST : 02/12/80

Recom. by NIST : $09 / 30 / 80$

Award Date : 08/06/81

Contract Period: 08/06/81

Award Amount: $\$ 77,500$ Grant No: FG01-81CS15063

Summary:

A grant of $\$ 77,500$ was awarded to design, build and test a prototype model of the vehicle gas warm-up system. ERIP assistance is complete. Other innovations in this area may have made this invention obsolete. 
DOE No: 0153 DOE Coord: D.G.Mello

Title: A New Equipment Design Concept for Storage of Hot Foods

Description: A series of food handling systems designed to reduce heat loss/gain during storage or transport. The basic concept is that of including a heat storage material with the food enclosed in an insulated container to allow the food to stay warm/cool longer.

Inventor: Carl E Pearl

State : CA

Status: No DOE Support
- Contact:

Carl E Pearl

\section{Patent Status : Not Applied For \\ Development Stage : Concept Development \\ Technical Category: Miscellaneous}

Recv. by NIST : $08 / 10 / 79$

Recom. by NIST : 09/30/80

Summary: The inventor has decided to suspend effort on this project in favor of another, more promising invention not supported by ERIP.

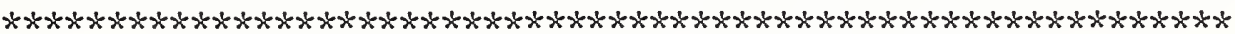

DOE No: 0154

DOE Coord: J.Aellen

Title:

Rotating Horsehead for Pumping Units

Description: An ellipsoidal head for an oil well pump beam unit used in sucker-rod pumping. The ellipsoidal head increases the strokes of the sucker-rod over that of the conventional "horse" head and thus causes an increase in flow.

Inventor: Forrest E Chancellor

State : CA

Status: No DOE Support
Contact:

Forrest E Chancellor

Status Date: 06/30/86

OERI No.: 005750

Patent Status : Patent Number: 4121471

Development Stage : Limited Production/Marketing

Technical Category: Fossil Fuels

Recv. by NIST : 09/07/79

Recom. by NIST : 10/29/80

Summary: Needs licensing and marketing assistance. 
DOE No: 0155

DOE Coord: J.Aellen

Title: Slip Mining

Description: A method of surface mining coal that involves skidding a series of overburden blocks off the coal. The blocks are buoyantly supported stabilized and displaced by a dense mud slurry. Slabs of coal uncovered by block movement are floated to the surface of the dense mud and recovered from the surface of the mud filled pit.

Inventor: James $\mathrm{M}$ Cleary

State : MA

Status: Complete

Patent Status

Development Stage
Technical Category

Recv. by NIST : 07/23/80

Recom. by NIST : $10 / 31 / 80$

Award Date : 12/10/84

Contract Period: 12/10/84

Award Amount: $\$ 109,385$ Grant No: FG01-85CE15195

$-12 / 10 / 86$

\author{
Contact: \\ James M Cleary \\ 92 McCallum Drive \\ Box \#541 \\ Falmouth MA 02541 \\ 617-548-6686
}

OERI No.: 007292

Summary: A grant of $\$ 109,385$ was awarded in three phases to build and field test a prototype slurry trenching machine.

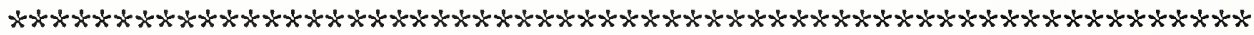

DOE No: 0156

Title:

Description:

Direct-Current Electrical Protective Atmosphere.

DOE Coord: J.Aellen

Inventor: James J Dolan

State: FL

Status: Complete

Status Date: 07/23/81

Patent Status A new appl
of rolled
es J Dolan

Development Stage : Limited Production/Marketing

Technical Category: Industrial Processes

Recv. by NIST : 07/03/79

Recom. by NIST : $10 / 31 / 80$

Award Date : $07 / 23 / 81$

Contract Period: 07/23/81

Award Amount: $\$ 99,485$ Grant No: FG01-81CS15058

- $07 / 23 / 82$

Summary:

A 12 -month grant of $\$ 99,485$ was awarded to design a plant for Southwest Pipe Company, prepare a design manual, and to collect data on energy savings. Two installations are now running: one in Texas and one in Alabama. Negotiations underway for three more in Indian steel Mills. 
DOE No: 0157

DOE Coord: J.Aellen

Title:

Magnaseal Method and Means for Sealing Steel Ingot Casting Molds to Stools

Description: A means of sealing steel ingot casting molds to stools by use of fine metallic particles and an electromagnetic field to emplace the particles.

Inventor: Albert L McQuillen, Jr State : PA

Status: Complete

Patent Status

Development Stage

Technical Category

Recv. by NIST : 11/01/79

Recom. by NIST : $10 / 31 / 80$

Award Date : $06 / 18 / 81$

Contract Period: 06/18/81
A grant of $\$ 91,202$ was awarded to build and install a Magnaseal system in the U. S. Steel plant in Lorrain, Ohio; and to demonstrate and test it.

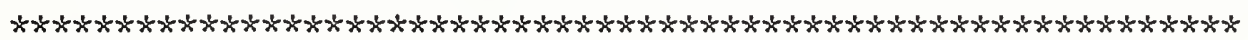

DOE No: 0158

DOE Coord: G.K.Ellis

Title:

Energy Conservative Electric Cable System

Description: A low-loss shielded power cable using a naturally cooled sodium conductor and a pressurized gas insulator.

Inventor: Paul F Pugh

State: CA

Status: Complete

Patent Status

Development Stage : Limited Production/Marketing

Technical Category:

Recv. by NIST : 04/13/77

Recom. by NIST : $10 / 31 / 80$

Award Date: :09/16/81

Contract Period: 09/16/81

Summary:
Contact:

Albert L McQuillen, Jr

1701 Partridge Run Road

Pittsburgh PA 15241

$412-745-9200$

Award Amount: \$91,202 Grant No: FG01-81CS15051

- $12 / 31 / 82$

OERI No.: 005968 
DOE No: 0159

DOE Coord: J.Aellen

Title: Non-Tubing Type Lift Device, Described as the NTT Rabbit

Description: A gas powered lift device designed to collect oil from low producing (or non-producing) wells. It is a piston device which is lowered inside the oil well casing into the liquid. A pressure operated valve closes, the gas pressure below increases, and the device rises lifting the fluid trapped above.

Inventor: William D Gramling

State : MD

Contact:

William D Gramling

5144 Newport Avenue

Chevy Chase MD 20016

$301-686-4125$

Status: Complete

Status Date: 07/24/81

OERI No.: 005380

Patent Status : Patent Number: 4113010 and others

Development Stage : Prototype Development

Technical Category: Fossil Fuels

Recv. by NIST : 05/07/79

Recom. by NIST : $11 / 25 / 80$

Award Date : $07 / 24 / 81$

Contract Period: 07/24/81

Award Amount: $\$ 71,298$ Grant No: FG01-81CS15062

Summary:

A grant of $\$ 71,298$ was awarded to modify, design, install and test the device in several gas/oil wells in Glenville, West Virginia and to investigate and test the feasibility of installing the devices in other areas. After several modifications the unit was tested and operates successfully. However, there appears to be no market for this invention.

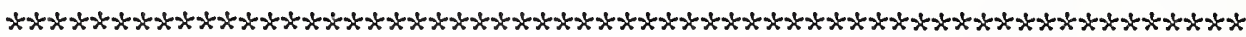

DOE No: 0160

DOE Coord: D.G.Mello

Title:

High Efficiency Absorption Refrigeration Cycle

Description: An improved absorption refrigeration cycle employing a novel combination of absorbent and refrigerant fluids. Both a simple stage and two-stage cycle system are presented.

Inventor: Leon Lazare

State : CT
Contact:

Leon Lazare

$c / 0$ The Puraq Company

111 Hanna's Road

Stamford CT 06903

$203-322-4125$

Status: Complete

Status Date: 04/30/82

OERI No.: 006900

Patent Status : Not Applied For

Development Stage : Engineering Design

Technical Category: Buildings, Structures \& Components

Recv. by NIST : 05/22/80

Recom. by NIST $111 / 25 / 80$

Award Date : $04 / 30 / 81$

Contract Period: 04/30/81

Award Amount: $\$ 87,537$ Grant No: FG01-81CS15046

Summary:

A grant of $\$ 87,537$ was awarded for a plan leading to the installation of the system in four chemical plants to demonstrate the technical and economic feasibility of the process when applied to four different, but representative chemical lines. The grant is complete. Best market for the technology was found to be in ammonia plants. Sales have not yet been closed. 
DOE No: 0161

DOE Coord: J.Aellen

Title:

duPont Connell Energy Coal Gasification Process

Description: A method of making low-to-medium Btu gas from coal is described. A key feature is control of retort heat fluxes.

Inventor: Anthony A duPont

State : CA

Status: Complete

Patent Status

Development Stage

Technical Category

Recv. by NIST : 03/31/76

Recom. by NIST $\vdots 11 / 28 / 80$

Award Date $\vdots 08 / 05 / 81$

Contract Period: 08/05/81

Award Amount: $\$ 98,074$ Grant No: FG01-81CS15068

- 02/05/83
Contact:

Anthony A duPont

DuPont Aerospace Company, Inc

1111 East Wakeham, Suite' J

Santa Ana CA 92705

714-953-9380

Status Date: 06/30/86 OERI No.: 000854

Patent Applied For

Working Mode1

Fossil Fuels

Summary:

A grant of $\$ 98,074$ was awarded to design, build, and test a laboratory scale model of the inventor's concept.

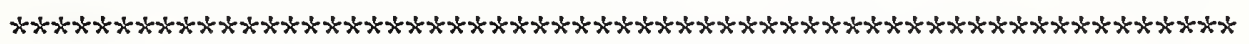

DOE No: 0162

DOE Coord: G.K.Ellis

Title:

Tubular Pneumatic Conveyor Pipeline

Description: A pneumatic tubular conveyor pipeline for transporting dry granular materials such as coal, barite or cement over long distances. The pipeline has an outer impervious pipe and an inner porous pipe radially spaced.

Inventor: Lemuel Leslie Ply

State : TX

Status: Complete

Patent Status

Development Stage

Technical Category:

Recv. by NIST : 05/23/80

Recom. by NIST : $11 / 28 / 80$

Award Date : 09/30/82

Contract Period: 09/30/82

Summary:
Contact:

Lemuel Leslie P1Y

Ply International, Inc

Box \#899

Wimberly TX 78676

$512-847-9347$

Status Date: 09/30/84

OERI NO.: 006992
Patent Number: 4116491

Concept Development
Industrial Processes

Award Amount: $\$ 44,480$ Grant No: FG01-82CE15128

$-\quad 09 / 30 / 84$

A grant of $\$ 44,480$ was awarded to design, build, and test a prototype section of pipeline using several 10 -foot sections of pipe. This project is complete. 
DOE No: 0163

DOE Coord: P.M.Hayes

Title: Thermotropic Plastic Films

Description: A thermotropic plastic film which can be formulated to become opaque above a particular temperature. When sealed between two layers of glass it could serve as a window shade for greenhouses or other solar heated structures.

Inventor: Dennis D Howard

State : PA

Status: Complete

Status Date: $07 / 13 / 82$

Contact:

Dennis D Howard

200 West Grandview Boulevard

Erie PA 16512

$814-868-3611$

Patent Status

Development Stage : Engineering Design

Technical Category: Buildings, Structures \& Components

Recv. by NIST : 05/15/80

Recom. by NIST : $12 / 04 / 80$

Award Date : 07/09/81

Contract Period: 07/09/81

Award Amount: $\$ 99,093$ Grant No: FG01-81CS15045 $07 / 13 / 82$

Summary:

A grant of $\$ 99,093$ was given to perform research and development leading to a practical design with special attention given to edge sealing and general weather proofing of the laminated panes. The grant is complete; double glass enclosures were found to be too costly. Inventor is using his own funds to develop an embossed plastic seal via small compartments of fluid separated by heat-sealed pattern. Company seeks joint venture and/or licensing.

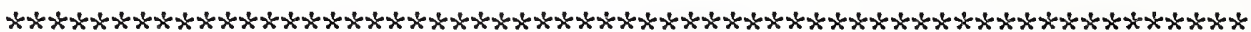

DOE No: 0164

DOE Coord: J.Aellen

Title: Elastomer Energy Recovery Elements and Vehicle Component Applications

Description: A regenerative braking device, for a small urban automobile, that stores energy during downhill operation for additional acceleration and power when needed with a minimum of fuel consumption. Energy is mechanically stored by an elastomeric storage device.

Inventor: John D Gill

State : MD

Status: Complete

Patent Status

Development Stage

Technical Category:

Recv. by NIST : $12 / 12 / 79$

Recom. by NIST : $12 / 04 / 80$

Award Date $\quad 07 / 09 / 81$

Contract Period: 07/09/81

Award Amount: $\$ 89,507$ Grant No: FG01-81CS15054

Contact:

John D Gill

Elastomer Energy Recovery Inc

419 Fourth Street

Annapolis MD 21403

301-263-5735

Summary:

A grant of $\$ 89,507$ was awarded to design, build, and test a scale model to determine optimum design after which a full scale model will be built and tested. The grant is complete. Inventor now seeks $\$ 100,000$ private sector support to demonstrate proof of concept of a two-person, enclosed, three wheel moped using a small gasoline motor. Energy is stored in elastomer via pedals on downhill runs and upon deceleration. 
DOE No: 0165

DOE Coord: D.G.Mello

Title:

Process for Recovering Hydrogen and Elemental Sulfur from Hydrogen Sulfide and/or Mercaptans-Containing Hydrogen

Description: A new process for recovering hydrogen and elemental- sulfur from hydrogen sulfide using iodine slurry

Inventor: Wu-Chi Chen

State : TX

Status: Complete

Patent Status

Development Stage

Technical Category

Recv. by NIST

Recom. by NIST : $12 / 29 / 80$

Award Date : $08 / 04 / 81$

Contract Period: 08/04/81

Award Amount: $\$ 70,000$ Grant No: FG01-81CS15065
Contact:

Wu-Chi Chen

859 Brittmore Road

Houston TX 77079

$713-461-6811$
Status Date: 10/29/84

OERI No.: 006985

Patent Number: 4066739

Concept Development

Fossil Fuels

- $01 / 15 / 83$

Summary:

A grant of $\$ 70,000$ was awarded to investigate the feasibility of the process by performing laboratory and economic studies. Inventor is discussing licensing possibilities with private research corporations. The project is now complete.

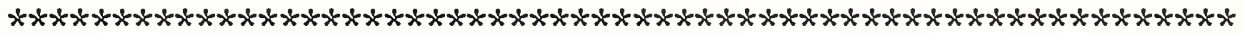

DOE No: 0166

DOE Coord: J.Aellen

Title:

Borehole Angle Control

Description: A modified oil well drill bit which can correct the course of the borehole as the hole is being drilled. It selectively injects cuttings to one side of the drill bit to provide a wedging action between the bit and the borehole.

Inventor: Robert F Evans

State : TX
Contact:

Robert $\dot{F}$ Evans

Evergreen Drilling Research

12820 Montford

Apartment \#150

Dallas TX 75230

214-943-2181

Status: Complete

Status Date: 11/26/85

OERI No.: 004656

Patent Status : Not Applied For

Development Stage : Concept Development

Technical Category: Fossil Fuels

Recv. by NIST : $11 / 27 / 78$

Recom. by NIST : $12 / 29 / 80$

Award Date: :07/28/81

Contract Period: 07/28/81

Award Amount: \$98,148 Grant No: FG01-81CS15067

- $11 / 26 / 85$

Summary: A grant of $\$ 98,148$ was awarded to design, fabricate and conduct field tests on the drill bits and control system. 
DOE No: 0167

DOE Coord: J.Aellen

Title: Vaned Pipe for Pipeline Transport of Solids

Description: A slurry pipeline with helical vanes to maintain a rotating motion in the slurry to hold the solids in suspension in the laminar flow range, thus increasing the range of flow rates at which solids can be transported without settling.

Inventor: Edward B Connors

State : ID

Status: Complete

Patent Status

Development Stage : Engineering Design

Technica1 Category: Industrial Processes
Recv. by NIST : 02/25/80

Recom. by NIST : $01 / 19 / 81$

Award Date : $08 / 11 / 82$

Contract Period: 08/11/82
A grant of $\$ 111,577$ was awarded to design, build and test several configurations of the basic idea under various flow conditions with various slurry mixtures. The project was completed on October lst, 1983.

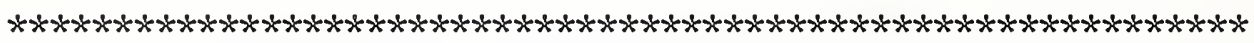

DOE No: 0168

DOE Coord: G.K.E11is

\section{Title: The Hot Water Saver}

Description: Modifications to a residential hot water system so that hot water trapped in the pipes between the water-heater and the point of use is returned to the water heater thus reducing heat loss and water consumption.

Inventor: Spencer Kim Haws

State : WA
Contact:

Spencer Kim Haws

P. O. Box \#315

Mesa WA 99343

$509-265-4327$

Status: Complete

Status Date: 10/09/84

OERI No.: 006783

Patent Status : Patent Applied For

Development Stage $\vdots$ Limited Production/Marketing

Technical Category: Buildings, Structures \& Components

Recv. by NIST : 04/07/80

Recom. by NIST : $01 / 28 / 81$

Award Date $\quad 09 / 30 / 82$

Contract Period: 09/30/82

Award Amount: $\$ 90,000$ Grant No: FG01-82CE15134 $-09 / 29 / 83$

Summary: A grant of $\$ 90,000$ was awarded to laboratory and field test the unit, and to document savings and find optimum application. The test results showed $17 \%$ of the energy used for water heating could be saved by using this invention. Mr. Haws sold his invention to Metlund Enterprises of Stockton, CA in exchange for royalties. Methlund Enterprises had sold about 400 units as of April, 1986. 
DOE No: 0169

DOE Coord: P.M.Hayes

Title: MIRAFOUNT

Description: A cattle waterer which is functional in the coldest climate without the use of an immersed electric or gas heater. It consists of a heavily insulated tank with a floating, insulated cover and a float valve assembly.

Inventor: Mervin W Martin

State : MO

Status: No DOE Support
Contact:

Carter Thompson

Status Date: 03/15/85 OERI No.: 006239

Patent Status : Patent Number: 3745977

Development Stage : Limited Production/Marketing

Technical Category: Industrial Processes

Recv. by NIST : $12 / 27 / 79$

Recom. by NIST : $01 / 30 / 81$

Summary: The inventor wanted support for a marketing study, which it is not DOE policy to provide.

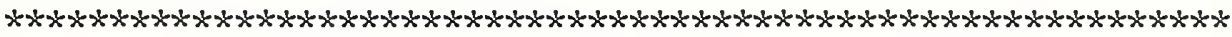

DOE No: 0170

DOE Coord: J.Aellen

Title:

Fog System - Low Energy Freeze Protection for Agriculture

Description: A low energy-consuming agricultural freeze protection system using a non-polluting man-made water fog to cover crops and prevent heat loss and freeze damage. The fog system is designed to use significantly less energy than oil-burning agricultural heaters. The inventor has also developed instruments to increase quality of the clouds.

Inventor: Thomas $\mathrm{R}$ Mee

State : CA

Status: No DOE Support

Patent Statu

Development Stage

Technical Category

Recv. by NIST : $08 / 22 / 79$

Recom. by NIST : 01/30/81

Summary:
Contact:

Thomas $\mathrm{R}$ Mee

\section{Status Date: 07/09/86 OERI No.: 005622}

Inventor reports net income of $\$ 400,000$ in 1984 with gross sales of $\$ 1.9$ million. First three months of 1985 have yielded $\$ 700,000$ gross. Sales have doubled annually over the last three years. Firm now employs thirty individuals. 
DOE No: 0171

DOE Coord: P.M.Hayes

Title: A Method of Preserving Fruits and Vegetables without Refrigeration

Description: A method for preserving fruits and vegetables without refrigeration by using controlled atmosphere packages to keep oxygen levels low and the water vapor and carbon dioxide levels at desired optimums.

Inventor: Karakian Bedrosian

State : NJ

Contact:

Karakian Bedrosian

Sherwood Court

Alpine NJ 07620

201-767-3260

Status: Complete

Status Date: 10/31/82

OERI No.: 006950

\section{Patent Status \\ Development Stage : Limited Production/Marketing \\ Technical Category: Industrial Processes}

Recv. by NIST : 04/28/80

Recom. by NIST : $02 / 23 / 81$

Award Date : $08 / 25 / 81$

Contract Period: 08/25/81

Award Amount: $\$ 97,300$ Grant No: FG01-81CS15061

Summary:

A grant of $\$ 97,300$ was awarded to conduct laboratory studies and field trials of various package configurations suitable for shipment of tomatoes by truck from point of growth to point of consumption. Demonstrations were successful. Marketed under the trade name of "TomAHtoes", 751,000 25-pound boxes were shipped in 1987 , with $\$ 35$ million in retail sales. With its potential for use with other fresh fruits and vegetables, this innovative packaging can provide significant national energy savings.

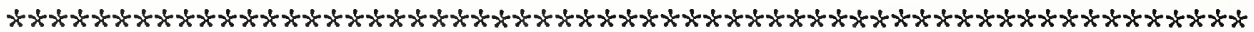

DOE No: 0172

DOE Coord: D.G.Mello

Title:

GEM Electrostatic Filtration System

Description: An electrostatic filter for removing suspended particles from fluids such as hydraulic fluids, liquid fuels, engine lubricants and waste oil.

Inventor: Edward A Griswold

State : CA
Contact:

Edward A Griswold

Special Equipment Company

26022 Cape Drive, \#G

Laguna Niguel CA 92677

$714-581-6930$
Status: Complete

Patent Status

Development Stage:

Technical Category:
Status Date: 09/29/82

OERI No.: 004255

Recv. by NIST : 08/03/78

Recom. by NIST : 02/26/81

Award Date $\quad 10 / 01 / 82$

Contract Period: 10/01/82

Award Amount: $\$ 88,285$ Grant No: FG01-83CE15139

- 06/30/83

Summary:

An 8 -month grant of $\$ 88,285$ was awarded for demonstration of the GEM filtration system. The unit was designed and installed on several types of diesel engines under controlled conditions. Filtered material was analyzed. ERIP assistance is complete. 
DOE No: 0173

DOE Coord: J.Aellen

Title: Thermal Ice Cap

Description: An insulating blanket to reduce refrigeration loads in ice skating rinks during periods of non-use, combined with an advanced method of applying and removing the $17,000 \mathrm{sq}$. ft of thermal insulation.

Inventor: Bill Burley

State : PA

Status: Complete

Patent status

Development Stage: Working Model

Technical Category: Buildings, Structures \& Components

Recv. by NIST : 01/07/80

Recom. by NIST : 02/26/81

Award Date $\vdots 08 / 19 / 81$

Contract Period: 08/19/81

Summary:

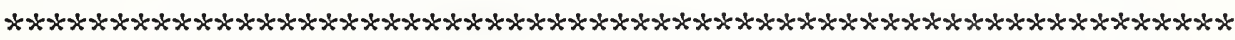

DOE No: 0174

DOE Coord: J.Aellen

Title: Skate on Plastic Ice Skating System

Description: A non-refrigerated plastic skating surface to replace energy intensive ice skating surfaces.

Inventor: $E$ O Nathaniel

State : MO

Status: No DOE Support

Patent Number: 4030729

Patent Status

Limited Production/Marketing

Development Stage

Technical Category: Buildings, Structures \& Components

Recv. by NIST : 12/31/79

Recom. by NIST : 03/05/81

Summary:

Invention coordinator and inventor agreed to scope of work for a grant. Prior funding by the Small Business Administration has led to sales of some units. Units were not a commercial success because of perceived "extra skating effort".
Contact:

Bill Burley

Peterson Drive

Johnstown PA 15905

$814-288-1750$

Award Amount: \$ 79,726 Grant No: FG01-81CS15066

- 05/15/82 
DOE No: 0175

DOE Coord: J.Aellen

Title: A Low-Energy Carpet Backing System

Description: A low energy carpet backing system which uses a hot- melt thermoplastic coating. The hot-melt coating replaces the present latex adhesive coating which locks the tufts or stitches into the primary backing fabric.

Inventor: Den M Acres

State : GA
Contact:

W W Seward

c/o DASH, Inc.

1303 Dug-Gap Road

Dalton GA 30720

404-278-2556

Status: Complete

Status Date: 08/01/81

OERI No.: 006931

Patent Status : Patent Applied For

Development Stage : Prototype Development

Technical Category: Industrial Processes

Recv. by NIST : 05/05/80

Recom. by NIST : 03/26/81

Award Date : $08 / 01 / 81$

Contract Period: 08/01/81

Award Amount: $\$ 79,173$ Grant No: FG01-81CS15070

- $01 / 31 / 83$

Summary:

A grant of $\$ 79,173$ was awarded and completed to refit a carpet backing machine with automatic control elements and test on a variety of carpet products. Grantee intends to market the product directly to carpet mills, and predicts an estimated $86 \%$ energy savings in manufacture of coated carpeting. Commercial viability of the technology was demonstrated. Inventor is in commercial production. He seeks venture capital assistance.

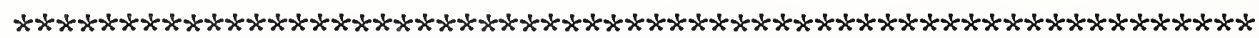

DOE No: 0176

DOE Coord: J.Aellen

Title:

Self-Contained, Water Proof, Stoker Fired, Fully Automatic, Portable Solid Fuel Furnaces

Description: An automatically fired portable furnace for burning coal and agricultural waste (e.g. corn, wood waste, poultry manure) for use in drying grain and heating homes and buildings.

Inventor: John D. Finnegan

State: MN

Status: No DOE Support

Patent Status

Development Stage : Working Model

Technical Category: Buildings, Structures \& Components

Recv. by NIST : 08/18/80

Recom. by NIST : 04/03/81

Summary: DOE found no basis for support.
Contact:

Dale Flickinger

Status Date: 06/30/86 OERI No.: 007428 
DOE No: 0177

DOE Coord: D.G.Mello

Title:

The Solar I Option

Description: A solar heating system using commercially available collectors and components and a concrete floor slab as a heat storage device and heat exchanger.

Inventor: Robert John Starr

State : VT
Contact:

Robert John Starr

R.F.D.

Sutton VT 05867

$802-626-8045$

Status: Complete

Status Date: 08/15/84

OERI No.: 006040

\section{Patent Status : Not Applied For}

Development Stage : Limited Production/Marketing

Technical Category: Direct Solar

Recv. by NIST : 12/03/79

Recom. by NIST : $05 / 07 / 81$

Award Date : 09/24/82

Contract Period: 09/24/82

Award Amount: \$ 52,960 Grant No: FG01-82CE15140

- 06/30/84

Summary: A grant of $\$ 52,960$ was awarded to test the effectiveness of a previously installed system. The University of Massachusetts furnished instrumentation, data analysis and computer programs for future design analysis. Energy savings were essentially as predicted. Some sales have been made, but generally "solar" market is slow. This project has been completed.

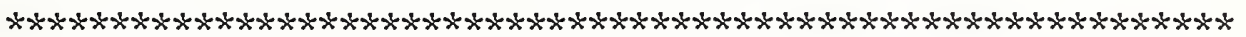

DOE No: 0178

DOE Coord: D.G.Mello

Title:

Process and Apparatus for Producing Cellulated Vitreous Refractory Material

Description: A process and apparatus to produce cellular vitreous refractory material in prescribed shapes lighter than conventional brick or tile and more impermeable. The material will have high structural strength and will be highly insulative and light weight.

Inventor: John $\mathrm{W}$ North

State : GA
Contact:

John W North

$\mathrm{J}$ W North Company

c/o Silica-North, Ltd.

$\mathrm{P} 0$ Box \#838

Tuscombia AL 35674

205-381-3582

Status: Complete

Status Date: 07/23/84

OERI No.: 007726

Patent Status

Development Stage : Engineering Design

Technical Category: Industrial Processes

Recv. by NIST : 10/30/80

Recom. by NIST : 04/15/81

Award Date: :09/08/82

Contract Period: 09/08/82

Award Amount: $\$ 94,688$ Grant No: FG01-82CE15117

- 09/08/83

Summary:

A 12 -month grant of $\$ 94,688$ was awarded to design, build and operate a pilot plant for manufacture of cell glass building material. There appears to be no market for this product. 
DOE No: 0179

DOE Coord: G.K.Ellis

Title: Development and Commercialization of Low Cost, Non- Metallic, Solar Systems

Description: A solar hot water heating system consisting of a non-metallic flat plate solar collector made from ethylene-propylene-diene monomer and non-pressurized thermal storage.

Inventor: Charles E Edwards

State : MA

\section{Contact:}

Charles E Edwards

Six Reeves Road

Bedford MA 01730

$617-458-6463$

Status: Complete

Status Date: 01/03/84

OERI No.: 007158

\section{Patent Status : Patent Applied For}

Development Stage: Prototype Development

Technical Category: Direct Solar

Recv. by NIST : 06/19/80

Recom. by NIST : 04/17/81

Award Date : 08/17/81

Contract Period: 08/17/81

Award Amount: $\$ 99,999$ Grant No: FG01-81CS15071

- $01 / 03 / 84$

Summary: A grant of $\$ 99,999$ was awarded to Solex Corporation to finalize design and manufacturing methods for a low cost solar collector. Prototypes were manufactured and tested for efficiency and weatherability. The inventor got $\$ 500,000$ over a 5- year contract in Saudi Arabia. Governments of Saudi Arabia and Jordon have indicated interest in licensing his technology. He has received numerous inquiries about his technology from all over the world.

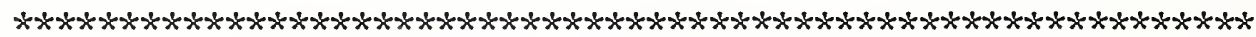

DOE No: 0180

DOE Coord: J.Aellen

Title: Adjustable Solar Concentrator (ASC)

Description: A Concentrating Solar Collector using movements and loads on edges of elastic sheets to form cylindrical parabolic reflector.

Inventor: Richard E Dame

State: $M D$

Status: Complete

Patent Status

Development Stage : Working Model

Technical Category: Direct Solar

Recv. by NIST : 04/27/77

Recom. by NIST : 04/20/81

Award Date : 08/26/81

Contract Period: 08/26/81

Summary:
Award Amount: $\$ 97,066$ Grant No: FG01-81CS15172

Contact:

Richard E Dame

10701 Harper Avenue

Silver Spring MD 20901

$301-681-6903$

OERI No. : 002116

- $12 / 28 / 83$ A grant of $\$ 97,066$ was awarded to develop a fabrication technique for a successful, but market for medium-temperature collectors is very poor. The project has been completed. 
DOE No: 0181

\section{Title:}

Description:
DOE Coord: J.Aellen

\section{The Karlson Ozone Sterilizer}

An ozone sterilizer for medical use in both field and hospital. It is low-powered and lightweight. It sterilizes in less than ten minutes, requires no steam and can automatically package sterilized instruments for storage up to several months.
Inventor: Eskil L Karlson

State : PA

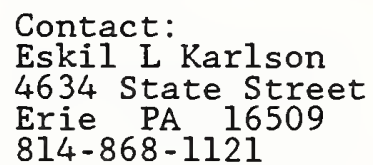

$814-868-1121$
Status: Complete

\section{Patent Status}

Development Stage

Technical Category
Status Date: 04/27/82

OERI No. : 008061
Recv. by NIST : 02/09/81

Recom. by NIST : 05/29/81

Award Date: :05/01/82

Contract Period: 05/01/82

Award Amount: $\$ 133,304$ Grant No: FG01-82CE15082

Summary:

A 24-month grant of $\$ 133,304$ was awarded to design, develop, and test the Karlson ozone sterilizer system. Inventor seeks venture capital and/or licensing for third world and other markets. This project has been completed.

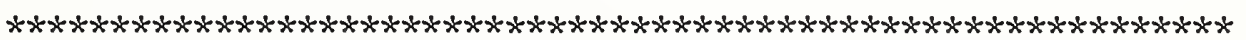

DOE No: 0182

DOE Coord: J.Aellen

Title:

Improved Seal for Geothermal Drill Bit

Description: A new type of sealing arrangement for the cone bearings of a standard rotary drill bit used for geothermal exploration which prolongs the bearing life for a given load and rotary speed.

Inventor: Robert F Evans State : CA

\author{
Contact: \\ Robert $\dot{F}$ Evans \\ Box \#62 \\ La Mirada CA 90637 \\ 213-697-8486
}

OERI No.: 007089

Status: Complete

Status Date: 07/09/86

Patent Status

Development Stage : Concept Development

Technical Category: Other Natural Sources

Recv. by NIST : 06/03/80

Recom. by NIST : $05 / 29 / 81$

Award Date $\quad 09 / 01 / 82$

Contract Period: 09/01/82

Award Amount: $\$ 94,898$ Grant No: FG01-82CE15104

- $08 / 31 / 83$

Summary:

A 12 -month grant of $\$ 94,898$ was awarded to select by research the best elastomer for use as a bearing seal, and then to test it in the laboratory and in the field. Inventor has made no decision yet on marketing strategy. 
DOE No: 0183

DOE Coord: J.Aellen

Title: Increased Vapor Generator Feature for a Reheat Vapor Generator

Description: A method to provide peak power more economically from a base steam/turbine electric plant.

Inventor: E. Stephen Miliaras

State : MA

Contact:

E. Stephen Miliaras

c\%o Energotechnology Corp

238 Main Street, Suite \#5i4

Cambridge MA 02142

$617-492-3700$

Status: Complete

Status Date: 12/31/83

OERI No.: 005961

Patent Status : Patent Number: 3826093 and others

Development Stage : Engineering Design

Technical Category: Industrial Processes

Recv. by NIST : 10/16/79

Recom. by NIST : $06 / 18 / 81$

Award Date $\vdots 06 / 07 / 82$

Contract Period: 06/07/82

Award Amount: $\$ 98,977$ Grant No: FG01-82CE15194

Summary:

A grant of $\$ 98,977$ was awarded to design the system for a specific installation that will need increased capacity. For the purpose, negotiations are under way with Southern California Edison. Extensive subcontracting of the installation will be done by Dynatech $R \& D$ of Boston. Design completed and 108 capacity increase predicted. Construction awaits SCE needs for additional capacity. The project is completed.

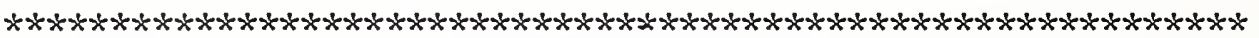

DOE No: 0184

DOE Coord: J.Aellen

Title: Coasting Fuel Shutoff

Description: A device suitable for new production or retrofit to turn off the fuel during coasting conditions for automobiles.

Inventor: Nathan Gold

State : CA

Status: No DOE Support
Contact:

Nathan Gold

Status Date: 06/30/86 OERI No.: 002111

Patent Status : Not Applied For

Development Stage : Prototype Test

Technical Category: Combustion Engines \& Components

Recv. by NIST : 04/27/77

Recom. by NIST : $06 / 23 / 81$

Summary: Several contacts have been made with the inventor, none of which elicited a response. Other similar devices are now on the market. Inventor was pursuing licensing agreements 
DOE No: 0185

DOE Coord: P.M.Hayes

Title: Insulated Garage Door

Description: An insulated overhead roll-up garage door with special seals to reduce direct heat transmission and infiltration. The door is sectionalized and is comprised of pivotally connected panels each having a cavity filled with insulation.

Inventor: Cecil H Wolf

State : IL

Status: No DOE Support
Contact:

Charles Bach

Status Date: 03/15/85 OERI No.: 002443

Patent Status : Patent Applied For

Development Stage : Working Model

Technical Category: Buildings, Structures \& Components

Recv. by NIST : $07 / 11 / 77$

Recom. by NIST : 07/27/81

Summary: Inventor has yet to furnish an acceptable work proposal to DOE. There is no basis for DOE support. The product is being marketed by Therma-Seal, Inc., 4100-B McDonald Avenue, Des Moines, Iowa - (515) 262-0600.

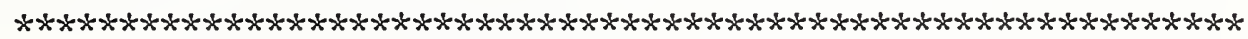

DOE No: 0186

DOE Coord: J.Aellen

Title: $\quad$ Oil Recovery by In-Situ Exfoliation Drive

Description: A process for recovering oil in-situ from oil shale which involves alternatively heating and cooling a rubble chamber to exfoliate the crushed rock. The rock releases hydrocarbons which are then pumped to the surface.

Inventor: Sylvain J Pirson

State : TX

Status: No DOE Support

Patent Status

Development Stage : Concept Development

Technical Category: Fossil Fuels

Recv. by NIST : 07/31/80

Recom. by NIST : 07/28/81

Summary:
Contact:

Ronald Hertzfeld

Status Date: 03/15/85 OERI No.: 007361

The inventor has chosen not to pursue this idea at this time, probably because the national interest in shale oil is very low. He is concentrating on \#146 which has also been recommended to ERIP. 
DOE No: 0187

DOE Coord: G.K.Ellis

Title: Variable Field Induction Motor

Description: A means of controlling the field current in an AC induction motor to improve the efficiency under partial load conditions.

Inventor: Louis W Parker

State: FL

Status: No DOE Support
Contact:

Rhey Hedges

Status Date: 03/17/85 OERI No.: 003145

\section{Patent Status : Patent Applied For}

Development Stage : Prototype Test

Technical Category: Miscellaneous

Recv. by NIST : 12/07/77

Recom. by NIST : 08/06/81

Summary: No work proposal was submitted. Technology was licensed to companies in the USA, UK, South Africa and Hong Kong. There is no basis for DOE support.

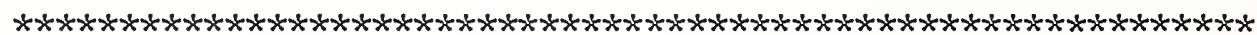

DOE No: 0188

DOE Coord: P.M.Hayes

Title: $\quad$ Remote Controlled Underground Mining System for Horizontal or Pitching Seams

Description: A remote controlled underground mining system which uses a unique guidance system for directional drilling of horizontal and pitching seams. Gaseous deposits can be mined without exposure of manpower to hazards.

Inventor: John C Haspert

State : CA

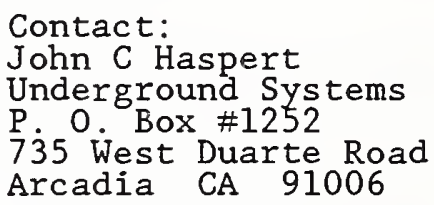

Status: Complete Status Date: 11/16/83 OERI No.: 007486

Patent Status : Patent Applied For

Development Stage : Working Model

Technical Category: Fossil Fuels

Recv. by NIST : 09/08/80

Recom. by NIST : 08/28/81

Award Date : 08/16/82

Contract Period: 08/16/82

Award Amount: \$ 98,251 Grant No: FG01-82CE15130

Summary: A grant of $\$ 98,251$ was awarded to design special mining equipment, specifying standard parts that are required to build the remote mining system. Grant completed. Designs and drawings submitted to DOE. There is no obvious commercial interest. 
DOE No: 0189

DOE Coord: D.G.Mello-

Title:

Pump Jack

Description: An oil well pumping system in which a hydraulic pump drives a double-acting hydraulic cylinder in an upward motion. During the down-stroke the pressure below the piston in bled through a flow control valve.

Inventor: Gerald Eastman

State : OK
Contact:

Gerald Eastman

P. O. Box \#145

Ocheiata OK 74051

$918-535-2393$
Status: Complete

Patent Status

Development Stage

Technical Category:

Recv. by NIST : 10/10/80

Recom. by NIST : $08 / 31 / 81$

Award Date : 06/15/82

Contract Period: 06/15/82

Summary:
Status Date: 12/15/83

OERI No.: 007658

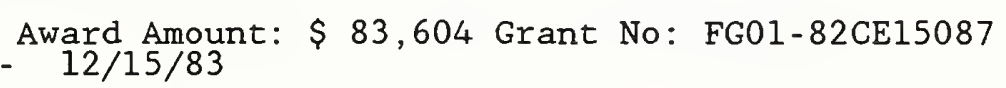

Not Applied For

Prototype Test

An grant of $\$ 83,604$ was awarded to field test and document the results of testing several of these units at varying depths from 2000 to 7000 feet. Rhino Engineering supervised the tests and documented the results. After several failures and corrections, units operated trouble free for 10 months. Medium-sized company seeks license from inventor. This project is complete.

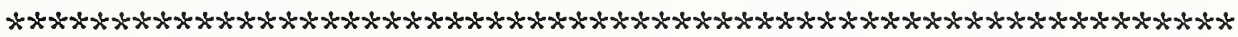

DOE No: 0190

DOE Coord: G.K.Ellis

Title:

Oxygen-Conducting Material and Oxygen-Sensing Method

Description: An improved oxygen sensing device formed by tape casting an oxygen-conducting between ceramic layers.

Inventor: W N Lawless

State : $\mathrm{OH}$
Contact:

W N Lawiess

Lake Shore Ceramics, Inc

64 East Walnut Street

Westerville $\mathrm{OH} 43081$

614-891-2243

Status: Complete

Status Date: 05/17/83

OERI No.: 007963

Patent Status

Development Stage $\vdots$ Engineering Design

Technical Category: Miscellaneous

Recv. by NIST : 01/07/81

Recom. by NIST : $09 / 30 / 81$

Award Date : $05 / 18 / 82$

Contract Period: 05/18/82

Award Amount: $\$ 89,076$ Grant No: FG01-82CE15098

$-\quad 05 / 17 / 83$

Summary:

A grant of $\$ 89,076$ was awarded to fabricate and test several ceramic compositions that will be useful for oxygen sensing and possibly be useful as a fuel cell material. First items fabricated under subcontract by Penn state $\mathrm{U}$. are promising. The potential fuel cell application was identified in ERIP's pilot testing of licensing opportunities, the inventor being told that it represented a potential significant advance in state-of-the-art for fuel cells. As indicated, recent tests have confirmed this. This project has been completed. 
DOE No: 0191

DOE Coord: G.K.Ellis

Title: Rotary Heat Pump Air Conditioner, Heater and Ventilator for Automotive, Mobile and Stationary Use.

Description: The invention is an air conditioning unit for mobile or internal stationary application, utilizing waste heat from an internal combustion engine. The refrigeration cycle is a conventional lithium- bromide absorption cycle. Various cycle components are enclosed in a hermetic cylinder, which is rotated by an electric motor. Heat is absorbed or rejected by rotating finned surfaces.

Inventor: Milton Pravda

State : MD
- Contact:

Gabriel S Joseph, III

Conserve Resources, Inc

8416 Stonewal1 Drive

Vienna VA 22180

Status: Complete

Status Date: 04/07/88

OERI No.: 004890

Patent Status

Development Stage: Prototype Test

Technical Category: Buildings, Structures \& Components

Recv. by NIST : 02/13/79

Recom. by NIST : $09 / 30 / 81$

Award Date : 05/08/86

Contract Period: 05/08/86

Award Amount: $\$ 94,171$ Grant No: FG01-86CE15266

- 04/07/88

Summary: A phase one grant was awarded to modify the heat exchanger part of the heat pump and test it. The results were encouraging. A phase II grant was awarded to have Pacific Northwest Laboratories (PNL) build prototype. A detailed concept evaluation and a sensitivity assessment of the inventor's earlier design analysis was initiated before building the prototype. Phase II is still in process. Manco Corp sold the invention to CRI.

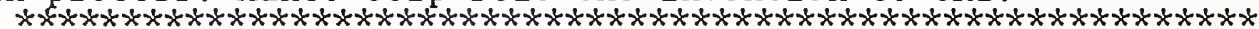

DOE No: 0192

DOE Coord: D.G.Mello

Title: Closed Cycle Dehumidification Clothes Dryer

Description: A clothes dryer that uses $a^{-}$vapor compression refrigeration cycle to dehumidify the air that passes through the dryer. Air temperature will gradually increase as the condenser restores heat lost to the evaporator and adds energy introduced into the refrigerant by the compressor.

Inventor: Donald C Lewis

State : $M E$
Contact:

Donald C Lewis

P. O. Box $\# 1107$

Bangor ME 04401

$800-648-9200$
Status: Complete

Patent Status

Development Stage

Technical Category:
Status Date: 06/15/83

OERI No.: 007943
Recv. by NIST : $12 / 30 / 80$

Recom. by NIST : $10 / 07 / 81$

Award Date : 07/16/82

Contract Period: 07/16/82
Award Amount: $\$ 81,648$ Grant No: FG01-82CE15100 $-\quad 06 / 15 / 83$

Summary: An 8-month grant of $\$ 81,648$ was awarded to design, construct and test the clothes dryer. Preliminary tests of the unit, which operates at $115 \mathrm{v}$, show 65 70 percent energy savings over the conventional dryer. Inventor expects profitable operation at 18 of total dryer market, and is looking for licensing opportunities with eventual sell-out if market share expands. 
DOE No: 0193

DOE Coord: J.Aellen

Title:

Engine Heating Device

Description: A truck diesel engine heater (Heat-exchanger/heat- sink) which stores heat from the exhaust for later use in warming a cold engine prior to startup. Crankcase oil or engine coolant is circulated through the heat exchanger and engine for warmup.

Inventor: Nicholas Archer Sanders
State

Contact:

Nicholas Archer Sanders

Weatheready, Incorporated

Eleven Green Ridge Road

Route One, Box \#175

Norwich VT 05055

603-643-4351

Status: Complete

Status Date: 09/30/83

OERI No.: 006928

Patent Status

Development Stage

Patent Applied For

Concept Development

Technical Category: Transportation Systems, Vehicles \& Components

Recv. by NIST : 05/07/80

Recom. by NIST : $10 / 30 / 81$

Award Date : $09 / 30 / 82$

Contract Period: 09/30/82

Award Amount: $\$ 91,150$ Grant No: FG01-82CE15141

- 09/30/83

Summary:

A 12-month grant of $\$ 91,150$ was awarded to construct and test a prototype unit. Results of testing showed large energy savings, but equipment cost needs to be reduced. Marketing proceeding: Honeywel1, State of Minnesota and US Army are among interested parties.

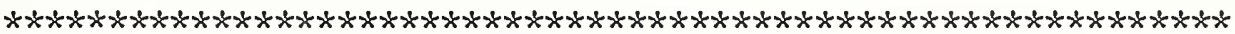

DOE No: 0194

DOE Coord: J.Aellen

Title:

Radiant Energy Power Source for Jet Aircraft

Description: Installation of photovoltaic cells in proximity to the liner of a jet engine combustion chamber to generate electrical power for replacing aircraft primary - and/or auxiliary-power units.

Inventor: Oscar Leonard Doellner

State : AZ

Contact:

Oscar Leonard Doellner

1943 South Plumer Avenue

Tucson AZ 85713

$602-623-7303$

Status: Complete

Status Date: 09/28/87

OERI NO.: 005673

Patent Status

Development Stage : Concept Development

Technical Category: Transportation Systems, Vehicles \& Components

Recv. by NIST : 08/30/79

Recom. by NIST : $11 / 12 / 81$

Award Date : $09 / 20 / 82$

Contract Period: 09/20/82

Award Amount: $\$ 65,000$ Grant No: FG01-82CE15144

- $09 / 28 / 87$

Summary:

A phase one grant of $\$ 10,000$ was awarded. Ground tests on the J-85 engine determine sufficient radiant energy is available to power photovoltaic cells. Tests were conducted at Williams AFB. The project has received national and international recognition. A phase two grant package for $\$ 55,000$ was used to build and test the hardware to harness radiant energy from a jet engine. 
DOE No: 0195

DOE Coord: J.Aellen

\section{Title: $\quad$ Proportional Current Battery}

Description: A proportional current electric storage battery with tapered plate thickness that can maintain high current drain and charging rates with minimal material and weight.

Inventor: Edward L Barrett

State: IL

Status: Complete

Patent Status

Development Stage:

Technical Category:

Recv. by NIST : 07/14/80

Recom. by NIST : $11 / 13 / 81$

Award Date : $09 / 15 / 82$

Contract Period: 09/15/82

Summary:
Award Amount: $\$ 87,757$ Grant No: FG01-82CE15103 - $01 / 15 / 84$
Contact:

Mark Pridmore

27 Elder Lane

La Grange IL 60525

$312-579-5287$

Status Date: 07/09/86

OERI No.: 007280

Patent Number: 3846174

Concept Development

Miscellaneous A grant of $\$ 87,757$ was awarded to build and test a working model of the
tapered plate battery. The inventor has no plans yet for marketing. Awaiting final report.

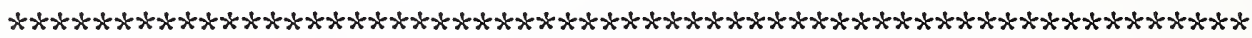

DOE No: 0196

DOE Coord: J.Aellen

Title:

Manufacturing and Using Nitrogen Fertilizer Solutions on a Farm

Description: The continuous manufacture, on a farm, of nitrogenous fertilizer by the reaction of nitrogen dioxide with water to produce nitric acid which is neutralized to ammonium nitrate or other nitrogenous compounds that can be applied to a field by way of an -irrigation system.

Inventor: John A Eastin

State : NE
Contact:

John A Eastin

P O Box \#30327

Lincoln $\mathrm{NE} 68509$

$402-467-2508$

Status: Complete

Status Date: 08/31/82

OERI No.: 000461

Patent Status : Patent Applied For

Development Stage : Prototype Test

Technical Category: Industrial Processes

Recv. by NIST : $12 / 05 / 75$

Award Date: $08 / 31 / 82$

Contract Period: 08/31/82

Award Amount: $\$ 99,592$ Grant No: FG01-82CE15142

$-08 / 31 / 83$

Summary: A 12 -month grant of $\$ 99,592$ was awarded to construct and test a prototype integrated unit, and measure its efficiency. Grantee plans to manufacture and sell units if process is successful. Farm co-ops will produce fertilizer, thus diversifying the process and reducing costs of transportation and storage. This project has been completed. 
DOE No: 0197

DOE Coord: D.G.Mello

Title: $\quad$ Frequency Regulator and Protective Devices for Synchronous Generators

Description: A solid-state frequency controller and protective device for small scale synchronous generators used for isolated power generation such as hydroelectric generation.

Inventor: Robert F Karlicek

State : CA
Contact:

Robert $\dot{F}$ Karlicek

Edison Engineering

1920 Camino Centraloma

Fullerton CA 92633

818-302-4331
Status: Complete

Patent Status

Development Stage :

Technical Category:

Status Date: 09/15/82

OERI No.: 007086

Recv. by NIST : 06/03/80

Recom. by NIST : $12 / 28 / 81$

Award Date : 09/20/82

Contract Period: 09/20/82

Award Amount: $\$ 65,990$ Grant No: FG01-82CE15132

- $09 / 20 / 83$

Summary: A 12 -month grant of $\$ 65,990$ was awarded to build, test and develop a solid state frequency controller and protective device for small scale synchronous generators of three sizes: 5,100 and $150 \mathrm{kw}$. ERIP assistance is complete. No further report is available.

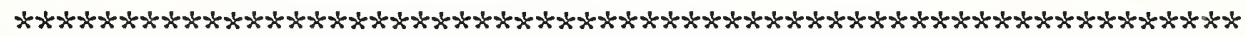

DOE No: 0198

DOE Coord: J.Aellen

Title:

The Thermatreat System

Description: An on-site aerobic sewage treatment plant for home use which recovers heat for space and water heating.

Inventor: Robert $\mathrm{H}$ Nealy

State : PA

Status: No DOE Support

Patent Status

Development Stage : Engineering Design

Technical Category: Industrial Processes

Recv. by NIST : 06/06/79

Recom. by NIST : $12 / 30 / 81$

Summary: Recommendation under consideration by DOE, with some further need for negotiation indicated. Inventor seeks $\$ 500,000$ for $R \& D$, and invention is in the concept stage. DOE action in abeyance in FY 84 pending inventor obtaining SEC approved prospectus.
Contact:

Robert $\mathrm{H}$ Nealy

Status Date: 06/30/86 OERI No.: 005281 
DOE No: 0199

Title:

Description:

Inventor: John Hunter

Country: Scotland
DOE Coord: J.Aellen

Rotary Coal Combustor and Heat Exchangers

A rotary multi-fuel fluidized-bed-combustor and heat exchanger that can be used in parallel with steam turbines for power generation or to provide a pressurized clean gas for use with high temperature gas turbines.

\section{Status: Complete}

Patent Status Development Stage:

Technical Category:
Recv. by NIST: 10/24/80

Recom. by NIST : 01/18/82

Award Date : 08/16/85

Contract Period: 08/16/85

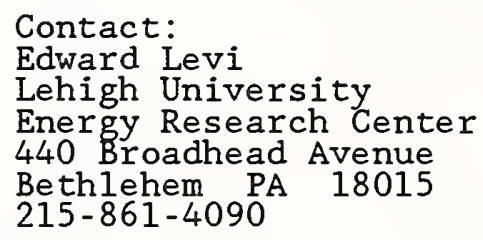

Summary:

A grant of $\$ 63,847$ was awarded on August 16,1985 , to Lehigh University to perform engineering analysis on Mr. Hunter's combustor/Gasifier. Designs will be prepared and economic analysis will be performed. The proposed combustor/Gasifier will be compared with state-of-the-art units. Award Amount: $\$ 63,847$ Grant No: FG01-85CE15242 $-06 / 30 / 87$

Patent Number: 1521088 and others

Engineering Design

OERI No.: 007718 
DOE No: 0201

Title:

Description:
Hydraulic, Variable, Engine Valve Actuation System

A modified hydraulic valve lifter which provides a means to vary valve timing and lift to improve fuel economy and reduce emissions. The device is actuated by engine oil pressure and is controlled by manifold vacuum in response to engine demand.

Inventor: Louis A Hausknecht

State : $\mathrm{OH}$
Contact:

Louis A Hausknecht

4504 State Road

Cleveland $\mathrm{OH} 44109$

$216-749-1686$
Status: Complete

Patent Status

Development Stage

Technical Category:

Recv. by NIST : 03/31/80

Recom. by NIST : 02/26/82

Award Date : $08 / 27 / 82$

Contract Period: $08 / 27 / 82$

Award Amount: $\$ 85,060$ Grant No: FG01-82CE15137

Status Date: 12/31/84 OERI No.: 006680

Summary:

A 12 -month grant of $\$ 85,060$ was awarded for the design, assembly and testing of a prototype hydraulic variable valve actuating system to be used in automobile engines.

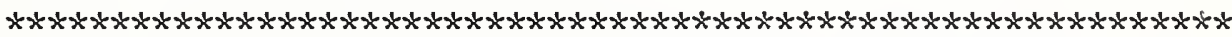

DOE No: 0202

DOE Coord: D.G.Mello

Title:

Wobbling Type Distillation Apparatus

Description: A multiple-effect vacuum distillation system employing sets of wobbling tubes to produce a thin liquid film thereby improving the evaporation efficiency.

Inventor: Yao Tzu Li

State : MA
Contact:

Yao Tzu Li

Huckleberry Hill

Lincoln MA 01773

$617-259-9592$

Status: Complete

Status Date: 09/16/83

OERI No.: 005495

Patent Status : Patent Applied For

Development Stage : Working Model

Technical Category: Miscellaneous

Recv. by NIST : 07/30/79

Recom. by NIST : $03 / 31 / 82$

Award Date $\vdots 09 / 17 / 82$

Contract Period: 09/17/82

Award Amount: $\$ 99,880$ Grant No: FG01-82CE15129

- $09 / 16 / 83$

Summary: A grant of $\$ 99,880$ was awarded to design, build and test a prototype
distillation device capable of 25 gallons/minute throughput. The inventor is seeking licenses or capital to build and market his machine. 
DOE No: 0203

DOE Coord: G.K.Ellis

Title: Microwave Methods and Apparatus for Paving and Paving Maintenance

Description: A method to repave asphalt roads in place using recycled material and microwave heating.

Inventor: Morris $\mathrm{R}$ Jeppson

State : CA

Status: Complete

Patent Status

Development Stage

Technical Category:
Contact:

Morris $\dot{R}$ Jeppson

Box \#221489

Carme1 CA 93922

$408-624-3152$

Recv. by NIST : 10/02/79

Recom. by NIST : 04/28/82

Award Date $\vdots 09 / 22 / 82$

Contract Period: 09/22/82

Award Amount: \$52,000 Grant No: FG01-84CE15173

Status Date: $12 / 21 / 84$

OERI No. : 005898

Summary:

A grant for $\$ 52,000$ was awarded on December 12,1984 to design a prototype machine. The inventor prepared a design for a full-scale automatic paving machine. He has a smaller prototype which appears to perform well. He is seeking capital or an industrial partner to build a full-scale prototype of his machine. He has received numerous inquiries about his machine from prospective users.

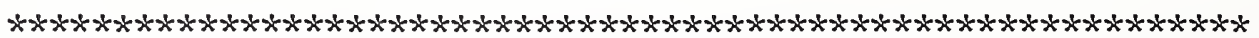

DOE No: 0204

DOE Coord: D.G.Me11o-

Title:

The Induction Propeller

Description: An induction propeller for ship propulsion designed to include forward hydrodynamic rake for increased mass flow and higher efficiency.

Inventor: Raymond P Holland Jr

State : NM

Status: No DOE Support
Contact:

Raymond $\mathrm{P}$ Holland $\mathrm{Jr}$

Status Date: $11 / 10 / 82$

OERI No.: 003872

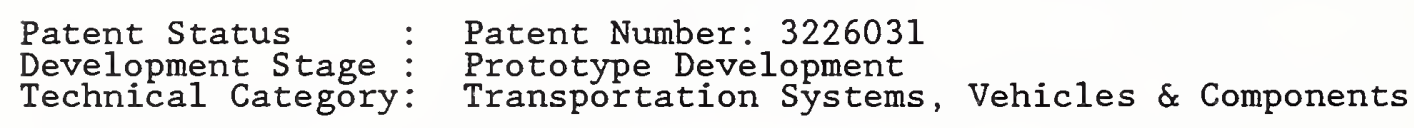

Recv. by NIST : 04/11/78

Recom. by NIST : 04/29/82

Summary: Inventor has abandoned this project in favor of another more promising invention not being supported by ERIP. 
DOE No: 0205

DOE Coord: J.Aellen

Title: $\quad$ Energy Efficient Solid State Multiple Operator Metallic Arc Welding System

Description: A system for distributing and controlling AC electric power for metal arc welding to multiple welding stations.

Inventor: Charles B James

Contact:

State : MO

Mister Raymo

Status: No DOE Support

Status Date: 06/09/83

OERI No.: 007178

Patent Status : Disclosure Document Program

Development Stage : Engineering Design

Technical Category: Industrial Processes

Recv. by NIST : 06/26/80

Recom. by NIST : $05 / 21 / 82$

Summary: Declined DOE assistance.

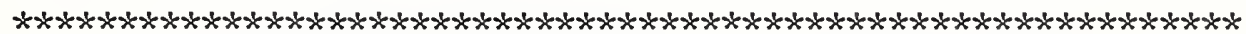

DOE No: 0206

DOE Coord: D.G.Mello

Title: Method and Apparatus for High Efficiency Operation of Electromechanical Energy Conversion

Description: An electrical controller for a separately-excited (shunt) DC motor which optimizes the ratio of armature and field currents to achieve minimum electrical I-squared-R losses for any load conditions.

Inventor: Jonathan Gabel

State : CA

Status: Complete

Patent Status

Development Stage: Patent Applied For

Technical Category: Combustion Engines \& Components

Recv. by NIST : $01 / 07 / 81$

Recom. by NIST : $05 / 26 / 82$

Award Date : $04 / 08 / 85$

Contract Period: 04/08/85

Summary: A grant of $\$ 49,500$ was awarded on April 8, 1985 to build and test a prototype. Grantee completed design of unit, but installation and testing of prototype will be done with private funds. There is no present plan to distribute the device.
- Contact:

Jonathan Gabe 1

5800 Ocean View Drive

Oakland CA 94618

415-653-8879

Status Date: 10/30/86 OERI No.: 007962

Award Amount: $\$ 49,500$ Grant No: FG01-85CE15159

$-04 / 07 / 86$ 
DOE No: 0207

DOE Coord: J.Aellen

Title: Glass Sheet Manufacturing Method and Apparatus

Description: A glass manufacturing process and apparatus having a vertical air-cooled electric furnace and transverse air-cooled refiner section. The furnace melts glass by passing an electric current through the composition and thus eliminates the emission of hot spent gasses that normally results from gas-fired furnaces.

Inventor: Frank L Anderson

State : WV

Contact:

Status: No DOE Support

Frank L Anderson

Patent Status : Patent Number: 4162907

Development Stage : Concept Development

Technical Category: Industrial Processes

Recv. by NIST : 06/15/81

Recom. by NIST : 06/23/82

Summary: No DOE support.

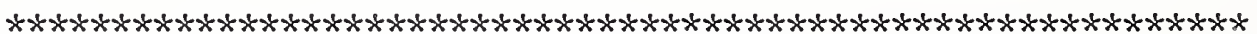

DOE No: 0208

DOE Coord: D.G.Mello

Title:

CNG Automotive Fuel Cylinders/Gas Transport Modules

Description: A lightweight aluminum gas transport vessel for storing compressed natural gas to fuel light transportation vehicles.

Inventor: Norman C Fawley

State : CA

Contact:

Norman $\dot{C}$ Fawley

NCF Industries

2320 Cherry Industrial Circle

Long Beach CA 90805

Status: Complete

Status Date: 12/31/85

OERI No.: 008406

Patent Status

Development Stage : Prototype Test

Technical Category: Fossil Fuels

Recv. by NIST : 06/01/81

Recom. by NIST : $06 / 23 / 82$

Award Date : 09/15/84

Contract Period: 09/15/84

Award Amount: $\$ 50,000$ Grant No: FG01-84CE15196

- $07 / 15 / 85$

Summary:

An award of $\$ 50,000$ was made to pressure test the inventor's transport module. Grantee successfully completed all tests; sold rights to major manufacturer of gas cylinders. 
DOE No: 0209

DOE Coord: A.R.Barnes

Title: Reclaiming Process for Resin Treated Fiberglass

Description: A process for reclaiming fiberglass from waste material for use as insulation by separating it from the urea-formaldehyde resin coating with which it is impregnated during manufacture.

Inventor: John W Yount State : NC
Contact:

John $\mathrm{W}$ Ỳount

$P$ O Box \#7

Bullock NC 27507

919-693-4839
Status: Complete

Patent Status

Development Stage : Production Engineering

Technical Category: Buildings, Structures \& Components

Recv. by NIST : $12 / 03 / 80$

Recom. by NIST : $06 / 28 / 82$

Award Date : 04/04/84

Contract Period: 04/04/84

Award Amount: \$ 50,000 Grant No: FG01-84CE15174

Summary:

A grant of $\$ 50,000$ was authorized on April 4th, 1984, for building and testing a fiberglass reclaiming machine. Inventor terminated grant during performance due to problems with sub- contractor.

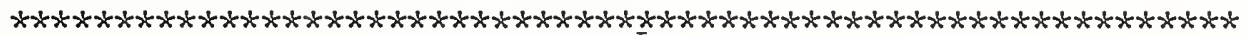

DOE No: 0210

DOE Coord: G.K. Ellis

Title: Ultra High Speed Drilling Device for Use in Hard Rock Formations

Description: A diamond cutting disk which is rotated at high linear velocities by twin downhole turbines to drill hard rock formations for deep oil recovery.

Inventor: Lloyd Flatland

State : CA

Status: Complete

Patent Status

Development Stage:

Technical Category:

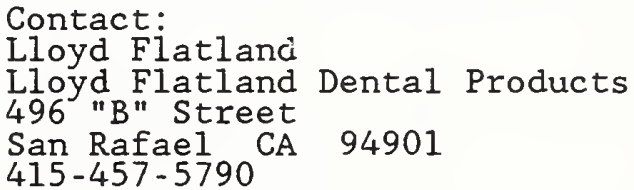

Contact

Lloyd Flatland

496 "B" Street

San Rafael CA 94901

Status Date: 09/30/88

OERI No. : 007631

Recv. by NIST : $10 / 03 / 80$

Recom. by NIST : $06 / 29 / 82$

Award Date $\vdots 09 / 30 / 86$

Contract Period: 09/30/86

Award Amount: $\$ 96,000$ Grant No: FG01-84CE15185

- $09 / 30 / 88$ Summary: A phase I grant of $\$ 46,000$ was awarded On August 28,1984 , to build and test determined. Phase I has been successfully completed. A phase II grant of $\$ 50,000$ was awarded on November 4 th, 1985 for further development and has been completed. However, some difficulties were encountered, and the inventor seeks additionai development funds. 
DOE No: 0211

DOE Coord: J.Aellen

Title: Shock Mounted Stratapax Bit

Description: An oil well drilling bit to support polycrystalline diamond cutters. It is designed with concentric spring tempered steel rings containing helical slots.

Inventor: Robert F Evans

State : TX

Status: Complete

Patent Status

Development Stage:

Technical Category:

Recv. by NIST : 12/18/80

Recom. by NIST : $06 / 29 / 82$

Award Date : $09 / 24 / 82$

Contract Period: 09/24/82

Award Amount: \$ 57,545 Grant No: FG01-82CE15149

- $02 / 28 / 84$
Contact:

Robert $F$ Evans

$P$ O Box \#45674

Dallas TX 75235

$214-351-6487$

Status Date: 06/30/86

OERI No.: 007918

Summary: A grant of $\$ 57,545$ was awarded for the grantee to design, fabricate and test, four variations of the invention.

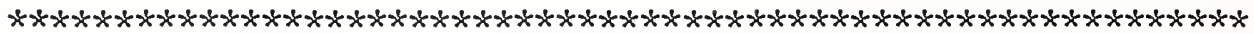

DOE No: 0212

DOE Coord: G.K.Ellis

Title:

Water Warden

Description: A plastic disc about two inches in diameter that installs in a commercial type of toilet water control valve to reduce the flushing cycle.

Inventor: Louis E Govear

State : CA

Status: Other Assistance
Contact:

- Hugh Huislander

Status Date: / / OERI No.: 008517

Patent Status : Patent Number: 4202525

Development Stage : Production \& Marketing

Technical Category: Buildings, Structures \& Components

Recv. by NIST : 06/14/81

Recom. by NIST : 06/30/82

Summary: Inventor requested assistance in marketing his invention in the Federal sector. A DOE letter of introduction and a listing of States' contacts has been provided. 
DOE No: 0213

DOE Coord: G.K. Ellis

Title:

The Kaunitz Process for Welding Pipe

Description: A pipe joining process particularly for large transmission pipelines that involves expanding and machining each end and then aligning both sections axially and radially prior to welding.

Inventor: Clyde F Kaunitz

State : MI

Status: Complete

Patent status

Development Stage

Technical Category:

Recv. by NIST : 02/20/8]

Recom. by NIST : $06 / 30 / 82$

Award Date : 06/11/86

Contract Period: 06/11/86

Summary:
A grant of $\$ 49,975$ was awarded on June 11th, 1986 to build and test a prototype. The device was built by CRC-Evans in Tulsa, and reportedly was

successfuily tested.

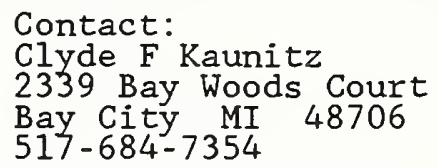

Status Date: 08/06/87

OERI No.: 008110
Award Amount: $\$ 49,975$ Grant No: FG01-86CE15267 - $03 / 11 / 87$

Not Applied For

Engineering Design

Industrial Processes

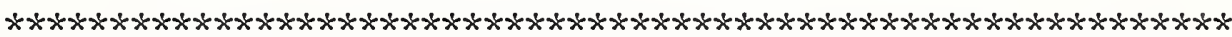

DOE No: 0214

DOE Coord: G.K.Ellis

Title:

Convertible Flat/Drop Trailer

Description: A removable bed trailer, constructed in three sections, that enables a single unit to function as a flat-bed trailer, drop-center trailer or a detachable-neck light-duty trailer.

Inventor: Donald E Wise

State : OR

Status: Complete

Patent Status

Technical Category: Transportation Systems, Vehicles \& Components

Recv. by NIST : 11/02/81

Recom. by NIST : $07 / 29 / 82$

Award Date $\vdots 09 / 18 / 84$

Contract Period: 09/18/84

Summary:
Contact:

Donald E Wise

5119 Jasper

Springfield OR 97447
$503-747-9255$
Status Date: 07/15/86 OERI No.: 008723

Award Amount: $\$ 63,069$ Grant No: FG01-84CE15175

- $12 / 15 / 85$

A grant of $\$ 63,069$ was awarded on September 18,1984 to build and test a prototype convertible trailer to determine fuel' savings. The inventor has icensed his technology to Trail King Company in Nebraska. 
DOE No: 0215

DOE Coord: G.K.E1lis

Title: Slag Waste Heat Boiler

Description: A slag waste heat boiler which produces wet steam from steel plant heat during the steel making process. Molten slag, a by-product, is poured over water-filled rotating cylinders. Steam is formed inside the cylinders and the solidified slag is scraped from the cylinders.

Inventor: Richard Jablin

State : NC

Status: Complete

Patent Status

Development Stage:

Technical Category:
Contact:

Richard Jablin

2511 Woodrow Street

Durham NC 27705

$919-286-4693$

Recv. by NIST : 06/07/77

Recom. by NIST : 06/29/82

Award Date : 06/11/86

Contract Period: 06/11/86

Award Amount: \$50,000 Grant No: FG01-86CE15264

Status Date: 06/11/87 OERI No.: 002333

Summary:

A grant was awarded for $\$ 50,000$ on June 11 th, 1986, to support the inventor in marketing the technology as part of an EPA SBIR Phase II project. The deal the deal the inventor anticipated did not materialize. Currently, he is seeking a steel company who would be interested in building the unit on their site. ERIP has referred him to CE's Improved Energy Productivity Division for possible assistance.

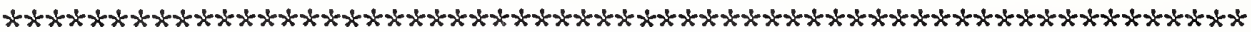

DOE No: 0216

DOE Coord: D.G.Mello

Title:

Method and Assembly for Mounting a Semiconductor Element Description: A method of packaging semiconductor wafers to achieve double-sided cooling of
the wafer without clamps, springs or studs; power semi-conductors, such as used in motor controllers, can thus operate at higher current levels.

Inventor: Richard F Kiley

State : MA

\author{
Contact: \\ Richard F Kiley \\ Thermal Associates Inc \\ 197 Main Street, P O Box \#248 \\ North Reading MA 01864 \\ $617-664-3342$
}

Status: Complete

Patent Status : Patent Applied For

Technical Category:

Combustion Engines \& Components
Recv. by NIST : 07/07/81

Recom. by NIST : 07/30/82

Award Date : 09/20/84

Contract Period: 09/20/84
Award Amount: $\$ 53,900$ Grant No: FG01-84SE15199 $-\quad 09 / 20 / 85$

Summary: A grant of $\$ 53,900$ was awarded to build and test prototype semiconductor elements. Market conditions precluded grantee from developing viable market plans for the product. 
DOE No: 0217

DOE Coord: J.Aellen

Title: Jointless Advanced Composite Material Tape for Operating Lift Pumps in Oil

Description: A jointless composite material tape (ribbon rod) made from carbon fibers, epoxy and fiber tape for use in place of steel sucker rods normally used in conjunction with beam pumping of oil wells.

Inventor: Curtis $\mathrm{J}$ Tanner

State : CA
Contact:

$\mathrm{H} \mathrm{N}$ Hensley

2010 Princeton

Midland TX 79701

$915-683-3534$

Status: Complete

Status Date: 10/16/88

OERI No.: 008074

Patent Status : Disclosure Document Program

Development Stage : Prototype Test

Technical Category: Fossil Fuels

Recv. by NIST : 02/12/81

Recom. by NIST : $07 / 30 / 82$

Award Date : 04/17/87

Contract Period: 04/17/87

Award Amount: \$ 82,742 Grant No: FG01-87CE15122

- $10 / 16 / 88$

Summary: A grant of $\$ 82,742$ was awarded on April fourteenth, 1987, to construct and test the product.

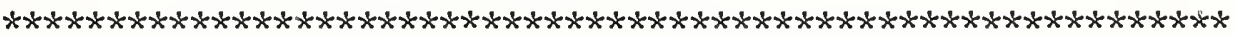

DOE No: 0218

DOE Coord: G.K.E11is

Title: Behemoth

Description: An apparatus and process for reclaiming waste oil at drilling sites by separating water and solids. Solids and water can be returned to the site and land restored to its natural state.

Inventor: Wilford Dean Tannehill

State : TX

Contact:

Wilford Dean Tannehill

Status: Other Assistance Status Date: 09/17/85 OERI No.: 008950

Patent Status : Patent Applied For

Development Stage : Production \& Marketing

Technical Category: Industrial Processes

Recv. by NIST : 03/17/82

Recom. by NIST : 07/30/82

Summary: The inventor is looking for a licensee or buyer of his invention. 
DOE No: 0219

DOE Coord: J.Aellen

Title: Method for Making Acelaldehyde from Ethanol

Description: A process to convert low proof ethanol directly to anhydrous acetaldehyde by an electrogenerative conversion process using fuel cell technology. During the conversion heat and electricity are produced.

Inventor: Thomas M Meshbesher

State : DE

Status: Complete

Patent Status

Development Stage:

Technical Category:

Recv. by NIST : 02/05/81

Recom. by NIST : 07/30/82

Award Date : 09/18/84

Contract Period: 09/18/84 A grant of $\$ 49,983$ was awarded to perform an economic study and mineral lab

work to determine the most ef
acetaldehyde and electricity.

Contact:

Thomas M Meshbesher

4507 Weldin Road

Wilmington DE 19899

$302-658-9141$

Summary:

Status Date: 06/30/86

OERI No. : 008054

Patent Applied For

Laboratory Test

Combustion Engines \& Components

Award Amount: $\$ 49,983$ Grant No: FG01-84CE15191

- $09 / 18 / 85$

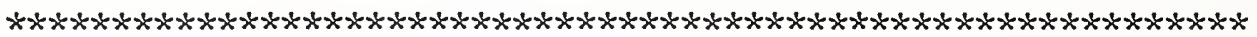

DOE No: 0220

DOE Coord: D.G.Mello

Title:

Deep Throat Resistance Welder Description: A high-frequency spot-welding system which permits relatively small and the heavy cabling required of either 60 -hertz or DC systems. This allows a greater proportion of the power-line energy being transferred to the weld rather than dissipated in the system conductors.

Inventor: Charles A Schwartz

State : $\mathrm{OH}$

Status: Complete

Patent Status

Development Stage : Prototype Test

Technical Category: Industrial Processes

Recv. by NIST : 11/04/80

Recom. by NIST : $08 / 30 / 82$

Award Date : 09/19/84

Contract Period: 09/19/84

Summary:

- 09/18/85
A grant of $\$ 45,920$ was awarded on September 14,1984 to build and test a prototype. The tests confirmed theoretical analysis showing the merits of the new system. Grantee attempting licensing of product.
Contact:

Charles A Schwartz

24545 Bryden Road

Beachwood OH 44122

$216-831-3099$

Award Amount: $\$ 45,920$ Grant No: FG01-84CE15192 
DOE No: 0221

DOE Coord: J.Aellen

Title: Strainercycle

Description: A means for providing cooling in a building, when the outside temperature drops below 65 degrees Fahrenheit, by injecting strained cooling tower water into chilled water circuits in order to eliminate the use of mechanical refrigeration during this time.

Inventor: Rudolf o Iverson

State : NY

Status: Other Assistance

Patent Status

Devel opment Stage: Patent Number: 3995443

Technical Category: Buildings, Structures \& Components

Recv. by NIST : 03/25/82

Recom. by NIST : 09/13/82

Summary:

ERIP identified government market for inventor.
Contact:

Paul Ginouves
Status Date: 09/23/82 OERI No.: 008964

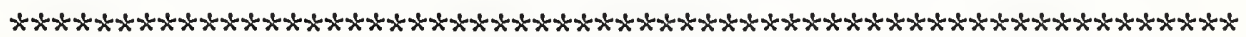

DOE No: 0222

DOE Coord: D.G.Mello

Title: Louver Trombe Solar Storage Unit

Description: A jalousie shutter, Trombe-type, phase change storage unit. Each shutter is prism shaped and exposes, alternately, a transmission, absorption or combination, side toward the sun.

Inventor: Donald $\mathrm{R}$ Thomas

Contact:

State : VT

Donald $R$ Thomas

Status: Other Assistance Status Date: / / OERI No.: 007979

Patent Status : Not Applied For

Development Stage : Laboratory Test

Technical Category: Direct Solar

Recv. by NIST : $01 / 15 / 81$

Recom. by NIST $\vdots 10 / 07 / 82$

Summary: ERIP assistance has been completed. Referred to National Appropriate Technology Assistance Service (NATAS) for assistance. 
DOE No: 0223

DOE Coord: J.Aellen

Title: Minimizing Subsidence Effects during Production of Coal In Situ

Description: The invention is a process for using a foaming mud cement to prevent or minimize subsidence in underground gasification sites.

Inventor: Ruel Carlton Terry

Status: Complete

Patent Status

Development Stage:

Technical Category:

Recv. by NIST : 06/17/81

Recom. by NIST : $10 / 14 / 82$

Award Date $: 04 / 04 / 84$

Contract Period: 04/04/84

Award Amount: $\$ 53,964$ Grant No: FG01-84CE15169

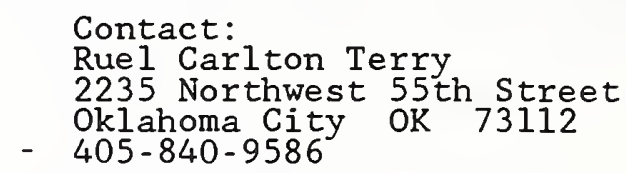

Status Date: 06/30/86

OERI No.: 008456

Patent Applied For

Concept Development

Fossil Fuels
State : OK

Summary:

A grant of $\$ 53,964$ was awarded to perform lab work. Follow-up funding of $\$ 248,000$ was received from the state of Wyoming using funds provided by the Department of Interior. $\$ 60,000$ for additional R\&D has since been awarded by the US Bureau of Mines.

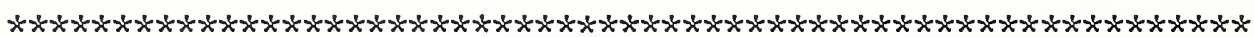

DOE No: 0224

DOE Coord: J.Aellen

Title:

Haile Alternate Fuel Grain Dryer Description: This is a design for a grain dryer which is capable of using grain dust
collected from grain elevators as an alternate fuel.

Inventor: Jack D Haile

State : NE

Contact:

Gwyer Grimminger, Presiden

COMET, Inc

3221 Ramada Road

Grand Island NE 68801

$308-381-2990$

Status: Complete

Status Date: 06/30/86

OERI No.: 006782

Patent Status : Patent Applied For

Development Stage : Engineering Design

Technical Category: Industrial Processes

Recv. by NIST : 04/09/80

Recom. by NIST : $10 / 14 / 82$

Award Date $: 06 / 01 / 84$

Contract Period: 06/01/84

Award Amount: $\$ 50,000$ Grant No: FG01-84CE15190

- $12 / 01 / 85$

Summary:

A grant of $\$ 50,000$ was awarded for design and engineering analysis of the grain dryer using grain dust as fuel. The technology is available for licensing. 
DOE No: 0225

DOE Coord: J.Aellen

Title:

ROVAC High Efficiency Low Pressure Air Conditioning System

Description: An air conditioning unit which utilizes rotary vane compressor with multiple vanes and low pressure refrigerant such as R-114. The vanes in the compressor are mechanically restrained so that they do not touch the casing.

Inventor: Thomas C Edwards

State : FL

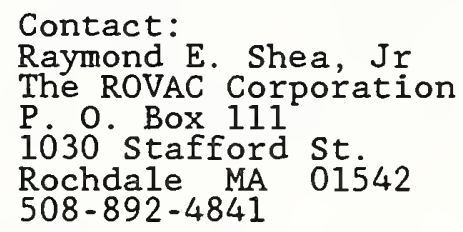

Summary: A grant of $\$ 64,900$ was awarded on July 22 nd, 1988 , to

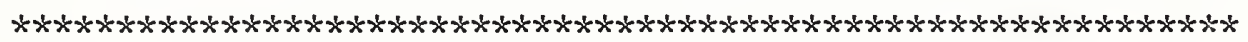

DOE No: 0226 DOE Coord: D.G.Mello

\title{
Title:
}

An Electronic Anemometer System for Locating Air-Infiltration Heat Leaks in Buildings

Description: An electronic anemometer system for detection and location of air infiltration in residential and commercial structures. A fan creates a negative pressure inside the structure and an electronic leak detector detects air motion at cracks in the building.

Inventor: Stewart Ryan

State : OK

\author{
Contact: \\ Stewart Ryan \\ Status Date: 07/31/85 \\ OERI No.: 008826
}

Status: No DOE Support

Patent Status : Not Applied For

Development Stage : Prototype Development

Technical Category: Buildings, Structures \& Components

Recv. by NIST : $12 / 28 / 81$

Recom. by NIST : $11 / 29 / 82$

Summary:

Action temporarily suspended at inventors request. Inventor sold six month option. Inventor subsequently abandoned project. Competing products now exist. 
DOE No: 0227

DOE Coord: D.G.Mello -

Title: $\quad$ CRM Pipe

Description: A process for manufacturing pipe for high pressure gas transmission lines. Metal pipe is wound with resin impregnated composite-fibre reinforcement.

Inventor: Norman C Fawley

State : CA

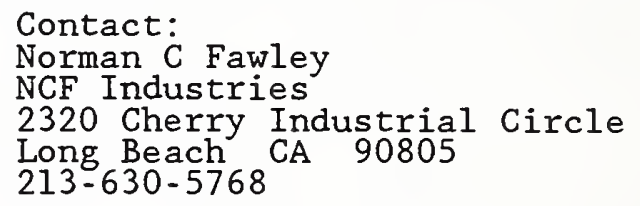

Status: Complete

Status Date: 12/31/85

OERI No.: 009055

Patent Status : Not Applied For

Development Stage : Concept Development

Technical Category: Miscellaneous

Recv. by NIST : 03/01/82

Recom. by NIST : $12 / 14 / 82$

Award Date: $07 / 15 / 84$

Contract Period: 07/15/84

Award Amount: \$ 50,000 Grant No: FG01-84CE15197 $-\quad 07 / 15 / 85$

Summary:

A grant of $\$ 50,000$ was awarded to test inventor's device to arrest crack progagation in gas pipelines. Test at Battelle prove value of system. Grantee attempting to license to major steel pipe manufacturer.

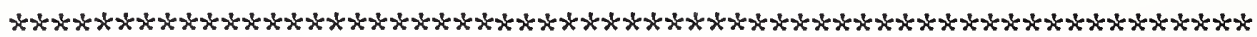

DOE No: 0228

DOE Coord: J.Aellen

Title:

EGD Fog Dispersal System

Description: An electrogasdynamic device for dispersing fog that propels a stream of negatively charged water droplets into the air causing fog droplets to become charged and electrically attracted to the ground.

Inventor: Meredith C Gourdine

State : TX

Status: Complete

Patent status

Development Stage

Technical Category: Transportation Systems, Vehicles \& Components

Recv. by NIST: 06/19/81

Recom. by NIST : $12 / 15 / 82$

Award Date : $06 / 26 / 85$

Contract Period: 06/26/85

Award Amount: $\$ 88,840$ Grant No: FG01-84CE15184

Contact:

Meredith C Gourdine

Post Office Box \#1228

Friendswood TX 77546

$713-790-9892$

Summary:

An $\$ 88,840$ cost sharing grant with Federal Express was awarded to install and demonstrate the technology at the Elmira, New York airport. 
DOE No: 0229

DOE Coord: D.G.Mello

Title:

Contoured Finger Follower Variable Valve-Timing Mechanism for Internal Combustion Engines

Description: An inexpensive mechanism for varying the valve-timing of internal combustion engines in response to variations in engine operating conditions.

Inventor: Edward M Tourtelot

State : IL

Status: No DOE Support

Patent Status

Development Stage

Technical Category:

Patent Applied For

Concept Development

Combustion Engines \& Components

Recv. by NIST : 04/14/82

Recom. by NIST : 01/20/83

Summary:

Inventor's son will carry project forward. A proposal is being prepared for DOE consideration. Inventor's successor abandoned project. No DOE support required.

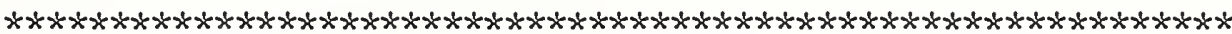

DOE No: 0230

DOE Coord: J.Aellen

Title:

Absorption Heat Pump Augmented Separation Process

Description: A reverse absorption heat pump which transfers heat from the condenser of a distillation column to the reboiler using a lithium-bromide-water system.

Inventor: Donald C Erickson

State : MD

Status: Complete

Patent Status

Development Stage

Technical Category

$\operatorname{Re}$

Recom. by NIST : $01 / 24 / 83$

Award Date $\vdots 04 / 09 / 84$

Contract Period: 04/09/84

Award Amount: $\$ 25,000$ Grant No: FG01-84CE15172

Contact:

Donald C Erickson

627 Ridgely Avenue

Annapolis MD 21401

301-266-6521

Status Date: 11/26/85

OERI No.: 007530

Summary:

A first phase grant of $\$ 25,000$ was awarded on April 9, 1984 to find a suitable application and perform initial design. The inventor is still looking for an industrial partner to install and test a full- scale absorption heat pump. Phase one of this project has been completed. 
DOE No: 0231

DOE Coord: G.K.Ellis

Title: Natural Gas from Deep-Brine Solutions

Description: A process for recovering geopressure methane gas by use of a deep-submerged separator of special design which separates the methane at depth and continuously recirculates the spent brine back into the formation of origin.

Inventor: Guy R B Elliott

State: NM
Contact:

Guy R B Elliott

Los Alamos Cons Alpha Inc

133 La Senda Road

Los Alamos NM 87544

$505-672-3603$

Status: Complete

Status Date: 09/30/86

OERI No.: 009008

Patent Status : Patent Number: 4262747

Development Stage : Prototype Development

Technical Category: Fossil Fuels

Recv. by NIST : 05/05/82

Recom. by NIST : $01 / 24 / 83$

Award Date $\vdots 04 / 02 / 84$

Contract Period: 04/02/84

Award Amount: $\$ 75,000$ Grant No: FG01-84CE15171

Summary:

An grant of $\$ 75,000$ was awarded to build and test a prototype on the $1 \mathrm{ab}$ scale. Carbon dioxide dissolved in water will be used to operate the pump. The tests were performed and the results were encouraging.

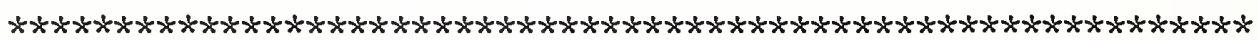

DOE No: 0232

DOE Coord: J.Aellen

Title:

Method of Separating Lignin and Making Epoxide- Lignin

Description: A process for low cost separation of lignin from the black cooking liquor which is a waste product from the kraft and sulfite paper pulping process, and for producing lignin-epoxide resins.

Inventor: Kenneth $\mathrm{R}$ Kurple

State : MI
Contact:

Kenneth $\mathrm{R}$ Kurple

9533 Springborn Road

Anchorvilie MI 48004

- 313-727-7631
Status: Complete

Patent Status

Development Stage:

Technical Category:

Recv. by NIST : 10/14/80

Recom. by NIST : $01 / 26 / 83$

Award Date : 07/19/84

Contract Period: 07/19/84
Status Date: 04/30/87

OERI No.: 007662

Summary: A $\$ 61,739$ first phase grant was awarded to perform lab analysis. A second phase of $\$ 35,175$ was awarded to complete the laboratory work. Award Amount: $\$ 96,914$ Grant No: FG01-84CE15193

Patent Number: 4111928

imited Production/Marketing

Industrial Processes 
DOE No: 0233

DOE Coord: J.Aellen

Title:

Mounted Steerable Ripper for Deep Soil Ripping and Subsoil Operations

Description: An hydraulically-actuated, rear-mounted, steerable ripper for crawler tractors intended for agricultural deep tillage operations. The steering action of the ripper assists or affects tractor steering, permitting more effective utilization of power transmitted to the tractor tracks.

Inventor: Daniel A Lockie

State : CA

Status: No DOE Support

\section{Contact:}

Daniel A Lockie

Patent Status : Not Applied For

Development Stage : Concept Development

Technical Category: Industrial Processes

Recv. by NIST : 04/15/82

Recom. by NIST : $02 / 01 / 83$

Summary: Comparable technology is already on the market.

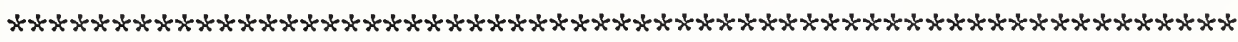

DOE No: 0234

DOE Coord: G.K.Ellis

Title:

Geodesic Solar Paraboloid

Description: A parabolic point-focusing solar concentrator consisting of a dish reflecting surface, a track and a geodesic reflector support system.

Inventor: Douglas E Wood

State : WA
Status: Complete

\section{Patent Status}

Development Stage

Technical Category:

Recv. by NIST

Recom. by NIST

Award Date

Contract Period: $04 / 17 / 85$

Summary:
A grant of $\$ 50,000$ was awarded on April 17, 1985 to make design improvements to the existing prototype. It is currently being tested for improvement of efficiency.

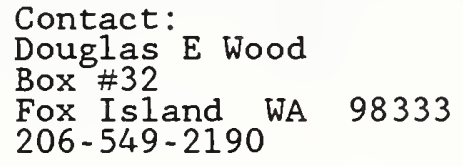

Status Date: 02/14/86

OERI No.: 002968

Patent Number: 4171876

Prototype Test

Direct Solar

Award Amount: $\$ 50,000$ Grant No: FG01-85CE15203 - $09 / 16 / 86$ 
DOE No: 0235

DOE Coord: G.K.Ellis

Title:

Single Stage Anaerobic Digestion Process

Description: A process for accelerating the manufacture of relatively high-purity methane fuel gas through a process of anaerobic digestion, involving retention of organic material in an aqueous slurry which is maintained at a predetermined $\mathrm{V} / \mathrm{I}$ ratio, temperature, and minimizes the production of carbon dioxide.

Inventor: Jay E Ort

State : PA

\author{
Contact: \\ Harry Curtin \\ Penn State Engineering Inc \\ 522 East College Avenue \\ P O Box \#177 \\ State College PA 16801 \\ 814-238-5013
}

Status: Complete

Status Date: 12/04/85

OERI No.: 008644

Patent Status

Development Stage : Concept Development

Technical Category: Fossil Fuels

Recv. by NIST : 09/18/81

Recom. by NIST : $03 / 30 / 83$

Award Date : 04/02/84

Contract Period: 04/02/84

Award Amount: $\$ 50,000$ Grant No: FG01-84CE15170

$-12 / 04 / 85$

Summary: A phase one grant of $\$ 50,000$ was awarded on April 2, 1984 to study and optimize the basic parameters of the process. The first run of tests were not successful due to defective equipment. Another series of tests was performed. The process is not as efficient as anticipated, and it is not economically feasible. Consequently, phase two of this project will not be initiated.

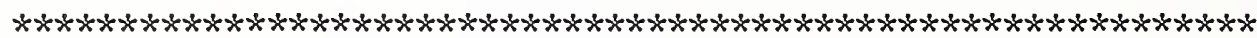

DOE No: 0236

DOE Coord: A.R.Barnes

Title: Steam Turbine Packing Ring

Description: A self-adjusting steam turbine packing ring that provides large shaft clearance during turbine start- up and reduced shaft clearance at normal turbine operating speeds. This action avoids packing ring damage during start-up and results in higher operating efficiency. A private sector publicutility is funding further development.

Inventor: Ronald E Brandon

State : NY
Contact:

- Ronald E Brandon

1734 Lenox Road

Schenectady NY 12308

$518-374-1220$
OERI No. : 009167

Status: Complete

Status Date: 07/02/87

Patent Status
Development Stage $:$ Patent Applied For

Technical Category: Combustion Engines \& Components

Recv. by NIST : 10/25/82

Recom. by NIST : 04/07/83

Award Date $\quad 08 / 08 / 84$

Contract Period: 08/08/84

Award Amount: $\$ 51,900$ Grant No: FG01-84CE15189

- $07 / 02 / 86$

Summary: Development was completed in 1987. Operating tests on 200MW PEPCO unit indicate $1.25 \%$ gain in heat rate efficiency. Exclusive license with Quabbin Industries, a manufacturer of steam turbine components, was signed in 1987 . In the first year of his license, 37 sets were sold, which includes a number of repeat orders. 
DOE No: 0237

DOE Coord: D.G.Mello

Title:

Hicks Alter-Brake System/Electric Charging Apparatus for Ground Vehicles

Description: An automotive electrical generating and battery charging system that is driven primarily by vehicle momentum during braking, thus reducing required engine power output.

Inventor: David E Hicks

State : CO
Contact:

David E Hicks

5244 Cracker Barrel Circle

Colorado Springs Co 80917

303-596-4390

Status: Complete

Status Date: 09/20/85

OERI No.: 009232

Patent Status

Development Stage

Prototype Test

Technical Category: Transportation Systems, Vehicles \& Components

Recv. by NIST : 01/19/82

Recom. by NIST : $05 / 12 / 83$

Award Date : 09/20/84

Contract Period: 09/20/84

Award Amount: $\$ 56,438$ Grant No: FG01-84CE15183

$-\quad 09 / 20 / 85$

Summary:

A grant of $\$ 56,438$ was awarded to build and test prototype battery charging system using automobile momentum only. Project successfully completed. Grantee attempting to license product. -

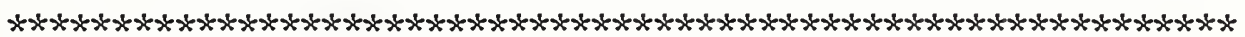

DOE No: 0238

DOE Coord: G.K.Ellis

Title:

Industrial and Residential Clothes Dryer Automatic Shut-Off at Dryness

Description: A sensing system to shut off clothes dryer when the clothes have been dried completely. The proposed system measures the time interval between consecutive peaks as the dryer is cycled on and off between high and low temperature limits and shuts the dryer off when the time intervals become constant.

Inventor: Harry $\mathrm{E}$ Wood

State : LA

Status: Complete

Patent Status : Not Applied For

Technical Category: Miscellaneous

Recv. by NIST : 08/31/82

Recom. by NIST : 05/12/83

Award Date : 03/07/84

Contract Period: 03/07/84

Award Amount: $\$ 57,000$ Grant No: FG01-84CE15168

- $03 / 26 / 85$
Contact:

Harry E Wood

6465 Oakland Drive

New Orleans LA 70118

$504-488-7853$

Summary:

A grant of $\$ 57,000$ was awarded on September 17,1985 for building and testing a prototype. The project was successfully concluded. The inventor licensed his technology. 
DOE No: 0239

DOE Coord: J.Aellen

Title: Electrochemical Separation and Concentration of Sulfur-Containing Gases from Gas Mixtures

Description: An electrochemical process for removing sulfur oxides from flue gas discharges from power plants which burn sulfur-containing fuels, principally high sulfur coals.

Inventor: Jack Winnick

State : GA

Status: Complete

Status Date: $06 / 30 / 86$

Contact:

Jack Winnick

3028 Vinings Way

Atlanta GA 30339

404-894-2839

Patent Status : Patent Number: 4246081

Development Stage : Working Model

Technical Category: Industrial Processes

Recv. by NIST : 10/01/81

Recom. by NIST : 05/18/83

Award Date $\vdots / / 2$ Award Amount: \$ 50,000 Grant No: FG01-84CE15178

Contract Period:

Summary:

ERIP provided and transferred a $\$ 50,000$ grant to PETC which added $\$ 200,000$. Work was performed at Georgia Tech Research Institute where electrode models were fabricated and tested in a bench scale model of the process.

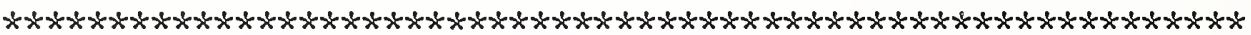

DOE No: 0240

DOE Coord: G.K.Ellis.

Title:

All Steam Heated Sadiron for Commercial Use

Description: A commercial use sadiron which is operated solely by superheated high pressure steam generated from an external boiler to supply both the heat to the iron sole plate and steam for moisture spray application as needed during the ironing practice.

Inventor: Jay R Royston

State : CA

Status: No DOE Support
Contact:

Uwe $\mathrm{H}$ Butenhoff

Status Date: 09/17/85 OERI No.: 008823

Patent Status : Patent Applied For

Development Stage : Engineering Design

Technical Category: Miscellaneous

Recv. by NIST : $12 / 28 / 81$

Recom. by NIST : $07 / 19 / 83$

Summary: Initial request for grant was rejected due to probable insufficient energy-saving potential. A study conducted by NATAS indicated insufficient market for this product. Two other companies are producing somewhat related product. 
DOE No: 0241

DOE Coord: J.Aellen

Title:

Polysulfide Oil Field Corrosion Control System

Description: A polysulfide additive to inhibit the corrosion of ferrous based metals in oil field and geothermal applications.

Inventor: Richard J Gay

State : TX
Contact:

Richard J Gay

9215 Clarewood - \#358

Houston TX 77036

$713-498-8553$

Status: Complete

Status Date: 09/05/85

OERI No.: 008601

Patent Status : Not Applied For

Development Stage : Prototype Development

Technical Category: Fossil Fuels

Recv. by NIST : 08/24/81

Recom. by NIST : $07 / 28 / 83$

Award Date : $12 / 07 / 84$

Contract Period: 12/07/84

Award Amount: $\$ 73,900$ Grant No: FG01-85CE15200

$-09 / 05 / 85$

Summary: A grant of $\$ 73,900$ was awarded on December 7 th, 1984 to perform lab test, analysis and field test.

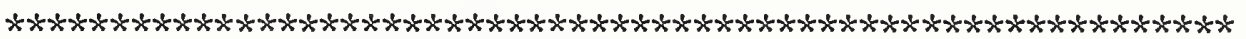

DOE No: 0242

DOE Coord: G.K.Ellis

Title: New Petersburg Beam Trawl

Description: An improved trawl design to reduce drag for either single rigged or double rigged vessels.

Inventor: Donald Shuler

State : AK

Status: Complete

Patent Status

Development Stage:

Technical Category:

Recv. by NIST : 12/22/82

Recom. by NIST : $09 / 29 / 83$
Award Date

Contract Period: 09/05/84

Summary:
A grant of $\$ 63,000$ was awarded on September 5,1984 to build and test a prototype beam-trawl fishing net to determine fuel efficiency per pound of catch. The inventor failed to submit quarterly technical reports. The beam trawl nets were built but never tested in the presence of an independent observer from the Sea Grant Program. Inventor's whereabouts are unknown. The contracting officer was informed of this fact. Further pursuit was determined not to be in the government's best interests. 
DOE No: 0243

DOE Coord: P.M.Hayes

Title:

An Electronic/Pneumatic Ejector System for Producing an Aluminum Rich Concentrate from Municipal Waste

Description: Method and apparatus for processing municipal waste to overcome the disadvantages of the mass burning and the refuse derived-fuel methods by combining the two processes and recovering aluminum and steel.

Inventor: Edward J Sommer, Junior

State : TN

Contact:

Garry R Kenny

Magnetic Separation Syst Inc

10528 th Avenue, South

Nashville TN 37212

615-329-0695

Status: Complete

Status Date: 09/13/85

OERI No. : 008031

Patent Status

Development Stage : Working Model

Technical Category: Industrial Processes

Recv. by NIST : 01/23/81

Recom. by NIST : 09/29/83

Award Date : 09/15/84

Contract Period: 09/15/84

Award Amount: $\$ 50,640$ Grant No: FG01-84CE15179

- 09/13/85

Summary: A grant of $\$ 50,000$ was awarded on August 15th, 1984 to design, build and test a prototype of the aluminum recovery system. The inventors have licensed the process to National Recovery Technology in Nashville, Tennessee and they are marketing the system. A new application to remove aluminum contaminants from crushed recycled glass and granulated beverage bottles was developed and the marketing rights for the European Common Market were licensed to a West German company.

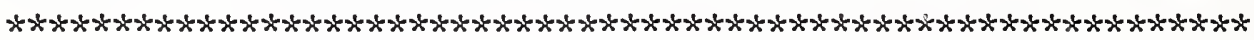

DOE No: 0244

DOE Coord: J.Aellen

Title:

CHARLIE - Trademark - Federally Registered \#1123957

Description: An electronic system for controlling engine-compression type brakes used on trucks.

Inventor: Charles E Robinson

State : CO

Contact:

Brad L Pfeifley

CAMACAN, Inc.

7730 Belleview

Suite \#204

Englewood CO 80111

303-850-0404

Status: Complete

Status Date: 04/10/86

OERI No.: 009459

Patent Status : Patent Number: 4305353 and others

Development Stage : Limited Production/Marketing

Technical Category: Transportation Systems, Vehicles \& Components

Recv. by NIST : 02/03/83

Recom. by NIST : $09 / 29 / 83$

Award Date : $09 / 11 / 84$

Contract Period: 09/11/84

Award Amount: $\$ 51,655$ Grant No: FG01-84CE15194 - 04/10/86

Summary: A grant of $\$ 51,655$ was awarded to build and test a prototype. 
DOE No: 0245

DOE Coord: J.Aellen

Title: Improved Oil Well Pumping Unit

Description: A vector force balanced oil well pumping assembly.

Inventor: Thomas Neil Parker, Junior State: OK

Contact:

Thomas Neil Parker, Junior

Thomas Parker Insurance

P O Box \#356

Boswell OK 74727

$405-566-2535$

Status: Complete

Status Date: 06/30/86

OERI No.: 009241

Patent Status : Disclosure Document Program

Development Stage : Working Model

Technical Category: Fossil Fuels

Recv. by NIST : $11 / 23 / 82$

Recom. by NIST : $09 / 29 / 83$

Award Date : $06 / 25 / 84$

Contract Period: 06/25/84

Award Amount: $\$ 61,801$ Grant No: FG01-84CE15177

Summary:

A grant of $\$ 59,121$ was awarded on June 25th, 1984 to build and test a prototype. Work to be conducted in cooperation with Rural Enterprises Inc. Potential exists for cost sharing in development and marketing. A supplemental grant of $\$ 2,680$ was awarded on April $8 \mathrm{th}, 1985$. Testing indicates that the pump is very efficient.

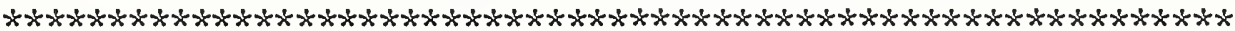

DOE No: 0246

DOE Coord: D.G.Mello

Title: $\quad$ Maximum Cruise Performance

Description: Maximum cruise performance of jet powered aircraft is achieved by maintaining the ratio of "fuel flow to ground speed" to a minimum by using a closed loop feedback system and a software algorithm package connected into the aircraft's avionic mission computer network.

Inventor: Juan M Garcia, Junior

Contact:

Juan M Garcia, Junior

State : MO

Status Date: 07/01/85

OERI No.: 008733

Status: No DOE Support

Patent Status
Development Stage Not Applied For

Tevelopment Stage : Engineering Design

Recv. by NIST : $11 / 09 / 81$

Recom. by NIST : $10 / 31 / 83$

Summary: Preliminary proposal received from inventor. Coordinator seeking private sector assistance. Grantee unable to define suitable test program leading to marketable product. 
DOE No: 0247

DOE Coord: D.G.Mello

Title: Energy Conservation by Improved Control of Bulk Power Transfers on Interconnected Systems

Description: In an interconnected electric power system, the parameters' system time deviation and area inadvertent interchange can be decomposed into components respectively caused by regulating deficiencies in each of the individual control areas. These components can serve as the basis for an equitable payment technique for unscheduled transfers to replace the present practice of "repayment in kind".

Inventor: Nathan Cohn

State : PA
Contact:

Nathan Cohn

8033 Via de Viva

Scottsdale AZ 85258

$602-991-7063$

Status: Complete

Status Date: 10/30/86

OERI No.: 009342

Patent Status : Patent Number: 4267571

Technical Category: Miscellaneous

Recv. by NIST : $01 / 19 / 83$

Recom. by NIST : $11 / 18 / 83$

Award Date: $09 / 05 / 84$

Contract Period: 09/05/84

Award Amount: $\$ 60,000$ Grant No: FGOl-84CE15187 - $02 / 15 / 86$

Summary: A grant of $\$ 60,000$ was awarded to study the uneconomical inadvertent interchange of electric power between a number of cooperating electric utility companies, and to recommend a method to correct the resulting energy losses. Grantee will license method to interested utilities.

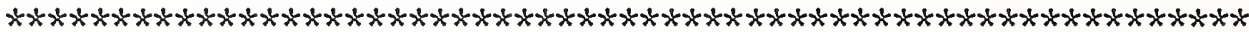

DOE No: 0248

DOE Coord: J.Aellen

Title:

Dyna-Bite Traction Intensifier, Model Agri, for Agricultural Tractors or the Like

Description: A device consisting of individual tire segments that are strapped to the driving wheels of a tractor or similar vehicle to improve traction and minimize the need for adding weight to get better traction.

Inventor: Thorvald G Granryd

State : IL
Contact:

Thorvald G Granryd

P 0 Box \#258

1260 North Western Avenue

Apartment \#109

Lake Forest IL 60045

$312-234-8250$

Status Date: 12/31/85

OERI No.: 008617

Status: Complete

Patent Number: 4225082 and others

Patent Status

Development Stage : Production Engineering

Technical Category: Industrial Processes

Recv. by NIST : 08/12/81

Recom. by NIST : $11 / 22 / 83$

Award Date:09/18/84

Contract Period: 09/18/84

Award Amount: $\$ 70,189$ Grant No: FG01-84CE15186

- $12 / 31 / 85$

Summary:

A grant of $\$ 32,064$ was awarded on September 18,1985 to build and test prototype traction intensifiers. Tests performed for traction were successful, but the device had minor durability problems. A phase two grant of $\$ 35,525$ was awarded to develop design modifications capable of overcoming problems. 
DOE No: 0249

DOE Coord: G.K.Ellis

Title: Subsurface Flow Control (Gas Wells) and High Gas- Oil-Ratio Oil Wells

Description: Subsurface gas well flow control and purge valve.

Inventor: Patrick S Swihart, Senior State : NM

Contact:

Patrick S Swihart, Senior

Box \#262

Timberon NM 88350

505-987-2449

Status: Complete

Status Date: 08/19/85

OERI No.: 009220

Patent Status : Patent Number: 4036297 and others

Development Stage : Prototype Test

Technical Category: Fossil Fuels

Recv. by NIST : 11/16/82

Recom. by NIST : $12 / 30 / 83$

Award Date

Contract Period: 08/19/85

Award Amount: $\$ 16,074$ Grant No: FG01-85CE15202

Summary:

An award was granted for $\$ 16,074$ on August 19,1985 to build and test a prototype. Grantee experienced various problems trying to get valid tests. Project has been completed.

*

DOE No: 0250

DOE Coord: P.M.Hayes

Title: A System to Adapt Diesel Engines to the Use of Crude Oils

Description: A three-part system for converting conventional diesel engines so they can be operated on either No. 2 diesel fuel or heavy fuels such as crude oil or vegetable oils.

Inventor: Hugh Edwin Whitted III

State : NC

Contact:

Hugh Edwin Whitted III

Route \#2, Box \#444-A

- East Bend NC 27018

Status: Complete

Status Date: 05/26/89

OERI No.: 009458

Patent Status

Development Stage : Prototype Test

Technical Category: Combustion Engines \& Components

Recv. by NIST : 03/14/83

Recom. by NIST : $12 / 30 / 83$

Award Date : $08 / 27 / 86$

Contract Period: 08/27/86

Award Amount: $\$ 82,057$ Grant No: FG01-86CE15284
$-05 / 26 / 89$

Summary: A fifteen month, $\$ 82,057$ grant was awarded to modify both a direct and indirectly injected Diesel engine to operate directly on crude oil. Preliminary results have shown no deterioration in critical engine components, and acceptable emission levels. The engines will find application in multi-fuel trucks and stationary engines. 
DOE No: 0251

DOE Coord: G.K.Ellis

Title: $\quad$ Process and Apparatus for Reducing the Energy Required to Separate Liquids by

Description: A method for heat recovery in distillation by providing heat exchange tubing directly on the trays of the tower. This method is used primarily in crude oil
stills.

Inventor: Victor $\mathrm{R}$ Thayer

State: DE
Contact:

E A Kiessling

Texim Associates

15402 Wandering Trail

Friendswood TX 77546

302-239-5059

Status: Complete

Status Date: $09 / 12 / 88$

OERI No.: 009260

Patent Status $\quad$ Patent Number: 4265736
Development Stage
Technical Category: Prototype Test
Industrial Processes

Recv by NIST : 12/03/82

Recom. by NIST : $01 / 31 / 84$

Award Date : $03 / 13 / 87$

Contract Period: 03/13/87

Award Amount: $\$ 41,565$ Grant No: FG01-87CE15303

Summary:

A grant was awarded to investigate the technology further. The technology was determined not to be cost effective under current economic conditions.

DOE No: 0252

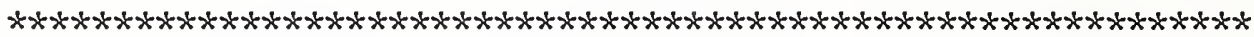

Title: DOE Coord: D.G.Mello

Description: The "Thermal Bank" is a latent heat type thermal energy storage system. Calcium chloride hexahydrate, the phase change salt, or any suitable phase
change material, is used as the working medium. Selected plastic film is employed to form, fill and seal the tube sheets for the "Thermal Bank" packaging.

Inventor: William $C$ Whitman

State : NJ
Contact:

- William C Whitman

Three Fourth Street

New Brunswick NJ 08901

201-545-3849

Status: Complete

Status Date: 08/26/86

OERI No.: 009217

Patent Status

Patent Number: 4287942

Development Stage : Production Engineering

Technical Category: Miscellaneous

Recv by NIST: $11 / 02 / 82$

Recom. by NIST : $01 / 31 / 84$

Award Date : $03 / 19 / 85$

Contract Period: 03/19/85

Award Amount: $\$ 70,778$ Grant No: FG01-85CE15211 $09 / 18 / 85$

Summary:

A grant was awarded to Rutgers University to test efficiency of various packaging materials and eutectic salts. The grantee reached agreement with Rutgers to continue $R \& D$ beyond grant period using private sector and state of New Jersey co-funding. 
DOE No: 0253

DOE Coord: J.Aellen

Title: High Performance Heat Pump

Description: A modified Brayton refrigeration cycle using injected liquid to achieve better performance.

Inventor: Anthony Peters

State : NJ

Status: Complete

Patent status

Development Stage : Engineering Design

Technical Category: Buildings, Structures \& Components

Recv by NIST: $09 / 10 / 81$

Recom. by NIST : $02 / 24 / 84$

Award Date : $09 / 27 / 84$

Contract Period: 09/27/84

Award Amount: $\$ 63,200$ Grant No: FG01-84CE15198
- Contact:

Anthony Peters

300 Winston Drive

Cliffside Park NJ 07010

$201-886-1320$

Summary:

An grant was awarded to perform a thermodynamic analysis, study component design and perform an economic analysis. Received the final report for the work done in phase I. The inventor worked on a different version of heat pump rather than the one that was recommended by N.B.S. Without prior approval of DOE. Work terminated on this project. About $\$ 25,000$ of the total grant has been spent so far.

DOE No: 0254

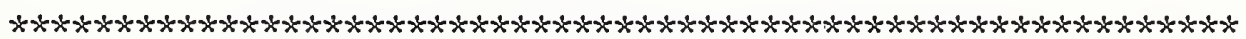

DOE Coord: D.G.Mello

Title: $\quad$ "Turbo-Glo" Immersion Furnace

Description: A gas-fired melting furnace designed for melting aluminum. The design uses a new type combustion chamber and heat transfer device.

Inventor: Daniel Douenias

State : NY

Status: Complete

Patent Status

Development Stage : Prototype Development

Technical Category: Industrial Processes

Recv by NIST: $01 / 10 / 83$

Recom. by NIST : $03 / 23 / 84$

Award Date $\quad 01 / 29 / 85$

Contract Period: 01/29/85

Award Amount: $\$ 74,700$ Grant No: FG01-85CE15201

- $07 / 29 / 86$
Contact:

Daniel Douenias

Gim Metal Products, Inc.

164 Glen Cove Road

Carle Place NY 11514

516-741-3005

Status Date: 09/30/86

OERI No.: 009327

Summary:

A grant was awarded to build and test a prototype under actual foundry conditions. Invention saves $66 \%$ of fuel formerly required for the same operation. Grantee plans to license technology to competitors. 
DOE No: 0255

DOE Coord: G.K.Ellis

Title: Method and Apparatus for Scrubbing Gas - Scrubbing Apparatus

Description: A patented stack gas scrubber which contains a rotatable impeller to duplicate high energy venturi scrubber performance and which is claimed, as a result of test, to use $50 \%$ the power consumption.

Inventor: Arthur F Stone

State : NJ

Contact:

Arthur $\dot{F}$ Stone

Status: No DOE Support

Status Date: 11/13/91

OERI No.: 009806

Patent Status : Patent Number: 4289506 and others

Development Stage : Prototype Test

Technical Category: Industrial Processes

Recv by NIST : $11 / 03 / 83$

Recom. by NIST : $03 / 27 / 84$

Summary:

This decision reached after several unacceptable proposals have been received from the inventor, and many unsuccessful attempts have been made to negotiate with him, being unable each time to reach agreement as to what constituted an acceptable proposal that DOE could support.

DOE No: 0256

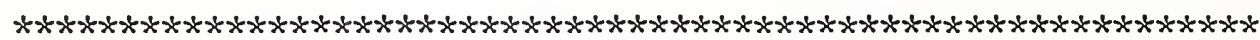
DOE Coord: J.Aellen

Title: Method and Apparatus for Irrigating Container Grown Plants

Description: A method and apparatus for irrigating container grown plants.

Inventor: Evert $S$ Green

State : NY

Contact:

Evert S Green

Status: Other Assistance

Status Date: 09/30/89

OERI No.: 009696

Patent Status : Patent Number: 4245434 and others

Development Stage : Production \& Marketing -

Technical Category: Miscellaneous

Recv by NIST : 09/14/83

Recom. by NIST : 04/25/84

Summary: Referred to NATAS for licensing assistance. 
DOE No: 0257

DOE Coord: A.R.Barnes

Title: Method and Apparatus for Melting Snow Description: A process to remove snow from city streets by melting instead of hauling to
dump sites.

Inventor: Richard $\mathrm{H}$ Baasch

State : NE

Contact:

Richard $\mathrm{H}$ Baasch

Post Office Box \#1013

Grand Isle NE 68802

$308-382-5749$

Status: Complete

Status Date: 08/25/86

OERI No.: 009758

Patent Status

Patent Applied For

Development Stage : Production Engineering

Technical Category: Miscellaneous

Recv by NIST: $10 / 07 / 83$

Recom. by NIST : $04 / 30 / 84$

Award Date : 08/26/85

Contract Period: 08/26/85

Award Amount: $\$ 60,492$ Grant No: FG01-85CE15204

- $08 / 25 / 86$

Summary:

A grant was awarded to build and test three prototypes in cooperation with various municipalities. Technology shelved on basis of cost effectiveness.

DOE No: 0258

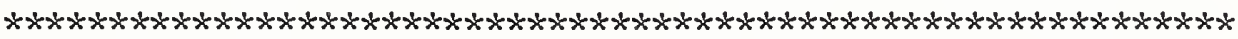

DOE Coord: J.Aellen

Title:

Corrosion Protection Process for Bore Hole Tool

Description: A process for providing an aluminum alloyed surface on iron-base alloys for down-hole tools and parts for improved corrosion resistance replacing more expensive alloys such as chromium and nickel-based alloys and others. This process would be used primarily for parts used in gas and oil wells.

Inventor: Anthony $\mathrm{T}$ Rallis

State : TX

Contact:

Anthony $T$ Raliis

4700 Polo Parkway

Apartment \#103

Midland TX 79705

915-684-8811

Status: Complete

Status Date: 09/30/89

OERI No.: 009525

Patent Status : Disclosure Document Program

Development Stage : Concept Development

Technical Category: Industrial Processes

Recv by NIST: 04/29/83

Recom. by NIST : $05 / 15 / 84$

Award Date : 04/22/85

Contract Period: 04/22/85

Award Amount: $\$ 67,766$ Grant No: FG01-85CE15213

- 04/30/87

Summary:

A grant was awarded to prepare samples suitable for laboratory and field tests. The technology is in limited production. 
DOE No: 0259

DOE Coord: G.K.Ellis

Title: Hydrostatic Support Sleeve and Rod - Gas Release Probe

Description: A mechanism for reducing or eliminating gas-lock problems with oil well pumps.

Inventor: William A Jones

State : CA
Contact:

William A Jones

P O Box \#621

Lotus CA 95651

$916-622-9171$

Status: Complete

Status Date: 07/15/86

OERI No.: 009812

Patent Status : Disclosure Document Program

Development Stage : Prototype Test

Technical Category: Industrial Processes

Recv by NIST : 11/07/83

Recom. by NIST: $05 / 17 / 84$

Award Date : $04 / 15 / 85$

Contract Period: 04/15/85

Award Amount: $\$ 81,220$ Grant No: FG01-85CE15216

- $04 / 04 / 86$

Summary:

A grant was awarded to build and test a prototype in cooperation with oil producing companies. Project completed with average production increase of $24.5 \%$ and average energy saving of $44.3 \%$. Inventor has licensed the technology.

DOE No: 0260

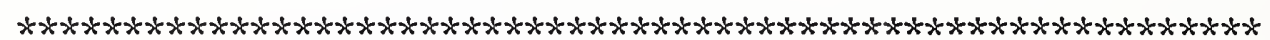
DOE Coord: G.K.Ellis

Title: Method and Apparatus for Handing and Dry Quenching Coke

Description: Method and apparatus for handling and dry quenching coke which is pollution free, producing higher yields of quality coke with a recovery means of sensible heat for a useful purpose.

Inventor: Edward $S$ Kress

State : IL
Contact:

Gene C Carpenter

227 Illinois Street

Brimfield IL 61517

309-446-3395

Status: Complete

Status Date: 08/06/87

OERI No.: 009736

Patent Status

Patent Number: 4285772

Development Stage : Production \& Marketing

Technical Category: Industrial Processes

Recv by NIST : 10/03/83

Recom. by NIST : 05/24/84

Award Date : $05 / 31 / 85$

Contract Period: 05/31/85

Award Amount: $\$ 57,773$ Grant No: FG01-85CE15227

- $08 / 06 / 87$

Summary:

A grant was awarded to build and test a prototype, which has been successfully tested and put in operation. As part of a $\$ 92$ cleanup of Bethlehem Steel's Sparrows Point $\mathrm{plant}$ in Baltimore, MD, the installation of a \$15 million Kress/coke-quenching system will be completed by October, 1991. Major benefits are anticipated in reduced maintenance requirements, increased yield per ton of coal treated, increased energy-saving from the hot coke, improved coke quality, and increased coke oven productivity. 
DOE No: 0261

DOE Coord: G.K.Ellis

Title:

A New Apparatus for Making Asphalt Concrete

Description: An asphalt concrete manufacturing process that reduces energy requirements by recovering the latent heat of vaporization from the moisture removed during the manufacturing process and eliminates air pollution by using modern heat transfer methods.

Inventor: Paul E Bracegirdle

State : PA

Status: Other Assistance
Contact:

Paul E Bracegirdle

Status Date: 09/17/85

Patent Status : Patent Number: 4378162 and others

Development Stage : Production Engineering -

Technical Category: Industrial Processes

Recv by NIST: $09 / 06 / 83$

Recom. by NIST : 05/24/84

Summary: Inventor licensed his technology to a foreign company. There is no further action required of DOE.

DOE No: 0262

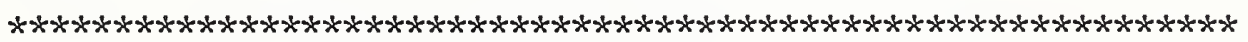

Title: DOE Coord: J.Aellen

Description: A centrifugal pump and pumping system that automatically provide recirculating flow at low output flows when pump cooling is needed and that recovers hydraulic energy in response to reduced output flows.

Inventor: Kai-Chih Cheng

State : WA
Contact:

Kai-Chih Cheng

Innovative Tech Laboratory

- 2339 Davison Avenue

Richland WA 99336

509-582-2660

Status: Complete

Status Date: 09/16/86

OERI No.: 009691

Patent Status

Development Stage : Working Modei

Technical Category: Miscellaneous

Recv by NIST: 09/06/83

Recom. by NIST : 06/20/84

Award Date $\vdots 04 / 17 / 85$

Contract Period: 04/17/85

Award Amount: $\$ 85,837$ Grant No: FG01-85CE15207

- 09/16/86

Summary:

A grant was awarded on to build and test the proposed pump. 
DOE No: 0263

DOE Coord: J.Aellen

Title: Method for Reconditioning Rivetless Chain Links

Description: An upsetting process used to recondition chain links of the type used on industrial conveyors.

Inventor: William Tunderman

State: IL

Status: No DOE Support

: Patent Number: 4229962

Development Stage : Limited Production/Marketing

Technical Category: Industrial Processes

Recv by NIST: $10 / 03 / 83$

Recom. by NIST : 06/22/84

Summary:

Inventor received an award to conduct a market survey from the state of Illinois. Further assistance will be considered by DOE at the completion of the market survey.

\section{Contact:}

William Tunderman

Status Date: 09/18/85 OERI No.: 009849 
DOE No: 0265

DOE Coord: G.K.Ellis

Title: Flozone method and Apparatus for Direct Application of Treatment Liquid to Growing Vegetation

Description: A new type of tractor-mounted applicator that wipes herbicide onto growing

Inventor: John W Richardson

State : LA
Contact:

John W Richardson

J Sherman Richardson

Route Three, Box \#81

Colfax LA 71417

$318-627-9171$
Status: Complete

Patent Status

Development Stage : Prototype Development

Technical Category: Industrial Processes

Recv by NIST: 01/06/84

Recom. by NIST : 07/18/84

Award Date : $07 / 15 / 86$

Contract Period: 07/15/86

Summary :

A grant was awarded to build and test a prototype. Inventor was given an additional awarded in view of some unanticipated development problems encountered. A production prototype was completed and is in the market place. Compared to the alternative technologies, Flozone's cost is less than half the cost for the wick method and about one-fifth the cost of overtop spray. Inventor is being helped to find licensing or joint venture opportunity.

DOE No: 0266

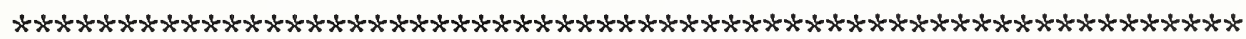
DOE Coord: J.Aellen -

\section{Title:}

Energy Conversion Method

Description: A novel "Heat Pump" using engine-driven compressor and steam ejectors to compress low pressure steam to more useful levels.

Inventor: Dan Egosi

Country: Israel

Status: Other Assistance
Contact:

Dan Egosi

Patent Status : Patent Number: 4282070

Development Stage : Concept Development

Technical Category: Buildings, Structures \& Components

Recv by NIST : 01/06/83

Recom. by NIST $\vdots 08 / 22 / 84$

Summary: Inventor needs licensing help; DOE sent him names of appropriate companies in the U.S. to be contacted for licensing. 
DOE No: 0267

DOE Coord: J.Aellen

Title: Integrated Gasification of Coal, Municipal Solid Wastes and Sludge

Description: Hardware and a process for gasifying coal, solid wastes and sewage sludge.

Inventor: Shang-I Cheng

State: NJ

Status: Complete

Patent Status

Development Stage : Prototype Development

Technical Category: Industrial Processes

Recv by NIST: 05/23/83

Recom. by NIST $\quad 08 / 22 / 84$

Award Date $\quad 05 / 10 / 85$

Contract Period: 05/10/85

Summary:

- 06/09/87
A grant was awarded to perform laboratory tests, computer simulation and preliminary design.
Contact:

Shang-I Cheng

Seventeen Woodsend Drive

Matawan NJ 07747

$212-254-6300$

Award Amount: $\$ 70,000$ Grant No: FG01-85CE15222

Status Date: 06/09/87 OERI No.: 009565 
DOE No: 0269

DOE Coord: G.K.Ellis

Title:

Refrigerant Accumulator and Charging Apparatus

Description: An accumulator-charger installed in the suction line of a vapor-compression refrigeration unit. It provides for accumulation of liquid refrigerant/oil thereby preventing liquid refrigerant from bring drawn into the compressor, and intended to prevent overcharging or undercharging the refrigerant system.

Inventor: Richard J Avery, Junior State : TX

Status: No DOE Support

Status Date: 09/30/91

Contact:

Richard J Avery, Junior

Development Stage

Technical Category

: Patent Applied For

Limited Production/Marketing

Buildings, Structures \& Components

Recv by NIST: $02 / 07 / 84$

Recom. by NIST : 08/30/84

Summary:

Inventor attended commercialization workshop, Leesburg, VA. The technology is being marketed by other parties :-
DOE No: 0270

Title:

Description:

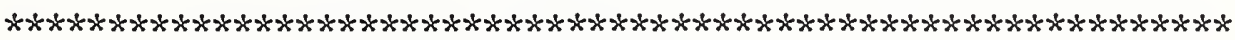
DOE Coord: G.K.Ellis

Method of Energy Recovery for Wastewater Treatment

A process and apparatus to recover available hydraulic energy for wastewater aeration by using a specially designed hydraulic gas compressor.
Inventor: Shih-Chih Chang

State : WA
Contact:

Shih-Chih Chang

2339. Davison Avenue

Richland WA 99352

$509-582-2664$
Status: Complete

Patent Status Development Stage

Technical Category:

Recv by NIST : 10/13/83

Award. by NIST : $09 / 07 / 84$

Award Date : 04/05/85

Contract Period: 04/05/85

Summary:
A grant was awarded to optimize the variables in a bench-scale test set-up. The inventor has prepared and instrumented this test set-up. He has conducted tests to determine optimum process variables. 
DOE No: 0271

DOE Coord: G.K.Ellis

Title: Hydrogen Storage System

Description: A new geometric design hydrogen storage system for rapid heat cycling, using metal hydride systems in finned tubes.

Inventor: William B Retallick

State : PA

Status: Complete

Patent Status

Development Stage :

Technical Category:
Contact:

William B Retallick

1432 Johnny's Way

West Chester PA 19380

215-399-1371

Recv by NIST: 10/04/83

Recom. by NIST : 09/26/84

Award Date : 06/21/85

Contract Period: 06/21/85

Award Amount: $\$ 50,338$ Grant No: FG01-85CE15230

Status Date: 07/15/86

OERI No.: 009734

Summary:

A grant was awarded to build and test a prototype storage system. Results were encouraging, prompting new research initiative. EPRI is presently actively sponsoring the technology, and seeks to transfer it to industry. Inventor has recently obtained DOE/SBIR Phase I support as a spinoff of this invention.

DOE No: 0272

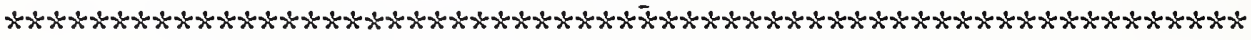

DOE Coord: P.M.Hayes

Title:

$\mathrm{V}$-Plus System

Description: A method to cool lubricating oil in a positive displacement rotary screw compressor. A variable speed pump injects liquid refrigerant into the compressor discharge line.

Inventor: Robert M Roeglin

State : WI

Contact:

Robert M Roeglin

2217 South First Street

Milwaukee WI 53207

414-744-0111

Status: Complete

Status Date: 12/31/88

OERI No.: 009730

Patent Status : Patent Number: 4275570

Development Stage : Production \& Marketing

Technical Category: Buildings, Structures \& Components

Recv by NIST: $09 / 14 / 83$

Recom. by NIST : 09/27/84

Award Date : $02 / 24 / 87$

Contract Period: 02/24/87

Award Amount: $\$ 149,986$ Grant No: FG01-87CE15245

$-12 / 31 / 88$

Summary: Grants were awarded to: 1) to test the lubricant cooling system at the Herrick Laboratory at Purdue University and 2) to concurrently test DOE \#284 Atomized oil-Injected Rotary Screw Compressors. Test results were inconclusive due to the low oil flow rate used. The -V-Plus system is commercially available from Viltes Manufacturing Corporation. 
DOE No: 0273

DOE Coord: P.M.Hayes

Title: Open Cycle Latent Heat Engine

Description: A novel engine that uses relatively low temperature water as a heat source.

Inventor: Julius Czaja

State : NY

Status: No DOE Support
Contact:

Julius Czaja

Status Date: 09/13/85 OERI No.: 009866

Patent Status : Patent Number: 4106294

Development Stage : Concept Development

Technical Category: Combustion Engines \& Components

Recv by NIST: $12 / 07 / 83$

Recom. by NIST : 09/27/84

Summary:

DOE had two meetings and several telephone conversations with the inventor. He cannot decide what course of action to follow. No work proposal has been submitted by the inventor.

DOE No: 0274

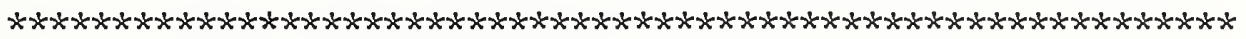
DOE Coord: T.M.Levinson

Title: Flexible Lighting - Fluorescent Lighting Operating at Radio Frequency

Description: A lighting system consisting of electrodeless gas-containing capsules, strung in a clear plastic tubular jacket. The capsules are excited by standing waves produced by a radio frequency generator.

Inventor: Nathan E Passman

State : CO
- Contact:

Nathan E Passman

Illuminating Technology Corp

2516 Forty-Ninth Street

Unit Six

Boulder CO 80301

$303-440-4486$
Status: Complete

Patent Status

Development Stage

Technical Category:

Recv by NIST

Recom. by NIST : $09 / 31 / 80$

Award Date $\vdots 09 / 30 / 85$

Contract Period: 09/30/85

Award Amount: $\$ 79,590$ Grant No: FG01-85CE15244

Status Date: 05/28/87

OERI No.: 007911

Summary:

A one-year grant was awarded to design, build, and demonstrate the unique lighting system. Bridge structures and coal mine passageways will be the first two applications. An unsatisfactory report was received on May 28 th, 1987. 
DOE No: 0275

DOE Coord: J.Aellen

Title: Low Head - High Volume Pump

Description: A low-head, high volume double-acting piston pump for use in wind-driven water pumping stations.

Inventor: Don E Avery

State: HI

Status: Complete

Patent Status

Development Stage :

Technical Category:

Recv by NIST : 04/23/84

Recom. by NIST : $10 / 15 / 84$

Award Date : 06/04/86

Contract Period: 06/04/86

Summary:

A grant was awarded to design and demonstrate a low-head, high-volume pump. The County of Maui in Hawail is cost-sharing. See recommendation \#301 for related work. First season test proved concept. Winter 1986, tested 2nd generation product. Present throughput rate uneconomical in urban test. Device installed and working successfully on U. S. Fish and Wildlife bait pond in Hawaii. Grant work not completed. No final report available.

DOE No: 0276

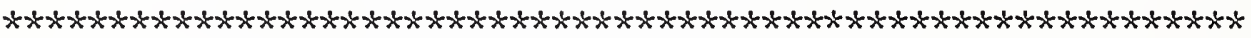

Title: DOE Coord: J.Aellen

Description:

Gas Concentration Cells as Converters of Heat into Electrical Energy

electricity electricity

Inventor: Robert E Salomon

State : PA

Status: Complete

Status Date: 09/30/87

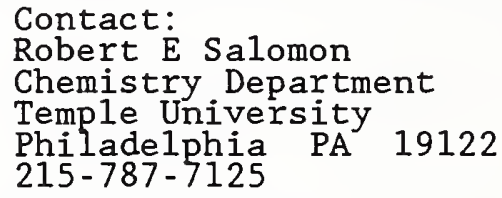

Robert E Salomon

Chemistry Department

215-787-7125

Patent Status : Not Applied For

Development Stage : Concept Development

Technical Category: Fossil Fuels

Recv by NIST: $09 / 27 / 83$

Recom. by NIST : $10 / 25 / 84$

Award Date $\vdots 06 / 01 / 85$

Contract Period: 06/01/85

Award Amount: $\$ 79,957$ Grant No: FG01-85CE15218

$-09 / 30 / 87$

Summary:

A grant was awarded on to Temple University for building and testing a
prototype model. 
DOE No: 0277

DOE Coord: J.Aellen

Title:

Electronic Conveyor Control Appäratus Description: Electronic conveyor control, U.S. Patent Number: 372,439 dated February 8 ,
1983, describes an automatic start/stop system for conveyor belts. Tests in three post offices over two 30 day periods (with and without the control) show a $50 \%$ reduction in energy used to drive the belts. No proposal submitted.

Inventor: Guy C Dempsey

State : VA

Status: No DOE Support
Contact:

Smart Technologies, Inc

Status Date: 09/30/90

Patent Status : Patent Number: 4372439

Development Stage : Limited Production/Marketing

Technical Category: Industrial Processes

Recv by NIST: $06 / 08 / 84$

Recom. by NIST : $11 / 23 / 84$

Summary: $\quad$ No proposal received.

DOE No: 0278

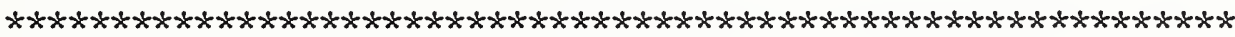

DOE Coord: P.M.Hayes

Title:

Complete System for Large Solar Water Heating and Storage

Description: An integrated system of solar collection and thermal storage for service water heating. It is a large- scale water heating system utilizing a heat pipe arrangement to extract thermal energy from an air-based solar collector.

Inventor: James M Stewart

State : SC

Status: Complete

Patent Status

Development Stage

Technical Category:

Recv by NIST

Recom. by NIST : $11 / 29 / 84$

Award Date : $06 / 27 / 85$

Contract Period: 06/27/85
Contact:

James M Stewart

115 Sylvan Way Greenville SC 29605

803-242-9492

Summary:

Award Amount: $\$ 71,581$ Grant No: FG01-85CE15223

\author{
Status Date: 08/07/87 OERI No.: 009238
}

Patent Number: 4340033 and others

Production Engineering

Direct Solar

- $06 / 26 / 87$

A grant was awarded to build and test a prototype solar water heating system. Grant objectives were successfully completed. Technology featured in the NASA Spinoff 88 publication. 
DOE No: 0279

DOE Coord: P.M.Hayes

Title: Method and Means for Preventing Frost Damage to Crops

Description: A mobile machine for preventing frost damage to crops by taking in warmer air from above crop level, heating the air slightly with a burner, and blowing the air horizontally through the crops at low level.

Inventor: Douglas R Reich

State: FL

Status: Complete

Patent Status

Development Stage : Working Model

Technical Category: Industrial Processes

Recv by NIST : $01 / 29 / 83$

Recom. by NIST : $11 / 29 / 84$

Award Date : $08 / 26 / 85$

Contract Period: 08/26/85

Summary:

A grant was awarded to fabricate, test and evaluate a new prototype. Field tests were conducted in conjunction with the University of Florida. The inventor leased a 7800 square foot production facility and has had sales in excess of $\$ 3$ million.

DOE No: 0280

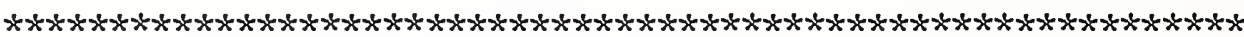
DOE Coord: J.Aellen

Title: Down Hole and Above Ground Resistance Heating for Paraffin Elimination

Description:

A method for removing paraffin from down-hole oil well tubing by use of resistance heating induced in the tubing to heat and melt the paraffin.

Inventor: Andrew W Marr, Junior

State : OK

Status: Complete

Status Date: 09/22/86

Contact:

Andrew $\dot{W}$ Marr, Junior

P O Box \#1464

Ardmore OK 73401

405-657-4202

Patent Status

Development Stage :

Technical Category:

Patent Number: 4303128 and others

Prototype Test

Fossil Fuels

Recv by NIST : 04/19/83

Recom. by NIST : $11 / 30 / 84$

Award Date $\quad 08 / 28 / 85$

Contract Period: 08/28/85

Award Amount: $\$ 58,286$ Grant No: FG01-85CE15220

Summary: A grant was awarded to 
DOE No: 0281

DOE Coord: J.Aellen

Title:

Sun Synchronous Solar Powered Refrigerator

Description: Photovoltaic powered refrigerator. Key features are durability, good insulation, efficient vapor/compression cycle, thermal storage, low cost, and sun synchronous operation without the use of batteries.

Inventor: Arthur D Sams

State : CA
Contact:

Arthur D Sams

Polar Products

2908 Oregon Court I-11

Torrance CA 90503

$213-320-3514$

Status Date: 11/12/86 OERI No.: 010256

Status: Complete

Not Applied For

Patent Status

Development Stage : Prototype Development

Technical Category: Buildings, Structures \& Components

Recv by NIST: $07 / 02 / 84$

Recom. by NIST : $12 / 18 / 84$

Award Date: $08 / 12 / 85$

Contract Period: 08/12/85

Award Amount: $\$ 69,415$ Grant No: FG01-85CE15219

- $12 / 11 / 86$

Summary:

A grant was awarded to build and test a prototype. Recipient contributed $\$ 24,960$ in addition to the grant.

DOE No: 0282

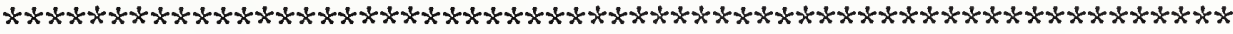

DOE Coord: J.Aellen

Title: Insulated Siding

Description: An insulated siding for use on houses. Both vinyl and aluminum siding are fabricated with urethane foam averaging 1/2" thick and lined with aluminum foil backing.

Inventor: Eugene Tippmann

State : IN
Contact:

Robert J Koester

Ball State University

Ctr for Energ Res \& Ed Svcs

Muncie IN 47306

$317-285-1135$

Status Date: 09/30/86 OERI No.: 010002

Patent Number:

Prototype Development

Buildings, Structures \& Components

Patent Status

Technical Category:
Recv by NIST $: 02 / 28 / 84$

Recv by NIST $: 02 / 28 / 84$

Award Date : $08 / 29 / 85$

Contract Period: 08/29/85

Award Amount: \$ 57,798 Grant No: FG01-85CE15240

$-09 / 30 / 86$

A grant was awarded to Ball State University to build and test prototype insulated sidings. 
DOE No: 0283

DOE Coord: P.M.Hayes ${ }^{-}$

Title: Aluminum Roofing Chips

Description: A reflective coating for application to built-up roofing. Aluminum chips are spray-applied to surfaces with good adhesion.

Inventor: Tom Atterbury

State: $\mathrm{OH}$

\author{
Contact: \\ Donald Cullen \\ Transmet Corporation \\ 4290 Perimeter Drive \\ Columbus $\mathrm{OH} 43228$ \\ $614-276-5522$
}

Status: Complete

Patent Status

Development Stage : Working Modei

Technical Category: Buildings, Structures \& Components
Recv by NIST : 05/17/84

Recom. by NIST : $12 / 18 / 84$

Award Date : $06 / 27 / 85$

Contract Period: 06/27/85
Status Date: $08 / 07 / 87$

OERI No.: 010182

Summary:

Award Amount: $\$ 78,878$ Grant No: FG01-85CE15232

- $02 / 01 / 87$

A grant was awarded to optimize the size, shape and composition of the aluminum roofing chip system. Tests showed $30-40 \%$ energy saving in summer due to the high reflectivity of the Al chips and 108 savings in winter due to low emissivity. The product is gaining acceptance in the market. The company expects several million dollars_in sales in 1990.

DOE No: 0284

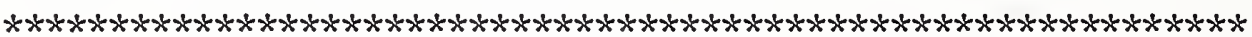
DOE Coord: P.M. Hayes

Title:

Atomized 0il-Injected Rotary Screw Compressors

Description: An atomized oil-injection system to improve the power and volumetric efficiencies of the rotary compressors.

Inventor: Anthony $\mathrm{N}$ Fresco

State: NY

Status: Complete

Patent Status

Development Stage

Technical Category: Buildings, Structures \& Components
Recv by NIST: $08 / 22 / 83$

Recom. by NIST : $01 / 24 / 85$

Award Date : 02/24/87

Contract Period: 02/24/87
Award Amount: $\$ 149,986$ Grant No: FG01-87CE15245

Award Amount
Contact:

Anthony $N$ Fresco

Post Office Box \#734

Upton NY 11973

$516-282-7214$

Summary:

A grant was awarded for two purposes: (1) to test the atomized oil injection concept for improved efficiency at Purdue University's Herrick Laboratory and (2) to test concurrently ERIP \#272, the V-Plus System. The oil injection system was found to improve the volumetric efficiency. Inventor seeking independent financial backing to prepare for licensing negotiation with manufacturers. 
DOE No: 0285

DOE Coord: T.M.Levinson

Title: Novel Fluid Ring (F/R) Seal Systems for Railroad Axle Bearing Systems

Description: A lubricant seal for railroad car axle bearings, the seal having no direct frictional contact between rotating and non-rotating parts and depending on dynamic effects for sealing.

Inventor: Hermann Ernst

State : CT
Contact:

- Hermann Ernst

Ernst Mechanical Devices

20 Crowley Drive

old Saybrook CT 06475

$203-722-5477$

Status: Award

Status Date: 09/30/91

OERI No.: 010167

Patent Status : Patent Number:

Development Stage : Laboratory Test

Technical Category: Transportation Systems, Vehicles \& Components

Recv by NIST: 05/10/84

Recom. by NIST : $01 / 25 / 85$

Award Date: :06/03/87

Contract Period: 06/03/87

Award Amount: $\$ 72,000$ Grant No: FG01-87CE15334

$-06 / 01 / 90$

Summary:

A grant was awarded to design a fluid-ring seal and test it in actual operation on a Burlington Northern railcar. testing was successful. Discussions regarding licensing are still underway with an American manufacturer of railroad wheel bearings and seals. The inventor applied for a patent for a simplified version of his prototype design that also prevents damage to railroad axles. He has considered applying the design of the seal system to over-the- road trucks and stationary machinery.

DOE No: 0286

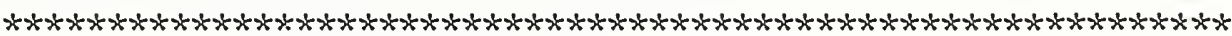

DOE Coord: G.K.Ellis

Title:

Use of Pulse-Jet for Atomization of Coal/Water Mixture

Description: Propane or a fuel gas is burned In a pulse-jet. The pulse-jet exhaust is used aerodynamically to atomize a stream of a coal-water mixture injected into a large steam boiler combustor.

Inventor: Momtaz N Mansour State : MD

Status: No DOE Support

Patent Status

Development Stage

Technical Category:

Not Applied For

Concept Development

Buildings, Structures \& Components

Recv by NIST: $08 / 02 / 84$

Recom. by NIST : 01/25/85

Summary:
Contact:

Momtaz $\dot{\mathrm{N}}$ Mansour

Status Date: 12/23/91 OERI No.: 010313

In lieu of an ERIP grant, inventor received contract from Pittsburgh energy Technology Center, A DOE Laboratory, to support the subject technology. 
DOE No: 0287

DOE Coord: J.Aellen

Title: Automatic Variable Pitch Marine Propeller

Description: A variable geometry marine propeller having the blades pivoted and balanced so as to automatically adjust propeller pitch, diameter, and basic area ratio in response to shaft speed and hydrodynamic load, thereby enabling the driving engine to function at optimum RPM and fuel efficiency over a broad range of huIl speeds and ladings.

Inventor: Don J Marshall

State : MD

\section{Contact:}

Don J Marshall

1087 Rodgers Road

P O Box \#159

Churchton MD 20733

301-867-2135

Status: Complete

Status Date: 12/15/87

OERI No.: 010259

Patent Status

Development Stage : Prototype Test

Technical Category: Transportation Systems, Vehicles \& Components

Recv by NIST: 06/26/84

Recom. by NIST : 01/25/85

Award Date : 09/06/85

Contract Period: 09/06/85

Award Amount: $\$ 41,593$ Grant No: FG01-85CE15243

- $12 / 15 / 87$

Summary:

A grant was awarded to build and test the proposed propeller. The test took place at Mississippi State University in cooperation with Sea Grant Advisory Service.

DOE No: 0288

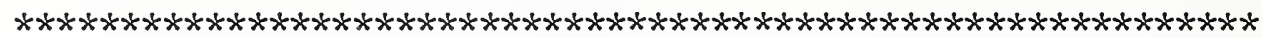
DOE Coord: G.K.Ellis

Title: Dickinson Pure Air Combustion (DIPAC) and Modified DIPAC (MODIPAC)

Description: A method of burning coal or coal/water/mixture at high pressure without resultant air pollution.

Inventor: Norman L Dickinson

State : CA

Status: No DOE Support

Patent Status

Development Stage :

Technical Category:

Recv by NIST

Recom. by NIST : 01/30/85

Summary:
The inventor attended Commercialization Planning Workshop. Unable to establish definitive marketing need.
Contact:

Norman $\dot{L}$ Dickinson

Status Date: 08/06/87

OERI No.: 010307
Patent Number: 4380960 and others

Engineering Design
Buildings, Structures \& Components 
DOE No: 0289

DOE Coord: P.M.Hayes

Title:

An Earthquake Barrier

Description: A concept to absorb the energy of an earthquake with bilinear force-deflection devices at the foundation of a building, thereby providing positive protection against inelastic distortions that cause building damage. This concept is claimed to avoid damage to the buildings during an earthquake and save human life.

Inventor: Marc S Caspe

State : CA

Status: Complete

Status Date: 01/09/87

Contact:

Marc S Caspe

1640 Oakwood Drive

San Mateo CA 94403

$415-573-8888$

Patent Status

Development Stage : Engineering Design

Technical Category: Buildings, Structures \& Components

Recv by NIST: 07/26/84

Recom. by NIST : 02/28/85

Award Date : $01 / 10 / 86$

Contract Period: 01/10/86

Award Amount: $\$ 68,749$ Grant No: FG01-86CE15250

- $01 / 09 / 87$

Summary: A grant was awarded to perform a conceptual study of the earthquake barrier's configuration, preliminary design, construction schedule and estimate of construction costs for four retrofit projects. An additional $\$ 31,745$ was awarded on July 28, 1986, to conduct shake table tests on the technology. Japanese architectural and construction firms have taken the lead in developing this type of technology. DOE Coord: J.Aellen

Title:

Low Energy Ice Making Apparatus

Description: In this ice-making apparatus, ice is progressively formed on evaporator plates and harvested by a secondary condenser grid heated by the warm liquid refrigerant discharged by the primary water cooler condenser.

Inventor: Jerry Aleksandrow

State : IL

\author{
Contact: \\ Greg Ross \\ Universal Ice Machine Mfg \\ 900 Jorie Boulevard \\ Suite Seventy-Two \\ Oakbrook IL 60521 \\ $312-990-1111$
}

Status: Complete Status Date: 05/20/87 OERI No.: 009807

Patent Status : Patent Number: 4357807

Development Stage : Limited Production/Marketing

Technical Category: Miscellaneous

Recv by NIST: 11/03/83

Recom. by NIST : $02 / 28 / 85$

Award Date $\vdots 05 / 21 / 86$

Contract Period: 05/21/86

Award Amount: $\$ 62,500$ Grant No: FG01-86CE15258

Summary: A grant was awarded to compare efficiency and safety with comparable machines. The testing program was not started. No final report submitted. 
DOE No: 0291

DOE Coord: G.K.Ellis

Title:

Selective Zone Isolation for HVAC System

Description: A method for controlling air flow from a central HVAC system in a programmed way so that only selected zones within a building receive air flow during specified time periods

Inventor: Jerry Tartaglino

State : TX

Status: Complete

Patent Status

Development Stage:

Technical Category:
Recv by NIST

Recom. by NIST:

Award Date

Contract Period:

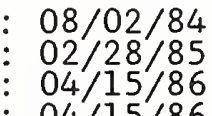

$04 / 15 / 86$
- Contact:

Jerry Tartaglino

4911 West Hanover

Dallas TX 75209

214-357-2665

Summary: An award was granted to build and demonstrate a prototype. A Phase II grant was awarded to build an advanced prototype. The prototype was completed and tested satisfactorily. The inventor is now actively marketing the invention and has it in production.

DOE No: 0292

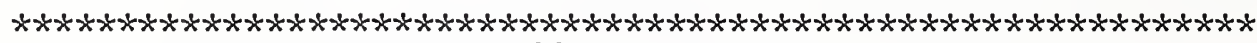
DOE Coord: J.Aellen

Title: $\quad$ Roof Construction Having Membrane and Photo Cells

Description: A building roof construction that also serves as a substrate, electrical interconnection, and protective covering for an array of flexible voltaic elements intended to generate electrical power for use in the building or elsewhere.

Inventor: Thomas F Francovitch

State : MD

Status: Complete

Patent Status

Development Stage :

Recv by NIST

Recv :07/19/84

Recom. by NIST : $02 / 28 / 85$

Award Date : 08/26/85

Contract Period: 08/26/85

Summary:
A grant was photocells.
Contact:

Thomas $\dot{F}$ Francovitch

216 Circle Road

Pasadena MD 21122

$301-437-3727$

Status Date: 08/25/86

OERI No.: 010297

Patent Applied For

Laboratory Test

Direct Solar

Award Amount: $\$ 40,130$ Grant No: FG01-85CE15239

- $08 / 25 / 86$ awarded to perform laboratory tests on the roof membrane and
Award Amount: $\$ 90,769$ Grant No: FG01-86CE15261 
DOE No: 0293

DOE Coord: J.Aellen

Title: "Therm-A-Valve" - Insulated Valve Coverings

Description: A solar powered system to keep critical flow control valves from freezing on gas wells during cold weather.

Inventor: Randell D Ball

State : OK

Status: Complete

Patent Status

: Patent Applied For

Development Stage : Limited Production/Marketing

Technical Category: Fossil Fuels

Recv by NIST: 04/24/84

Recom. by NIST $\vdots 03 / 29 / 85$

Award Date : 01/15/86

Contract Period: 01/15/86

Summary:

A grant was awarded to build and test prototype valve covers, first in the laboratory and then in the field, under actual conditions. No-cost grant extension for 1 year expired January 31, 1990. No final report.
Contact:

PFI, Inc

128 Northwest 67 th Street

Oklahoma City
405-354-4584 73116
DOE No: 0294

Title:

Description:

Inventor:

State

$\mathrm{CA}$

Status: Complete

Status Date: 08/15/86

DOE Coord: G.K.Ellis

Highway Power Patcher

A portable self-propelled pavement patching machine which blows debris from a distressed area of pavement, mixes and applies an unheated crushed rock and asphalt patching material, and compacts the patch by means of a roller.

\section{Patent Status}

Technical Category: Industrial Processes

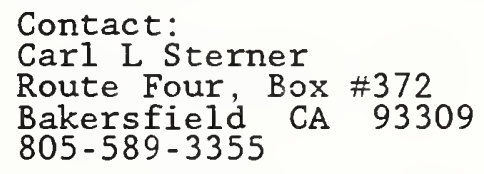

Recv by NIST: $03 / 20 / 84$

Recom. by NIST : $03 / 29 / 85$

Award Date $\vdots 08 / 15 / 85$

Contract Period: 08/15/85

Summary: A grant was awarded to build and test a self-propelled highway pavement patching machine. Mr. Sterner has received numerous inquiries about his machine from all over the U.S. and seeks to license the technology.

Award Amount: $\$ 60,031$ Grant No: FG01-85CE15241

- $08 / 15 / 86$

Award Amount: $\$ 56,193$ Grant No: FGOI-86CE15254 
DOE No: 0295

DOE Coord: J.Aellen

Title: Improved Method of Electroplating Aluminum for Corrosion Resistance

Description: A method for electroplating ferrous metals with aluminum for improved corrosion resistance.

Inventor: J Paul Pemsler

State: MA

Status: Complete

Patent Status

Development Stage :

Technical Category:
Contact:

J Paul Pemsler

Castle Technology Corporation

Fifty-Two Dragon Court

Woburn MA 01801

617-933-5634

Recv by NIST : 05/21/84

Recom. by NIST : 03/29/85

Award Date : 08/28/85

Contract Period: 08/28/85

Award Amount: $\$ 69,000$ Grant No: FG01-85CE15236

- $02 / 27 / 87$

Summary: A grant was awarded to build and test a prototype.

DOE No: 0296

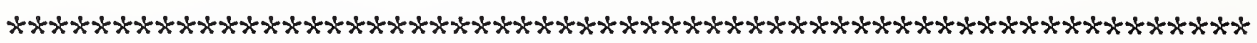

DOE Coord: P.M.Hayes

Title:

Shower Bath Economizer

Description:

A heat exchanger installed at a shower-bath or tub drain which transfers heat from the drain water to the incoming cold water, thereby reducing the amount of energy required to heat the water.

Inventor: Raymond Hunter

State: TN

Status: Complete

Patent Status

Development Stage : Production Engineering

Technical Category: Buildings, Structures \& Components

Recv by NIST : 04/26/83

Recom. by NIST : $03 / 29 / 85$

Award Date :02/01/86

Contract Period: 02/01/86

Summary:

- $07 / 31 / 86$

Status Date: 07/31/86
Award Amount: $\$ 58,000$ Grant No: FG01-86CE15251

Contact:

Raymond Hunter

Chattanooga TN 37404

OERI No.: 009516

A grant was awarded for the final design and development of the shower bath economizer. Test results were not reported to DOE. 
DOE No: 0297

DOE Coord: J.Aellen

Title: Series (Two-Wire) V-Controller

Description: An electronic light dimmer for fluorescent lamps, that will mount in a single two-wired switch box without the need for re-wiring or replacing conventional lamp ballasts with "dimming" ballasts.

Inventor: $\mathrm{E} M$ Talbott

State : $\mathrm{MD}$

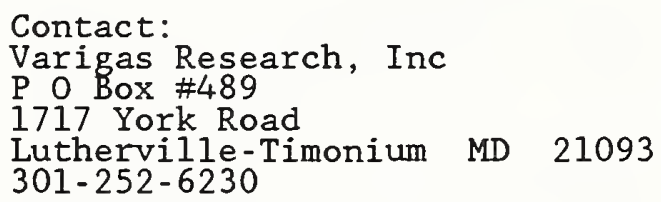

Status Date: 10/01/88

OERI No. : 010261
Status: Complete

Patent Status Development Stage: Patent Applied For

Technical Category: Buildings, Structures \& Components

Recv by NIST: 07/05/84

Recom. by NIST $\vdots 03 / 29 / 85$

Award Date : $08 / 19 / 85$

Contract Period: 08/19/85

Award Amount: $\$ 70,785$ Grant No: FG01-85CE15233

- $10 / 01 / 88$

Summary: A grant was awarded to design and build a prototype. Tests will be conducted in phase II.

DOE No: 0298

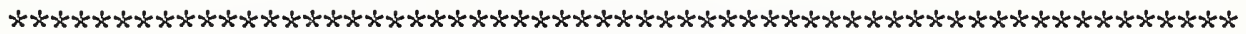

DOE Coord: J.Aellen

Title: Three Tenths Degree Kelvin Closéd Cycle Refrigeration System

Description: Closed-cycle refrigeration system to provide cooling to 0.3 Kelvin. Does not consume helium or other liquid cryogens.

Inventor: David L Swartz

State : AZ

Status: Complete

Patent Status

Development Stage : Concept Development

Technical Category: Buildings, Structures \& Components

Recv by NIST

Recom by NIST : 06/28/84

Award Date : $04 / 05 / 86$

Contract Period: 04/05/86

Summary: A grant was awarded to build and test a prototype.
Contact:

David L Swartz

Cryosystems, Inc.

1802 West Grant, Suite \#122

Tucson AZ 85745

$602-882-4628$

Status Date: 11/05/87

OERI No.: 010254

Award Amount: $\$ 63,500$ Grant No: FG01-85CE15248

- $11 / 05 / 87$

awarded to br 
DOE No: 0299

DOE Coord: G.K.Ellis

Title: Process for Using Cocurrent Contacting Distillation Column

Description: A new fractionator tray design which achieves higher distillation column output through high-velocity cocurrent vapor-liquid flow in the zones between the trays.

Inventor: William R Trutna

State : TX

Contact:

William $R$ Trutna

2213 Fenwood

Pasadena TX 77502

$713-472-5098$

Status: Complete

Status Date: 09/30/88

OERI No.: 009873

Patent Status : Patent Number: 4361469

Development Stage : Engineering Design

Technical Category: Industrial Processes

Recv by NIST : 12/07/83

Recom. by NIST : $04 / 19 / 85$

Award Date : 09/17/86

Contract Period: 09/17/86

Award Amount: $\$ 74,192$ Grant No: FG01-86CE15296

- $09 / 30 / 88$

Summary: A grant was awarded to build and demonstrate a workable prototype. Tests were completed satisfactorily at the University of Texas Separation Center, showing a $30 \%$ improvement in separations efficiency. The inventor seeks to license the technology.

DOE No: 0300

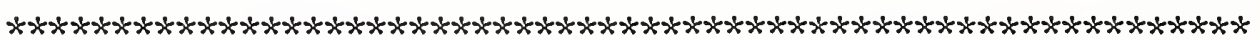
DOE Coord: G.K.Ellis

Title: Casing Stabbing Apparatus

Description: A retrofittable hardware design for the rapid alignment of well casing sections during rig operations to prevent thread damage due to misalignment and cross threading.

Inventor: James McArthur

State : OK

Status: Complete

Patent Status

Development Stage:

Technical Category:

Recv by NIST

$: 05 / 25 / 84$

Recom. by NIST : 04/30/85

Award Date : 07/18/86

Contract Period: 07/18/86
A grant was awarded to design, build and test a prototype. The prototype was completed and successfully tested. Inventor has sold the invention to Okie-Yoke, Inc., P. O. Box 105, Lindsay, OK 73052 (405/756-2188), which markets the invention as "Okie-Yoke". 
APPENDIX A 

CODE TITLE

1.00000

1.01000

1.10000

1.11000

1. 11100

1.11200

1. 11300

1.11400

1. 12000

1. 12100

1.12200

1.12300

1. 12400

1.13000

1.13100

1.14000

1. 14100

1.20000

1. 21000

1. 22000

1. 23000

1. 24000

1.25000

1. 26000

1. 27000

1.28000

1. 28100

1.29000

1. 30000

1. 40000

2.00000

2.10000

2.11000

2.12000

2.13000

2.14000

2.15000

2. 20000

2. 21000

2.30000

2.40000

2.41000

2.42000

2.50000

2.51000

2.60000

2. 61000

2.62000

2.63000 BIOMASS ADDITIVES SYSTEMS GEOTHERMAL

OCEAN THERMAI

WIND

WIND
CODE

TITLE
ENERGY CONVERSION FROM SECONDARY SOURCES (NOT INCLUDED BELOW)

3.01000

3. 10000

3.10100

3.10110

3.11000

3.11100

3. 12000

3.12100

3.13000

3.13100

3.14000

3.14100

3. 14200

3.14300

3.14400

3. 14500

3.14600

3.15000

3. 20000

3.21000

3. 30000

3.40000

3. 50000

3.51000

BIOENGINEERING AND MEDICAL

MISCELLANEOUS SYNTHETIC PROCESSES

GREASES AND LUBRICANTS

REFINED PETROLEUM PRODUCTS AND

ENERGY CONVERSION FROM NATURAL SOURCES (NOT INCLUDED BELOW)

SOLAR COLLECTORS

SOLAR TO DIRECT MECHANICAL ENERGY

SOLAR ELECTRIC POWER GENERATING

PHOTOVOLTAIC DEVICES

SOLAR CONCENTRATORS - PHOTOVOLTAIC

SOLAR CONCENTRATORS - THERMAL

ELECTRICAL POWER GENERATION

WIND DRIVEN MOTORS \& COMPONENTS

WIND PROCESSES USING ENERGY FROM

WATER POWER PROCESSES (INLAND)

ELECTRICAL POWER GENERATION BY

WATER POWER (INLAND)

OCEAN WATER POWER

WAVE POWER SYSTEMS

TIDAL POWER SYSTEMS

OCEAN CURRENT POWER SYSTEMS
3. 60000

3.61000

3.70000

3.80000

3.90000

4.00000

4.10000

4.11000

4.12000

4.20000

4.30000

4.40000

4.50000

4.60000

5.00000

5.10000

5.20000

5.30000

5.40000

5.41000
ENERGY CONVERSION FROM SECONDARY SOURCES - THERMODYNAMICS

COMBUSTION ENGINES AND COMPONENTS

STIRLING ENGINES, MECHANICAL

STIRLING ENGINES, THERMO

RECIPROCAL ENGINES, MECHANICAL

RECIPROCAL ENGINES, THERMO

ROTARY ENGINES, MECHANICAL

ROTARY ENGINES, THERMO

TURBINE ENGINES, MECHANICAL

TURBINE ENGINES, THERMO

FUEL SYSTEMS, MECHANICAL

CARBURETORS AND MODIFICATIONS

FUEL INJECTORS

WATER INJECTORS

MULTI - FUEL MIXERS

AIR AND OXYGEN INJECTION

COMBUSTION ANALYZERS

IGNITION SYSTEMS

STEAM ENGINES AND TURBINES, MECHANICAI

STEAM ENGINES AND TURBINES, THERMO AIR COMPRESSORS AND MOTORS

HYDRAULIC PUMPS AND MOTORS

ELECTRIC MOTORS AND GENERATORS

MISCELIANEOUS ELECTRIC POWER

GENERATING SYSTEM

CHEMICAL THERMODYNAMICS

PHOTO CHEMICAL

MECHANICAL THERMODYNAMICS

HEAT PUMPS AND REFRIGERATION

HIGHWAY POWER GENERATORS

ENERGY STORAGE AND DISTRIBUTION (NOT INCLUDED BELOW)

ELECTRICAL TRANSMISSION

ELECTRICAL STORAGE (BATTERIES)

ELECTRICAL DISTRIBUTION

(TRANSFORMERS, SWITCHGEARS, CONTROLS)

MECHANICAL ELECTRICAL GENERATION, STORAGE, DISTRIBUTION

THERMAL ENERGY STORAGE

PNEUMATIC ENERGY GENERATION, STORAGE, DISTRIBUTION

HYDRAULIC (WATER, PUMPED ENERGY STORAGE, ETC.)

MISCELLANEOUS POWER GENERATOR, STORAGE AND TRANSMISSION

TRANSPORTATION (NOT INCLUDED BELOW)

AIR TRANSPORTATION

WATER TRANSPORTATION

RAIL TRANSPORTATION

HIGHWAY VEHICLES AND SYSTEMS

HIGHWAYS, STREETS AND TRAFFIC CONTROL 
APPENDIX A

INVENTION CLASSIFICATIONS

5.42000 VEHICULAR POWER SYSTEMS(NOT

5.42100

5.42200

5.42300

5.42400

5.43000

5.43100

5.43200

5.43300

5.43400

5.43500

5.43600

5.43700

5.43800

6.00000

6.10000

6. 20000

6.20100

6.21000

6.22000

6.22100

6.23000

6. 23010

6.23100

6.23200

6.23300

6.23400

6.23500

6.23600

6.23700

6.23800

6.24000

6.25000

6.26000

6.27000

6.28000

6. 31000

6. 31100

6. 32000

6.40000

6.50000

6.60000
INCLUDED BELOW)

COMBUSTION ENGINE VEHICLES

ELECTRIC VEHICLES

STEAM VEHICLES

HYBRID VEHICLES

VEHICULAR COMPONENTS

VEHICLE TRANSMISSIONS

VEHICLE BRAKING SYSTEMS (INCLUDES

REGEN. BRAKING SYSTEMS, ETC.)

VEHICLE WHEELS AND TIRES

VEHICLE SUSPENSIONS

VEHICLE BODY AND CHASSIS DESIGN

VEHICLE LUBRICATION SYSTEMS

DRIVER AND FUEL ECONOMY CONTROL

SYSTEMS

VEHICLE AIR CONDITIONING

BUILDINGS, STRUCTURES AND

COMPONENTS

DESIGN, CONSTRUCTION AND

CONSTRUCTION PRACTICES

HEATING, COOLING, VENTILATING

HEATING, COOLING AND VENTILATING

INSTRUMENTS AND CONTROLS

FIREPLACES

SOLAR HEATERS

SOLAR HEATERS - HEAT STORAGE

BOILERS AND FURNACES (INDUSTRIAL)

SMALL BOILERS, FURNACES AND STOVES

BOILER AND FURNACE FLUE HEAT

RECOVERY

BOILER AND FURNACE AIR AND OXYGEN

INDUCTORS AND INJECTORS

BOILERS AND FURNACES FLUE VENT

CONTROI

BOILER AND FURNACE OIL BURNERS

BOILER AND FURNACE STOKERS

(INDUSTRIAL)

BOILER AND FURNACE COMBUSTION

CONTROLS AND EQUIPMENTS

BOILER AND FURNACE COAL-OIL-WATER MIXTURES

COMBUSTION, CHEMICAL

ELECTRIC HEAT

HEAT PUMPS

AIR CONDITIONING \& REFRIGERATION

VENTILATING SYSTEMS

HUMIDIFICATION SYSTEMS

HEATING SYSTEMS (HOT WATER)

SOLAR HEATERS

HOT WATER CONSERVATION DEVICES AND

PRACTICES

INSULATION AND INSULATING

PRACTICES

ELECTRICAL WIRING AND FIXTURES

PLUMBING AND FIXTURES
7.00000

INDUSTRIAL PROCESSES (NOT INCLUDED BELOW)

7.01000

7.01100

7.01200

7.01300

7.01400

7.01500

7.01600

7.01700

7.01800

7.01900

7.02000

7.02100

7.02200

7.02300

7.02400

7.03000

7.04000

7.05000

7.06000

7.07000

7.08000

7.09000

7.10000

7.20000

7.30000

7.40000

7.50000

8.00000

8.10000

8.20000

8.30000

8.40000

9.00000

9.10000

9.20000

9.30000

9.40000

9.50000

9.50100

9.50200

9.50300

9. 51000

9.60000

9.70000

9.80000

CHEMICAL, CHEMICAL PROCESS INDUSTRIES UNIT OPERATIONS IRON AND STEEL

PRIMARY NON-FERROUS METALS

FABRICATED METAL PRODUCTS

AIR SEPARATION

WATER AND WASTE TREATMENT

PACKAGING AND CONTAINERS

MISC . DESALINIZATION-ELECTROLYSIS

SOLAR DISTILLATION PROCESSES

SOLAR EVAPORATION PROCESSES

TEXTILES, FABRICS, RUGS, CLOTHING

POWDER METALIURGY

CERAMICS

COMPOSITE MATERIALS

STACK GAS SCRUBBERS

FOOD, FEEDS, LEATHER, FURS,

FEATHERS, ETC.

LUMBER, WOOD, WOOD PRODUCTS

INDUSTRIAL PROCESSES

PAPER AND ALIIED PRODUCTS

PETROLEUM, OIL AND NATURAL GAS

INDUSTRIES

RUBBER AND PLASTICS

STONE, CLAY AND GLASS

PRIMARY METALS

CIVIL ENGINEERING

AGRICULTURE EQUIPMENT AND FARM EQUIPMENT

OIL SPILL RECOVERY

MECHANICAL CONTRIVANCES

(NON - VEHI CULAR)

SOLAR INDUSTRIAL

CONSUMER PRODUCTS

CONSUMER EDUCATION AND BEHAVIOR APPLIANCES

TOOLS

LAMPS AND LIGHT BULBS (6.5 FOR

LIGHTING FIXTURES)

MISCELIANEOUS

NOT ENERGY-RELATED

NUCLEAR

PERPETUAL MOTION

UNINTERPRETABLE

INSTRUMENTATION

CHEMICAL, BIOCHEMICAL SENSORS AND

INSTRUMENTATION

ELECTRONIC, OPTICAL SENSORS AND INSTRUMENTATION

HEAT TRANSFER, FLUID MECHANICS

INSTRUMENTATION

ELECTRICAL DEMAND, OVERLOAD OR

CONSUMPTION INDICATORS

COMPUTER - DATA STORAGE AND

RETRIEVAL

COMMUNICATION SYSTEMS AND

EQUI PMENT

PRINTING SYSTEMS AND EQUIPMENT 
APPENDIX B 

APPENDIX B

TECHNICAL CATEGORIES AND ASSOCIATED INVENTION CLASSIFICATIONS

TECHNICAL CATEGORY

ASSOCIATED INVENTION CLASSIFICATIONS

1. Fossil Fuel Production

$\begin{array}{ll}1.00000 & \text { FUELS AND LUBRICANTS ACQUISITION, PRODUCTION, DISTRIBUTION } \\ 1.01000 & \text { GEOPHYSICAL PROSPECTING } \\ 1.10000 & \text { FOSSIL FUELS } \\ 1.11000 & \text { COAL } \\ 1.11100 & \text { COAL LIQUIFICATION } \\ 1.11200 & \text { COAL GASIFICATION } \\ 1.11300 & \text { GREATER RESOURCE RECOVERY METHODS } \\ 1.11400 & \text { GREATER RESOURCE RECOVERY EQUIPMENT } \\ 1.12000 & \text { OIL } \\ 1.12100 & \text { GREATER RESOURCE RECOVERY METHODS } \\ 1.12200 & \text { GREATER RESOURCE RECOVERY EQUIPMENT } \\ 1.12300 & \text { OIL AND GAS WELL PUMPS AND DRILIS } \\ 1.12400 & \text { OIL AND GAS PIPELINES } \\ 1.13000 & \text { OIL SHALE } \\ 1.13100 & \text { TAR SANDS } \\ 1.14000 & \text { NATURAL GAS } \\ 1.14100 & \text { CHEMICAL CONVERSION OF GAS TO LIQUIDS }\end{array}$

2. Direct Solar
2.10000
2.11000
SOLAR COLLECTORS
2.12000
SOLAR TO DIRECT MECHANICAL ENERGY
2. 13000
SOLAR ELECTRIC POWER GENERATING SYSTEMS
2.14000 PHOTOVOLTAIC DEVICES
2.15000
SOLAR CONCENTRATORS - PHOTOVOLTAIC
6.22000
6.22100
SOLAR CONCENTRATORS - THERMAL
6.31100
SOLAR HEATERS
SOLAR HEATERS - HEAT STORAGE

3. Other Natural Sources

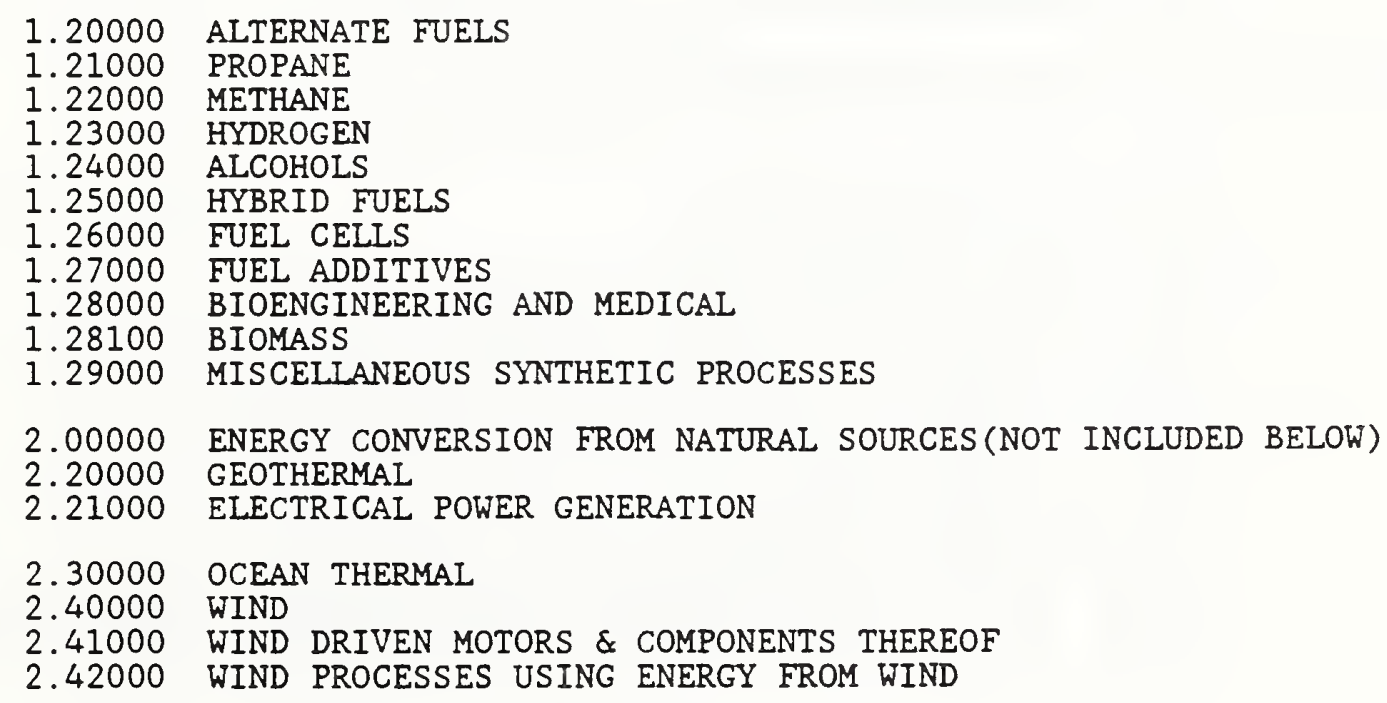


TECHNICAL CATEGORIES AND ASSOCIATED INVENTION CLASSIFICATIONS

TECHNICAI CATEGORY

ASSOCIATED INVENTION CLASSIFICATIONS

3. Other Natural Sources (cont.)

2.50000 WATER POWER PROCESSES (INLAND)

2.51000 ELECTRICAL POWER GENERATION BY WATER POWER (INLAND)

2.60000 OCEAN WATER POWER

2.61000 WAVE POWER SYSTEMS

2.62000 TIDAL POWER SYSTEMS

2.63000 OCEAN CURRENT POWER SYSTEMS

3.00000 ENERGY CONVERSION FROM SECONDARY SOURCES(NOT INCLUDED BELOW)

3.01000 ENERGY CONVERSION FROM SECONDARY SOURCES - THERMODYNAMICS

4. Combustion Engines \& Components

3.10000 COMBUSTION ENGINES AND COMPONENTS THEREOF

3.10100 STIRLING ENGINES, MECHANICAL

3.10110 STIRLING ENGINES, THERMO

3.11000 RECIPROCAL ENGINES, MECHANICAL

3. 11100 RECIPROCAL ENGINES, THERMO

3.12000 ROTARY ENGINES, MECHANICAL

3.12100 ROTARY ENGINES, THERMO

3.13000 TURBINE ENGINES, MECHANICAL

3.13100 TURBINE ENGINES, THERMO

3. 14000 FUEL SYSTEMS, MECHANICAL

3.14100 CARBURETORS AND MODIFICATIONS THEREOF

3.14200 FUEL INJECTORS

3.14300 WATER INJECTORS

3.14400 MULTI-FUEL MIXERS

3.14500 AIR AND OXYGEN INJECTION

3.14600 COMBUSTION ANALYZERS

3.15000 IGNITION SYSTEMS

3.20000 STEAM ENGINES AND TURBINES, MECHANICAL

3.21000 STEAM ENGINES AND TURBINES, THERMO

5. Transportation Systems: Vehicles \& Components




APPENDIX B

TECHNICAL CATEGORIES AND ASSOCIATED INVENTION CLASSIFICATIONS

TECHNICAL CATEGORY

ASSOCIATED INVENTION CLASSIFICATIONS

5. Transportation Systems: Vehicles \& Components (cont.)

5.43400 VEHICLE SUSPENSIONS

5.43500 VEHICLE BODY AND CHASSIS DESIGN

5.43600 VEHICLE LUBRICATION SYSTEMS

5.43700 DRIVER AND FUEL ECONOMY CONTROL SYSTEMS

5.43800 VEHICLE AIR CONDITIONING

6. Building, Structures \& Components

6.00000 BUILDINGS, STRUCTURES AND COMPONENTS

6.10000 DESIGN, CONSTRUCTION AND CONSTRUCTION PRACTICES

6.20000 HEATING, COOLING, VENTILATING

6.20100 HEATING, COOLING AND VENTILATING INSTRUMENTS AND CONTROLS

6.21000 FIREPLACES

6.23000 BOILERS AND FURNACES (INDUSTRIAL)

6.23010 SMALL BOILERS, FURNACES AND STOVES

6.23100 BOILER AND FURNACE FLUE HEAT RECOVERY

6.23200 BOILER AND FURNACE AIR AND OXYGEN INDUCTORS AND INJECTORS

6.23300 BOILERS AND FURNACES FLUE VENT CONTROL

6.23400 BOILER AND FURNACE OIL BURNERS

6.23500 BOILER AND FURNACE STOKERS (INDUSTRIAL)

6.23600 BOILER AND FURNACE COMBUSTION CONTROLS AND EQUIPMENTS

6.23700 BOILER AND FURNACE COAL-OIL-WATER MIXTURES

6.23800 COMBUSTION, CHEMICAL

6.24000 ELECTRIC HEAT

6.25000 HEAT PUMPS

6.26000 AIR CONDITIONING \& REFRIGERATION

6.27000 VENTILATING SYSTEMS

6.28000 HUMIDIFICATION SYSTEMS

6.29000 SOLAR AIR CONDITIONING

6.30000 HOT WATER SUPPLY

6.31000 HEATING SYSTEMS (HOT WATER)

6.32000 HOT WATER CONSERVATION DEVICES AND PRACTICES

6.40000 INSULATION AND INSULATING PRACTICES

6.50000 ELECTRICAL WIRING AND FIXTURES

6.60000 PLUMBING AND FIXTURES

7. Industrial Processes

7.00000

7.01000

7.01100

7.01200

7.01300

7.01400

7.01500

7.01600

7.01700

7.01800

7.01900

7.02000

7.02100
INDUSTRIAL PROCESSES (NOT INCLUDED BELOW)

CHEMICAL, CHEMICAL PROCESS INDUSTRIES UNIT OPERATIONS

IRON AND STEEL

PRIMARY NON-FERROUS METALS

FABRICATED METAL PRODUCTS

AIR SEPARATION

WATER AND WASTE TREATMENT

PACKAGING AND CONTAINERS

MISCELIANEOUS - DESALINIZATION - ELECTROLYSIS

SOLAR DISTILIATION PROCESSES

SOLAR EVAPORATION PROCESSES

TEXTILES, FABRICS, RUGS, CLOTHING

POWDER METALIURGY 
APPENDIX B

TECHNICAL CATEGORIES AND ASSOCIATED INVENTION CLASSIFICATIONS

TECHNICAL CATEGORY

ASSOCIATED INVENTION CLASSIFICATIONS

7. Industrial Processes (cont.)

7.02200 CERAMICS

7.02300 COMPOSITE MATERIALS

7.02400 STACK GAS SCRUBBERS

7.03000 FOOD, FEEDS, LEATHER, FURS, FEATHERS, ETC.

7.04000 LUMBER, WOOD, WOOD PRODUCTS INDUSTRIAL PROCESSES

7.05000 PAPER AND ALIIED PRODUCTS

7.06000 PETROLEUM, OIL AND NATURAL GAS INDUSTRIES

7.07000 RUBBER AND PLASTICS

7.08000 STONE, CLAY AND GLASS

7.09000 PRIMARY METALS

7.10000 CIVIL ENGINEERING

7.20000

7.30000

7.40000

7.50000

AGRICULTURE EQUIPMENT AND FARM EQUIPMENT

OIL SPILL RECOVERY

MECHANICAL CONTRIVANCES (NON-VEHICULAR)

SOLAR INDUSTRIAL

8. Miscellaneous

1.30000

GREASES AND LUBRICANTS

1.40000

REFINED PETROLEUM PRODUCTS AND ADDITIVES

3.30000

AIR COMPRESSORS AND MOTORS

3.40000

HYDRAULIC PUMPS AND MOTORS

3.50000

ELECTRIC MOTORS AND GENERATORS

3.51000

MISCELLANEOUS ELECTRIC POWER GENERATING SYSTEM

3.60000

CHEMICAL THERMODYNAMICS

3.61000

PHOTO CHEMICAL

3.70000

MECHANICAL THERMODYNAMICS

3.80000

HEAT PUMPS AND REFRIGERATION

3.90000

HIGHWAY POWER GENERATORS

4.00000

4.10000

ENERGY STORAGE AND DISTRIBUTION(NOT INCLUDED BELOW)

4.11000

ELECTRICAL TRANSMISSION

4.12000

ELECTRICAL STORAGE (BATTERIES)

4.20000

ELECTRICAL DISTRIBUTION (TRANSFORMERS, SWITCHGEARS, CONTROLS)

4.30000

MECHANICAL ELECTRICAL GENERATION, STORAGE, DISTRIBUTION

4.40000

THERMAL ENERGY STORAGE

4.50000

PNEUMATIC ENERGY GENERATION, STORAGE, DISTRIBUTION

4.60000

HYDRAULIC (WATER, PUMPED ENERGY STORAGE, ETC.)

MISCELIANEOUS POWER GENERATOR, STORAGE AND TRANSMISSION

8.00000

CONSUMER PRODUCTS 
TECHNICAL CATEGORIES AND ASSOCIATED INVENTION CLASSIFICATIONS

TECHNICAL CATEGORY

ASSOCIATED INVENTION CLASSIFICATIONS

8. Miscellaneous (cont.)

8.10000 CONSUMER EDUCATION AND BEHAVIOR

8.20000 APPLIANCES

8.30000 TOOLS

8.40000 LAMPS AND LIGHT BULBS ( 6.5 FOR LIGHTING FIXTURES)

9.00000 MISCELLANEOUS

9.50000 INSTRUMENTATION

9.50100 CHEMICAL, BIOCHEMICAL SENSORS AND INSTRUMENTATION

9.50200 ELECTRONIC, OPTICAL SENSORS AND INSTRUMENTATION

9.50300 HEAT TRANSFER, FLUID MECHANICS INSTRUMENTATION

9.51000 ELECTRICAL DEMAND, OVERLOAD OR CONSUMPTION INDICATORS

9.60000 COMPUTER - DATA STORAGE AND RETRIEVAL

9.70000 COMMUNICATION SYSTEMS AND EQUIPMENT

9.80000 PRINTING SYSTEMS AND EQUIPMENT

9. Out of Scope and Unclassifiable
9.10000 NOT ENERGY-RELATED
9.20000 NUCLEAR
9.30000 PERPETUAL MOTION
9.40000 UNINTERPRETABLE 


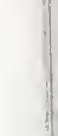


\begin{tabular}{ll}
\hline NIST-114A & U.S. DEPARTMENT OF COMMERCE \\
(REV. 3-90) & NATIONAL INSTITUTE OF STANDARDS AND TECHNOLOGY
\end{tabular}

\section{BIBLIOGRAPHIC DATA SHEET}

1. PUBLCATION OR REPORT NUMBER NISTIR 4898

2 PERFORMING ORGANIZATION REPORT MUMBER

3. PUBLCATION DATE DECEMBER 1991

4. TITLE AND SUBTITLE

Energy Related Inventions Program. A joint program of the Department of Energy and the National Institute of Standards and Technology Status Report for recommendations 1 through 300.

5. AUTHOR(S)

6. PERFORMING ORGANIZATION (IF JOINT OR OTHER THAN NIST, SEE INSTRUCTIONS)

7. CONTRACT/GRANT NUMBER

U.S. DEPARTMENT OF COMMERCE

MATIONAL INSTITUTE OF STANDARDS AND TECHNOLOQY

GATHERSBURG, MD 20899

8. TYPE OF REPORT AND PERIOD COVERED

Status of last 16 years

9. SPONSORING ORCANIZATION MAME AND COMPLETE ADDRESS (STREET, CITY, STATE, ZIP)

Terry Levinson, Director

Inventions and Innovation Division, CE-122

Conservation and Renewable Energy, Department of Energy

Forrestal Building, 5E-052, Washington, DC 20585

10. SUPPLEMENTARY NOTES

Supercedes NISTIR 4333

11. ABSTRACT (A 200-WORD OR LESS FACTUAL SUMMARY OF MOST SIGNIFICANT INFORMATION. IF DOCUMENT INCLUDES A SIGNIFICANT BIBUOORAPHY OR LTERATURE SURVEY, MENTION IT HERE)

A brief description of the Energy Related Inventions Program and all inventions recommended by the National Institute of Standards and Technology to the Department of Energy since the inception of the program, including a brief summary of the current status of each.

12. KEY WORDS (6 TO 12 ENTRIES; ALPHABETICAL OADER; CAPITALZE ONLY PAOPER MAMES; AND SEPARATE KEY WORDS BY SEMICOLONS)

status report; energy; inventions; innovations; new technology; NIST; DOE

13. AVAILABIUTY

$\mathrm{XX}$ UNLMITED

FOR OFFICIAL DISTRIBUTION. DO NOT RELEASE TO NATIONAL TECHNICAL INFORMATION SERVICE (NTIS).

ORDER FROM SUPERINTENDENT OF DOCUMENTS, U.S. GOVERNMENT PRINTING OFFICE, WASHINGTON, DC 20402.

$\mathrm{XX}$

ORDER FROM MATIONAL TECHNICAL INFORMATION SERVICE (NTIS), SPRINGFIELD, VA 22161.
14. NUMBER OF PRINTED PAGES

168

15. PRICE

A08 


